\title{
Opioid Guidelines in the Management of Chronic non-Cancer Pain
}

\author{
Andrea M. Trescot, MD, Mark V. Boswell, MD, Sairam L. Atluri, MD, Hans C. Hansen, MD, Timothy R. Deer, MD, \\ Salahadin Abdi, MD, Joseph F. Jasper, MD, Vijay Singh, MD, Arthur E. Jordan, MD, Benjamin W. Johnson, MD, \\ Roger S. Cicala, MD, Elmer E. Dunbar, MD, Standiford Helm II, MD, Kenneth G. Varley, MD, P.K. Suchdev, MD, \\ John R. Swicegood, MD, Aaron K. Calodney, MD, Bentley A. Ogoke, MD, W. Stephen Minore, MD, and \\ Laxmaiah Manchikanti, MD
}

Background: Opioid abuse has increased at an alarming rate. However, available evidence suggests a wide variance in the use of opioids, as documented by different medical specialties, medical boards, advocacy groups, and the Drug Enforcement Administration (DEA).

Objectives: The objective of these opioid guidelines by the American Society of Interventional Pain Physicians (ASIPP) is to provide guidance for the use of opioids for the treatment of chronic non-cancer pain, to bring consistency in opioid philosophy among the many diverse groups involved, to improve the treatment of chronic non-cancer pain, and to reduce the incidence of drug diversion.

Design: A policy committee evaluated a systematic review of the available literature regarding opioid use in managing chronic non-cancer pain. This resulted in the formu- lation of the essentials of guidelines, a series of potential evidence linkages representing conclusions, followed by statements regarding relationships between clinical interventions and outcomes.

Methods: Consistent with the Agency for Healthcare Research and Quality (AHRQ) hierarchical and comprehensive standards, the elements of the guideline preparation process included literature searches, literature synthesis, systematic review, consensus evaluation, open forum presentations, formal endorsement by the Board of Directors of the American Society of Interventional Pain Physicians (ASIPP), and blinded peer review. Evidence was designated based on scientific merit as Level I (conclusive), Level II (strong), Level III (moderate), Level IV (limited), or Level V (indeterminate).

Results: After an extensive review and analysis of the literature, the authors utilized two systematic reviews, two narrative reviews, 32 studies included in prior systematic reviews, and 10 additional studies in the synthesis of evidence. The evidence was limited.

Conclusion: These guidelines evaluated the evidence for the use of opioids in the management of chronic non-cancer pain and recommendations for management. These guidelines are based on the best available scientific evidence and do not constitute inflexible treatment recommendations. Because of the changing body of evidence, this document is not intended to be a "standard of care."

Key Words: Chronic pain, persistent pain, controlled substances, substance abuse, dependency, prescription accountability, opioids, prescription monitoring, diversion, guidelines

\section{CONTENTS \\ 1.0 Introduction \\ 1.1 Purpose \\ 1.2 Rationale and Importance \\ 1.3 Objectives and Benefits \\ 1.4 Population and Preferences \\ 1.5 Implementation and Review \\ 1.6 Application \\ 1.7 Focus \\ 1.8 Methodology}

From: American Society of Interventional Pain Physicians, Paducah, KY

Address Correspondence:

Laxmaiah Manchikanti, MD

Chief Executive Officer, ASIPP

81 Lakeview Drive, Paducah, KY 42001

E-mail:drm@apex.net

Disclaimer: There was no external funding in the preparation of this manuscript.

Conflict of Interest: None

Funding: Internal funding was provided by the American Society of Interventional Pain Physicians and was limited to travel and lodging expenses for the authors.
2.0 Chronic Pain
2.1 Definitions
2.2 Prevalence
2.3 Chronicity
2.4 Health and Economic Impact
3.0 Opioids in Chronic Pain
3.1 General Considerations
3.2 Response to Undertreatment
3.3 Opioid Use in Chronic Pain
3.4 Non-Medical Use of Prescription Drugs
3.4.1 Center on Addiction and
Substance Abuse (CASA)
Findings
3.4.2 Physician Survey Highlights
3.4.3 Pharmacist Survey Highlights
3.4.4 Substance Abuse and
Mental Health Services
Administration (SAMHSA)
Survey
3.4.5 Drug Abuse Warning Network (DAWN) Reports
3.5 Substance Abuse in Chronic Pain
3.6 Economic Impact

3.7 Drug Diversion

3.8 Controlling Diversion and Abuse

3.8.1 Drug Enforcement

Administration (DEA)

3.8.2 State Laws and Regulations

3.8.3 Prescription Drug Monitoring Programs

4.0 Pharmacological Considerations

4.1 Opioid Pharmacology

4.1.1 Opioid Receptors

4.1.2 Opioid Categories

4.1.3 Opioid Metabolism

4.2 Pharmacology of Specific Opioids

4.2.1 Morphine

4.2.2 Codeine

4.2.3 Dihydrocodeine

4.2.4 Hydrocodone

4.2.5 Oxycodone

4.2.6 Hydromorphone

4.2.7 Methadone

4.2.8 Fentanyl

4.2.9 Meperidine

4.2.10 Pentazocine

4.2.11 Propoxyphene

4.2.12 Tramadol 


$$
\begin{array}{ll}
4.3 & \text { Adverse Effects } \\
4.4 & \text { Drug Interactions } \\
4.5 & \text { Drug Conversions } \\
4.6 & \text { Opioid Therapy and Side Effects } \\
4.6 .1 \quad \text { Long-term opioid therapy } \\
4.6 .2 \quad \text { Opioid Induced Immunologic } \\
\text { Effects } \\
4.6 .3 \quad \begin{array}{l}
\text { Opioid Induced Hormonal } \\
\text { Changes }
\end{array} \\
4.6 .4 \quad \begin{array}{l}
\text { Opioid Induced Hyperalgesia } \\
4.6 .5
\end{array} & \begin{array}{l}
\text { Psychomotor Performance In } \\
\text { Opioid Therapy } \\
4.6 .6 \quad \begin{array}{l}
\text { Breakthrough Pain } \\
\text { Management }
\end{array}
\end{array}
\end{array}
$$

5.0 Terminology of Abuse and Addiction 5.1 Introduction 5.2 History
6.0 Clinical Effectiveness

6.1 Introduction

6.2 Systematic Reviews

6.3 Other Controlled Trials

6.4 Influence of Psychopathology on

Opioid Effectiveness

6.5 Summary of Evidence

7.0 Adherence Monitoring

7.1 Introduction

7.2 Screening for Opioid Abuse

7.3 Urine Drug Testing

7.4 Periodic Review and Monitoring

7.4.1 Periodic Review

7.4.2 Periodic Monitoring

7.4.3 Prescription Drug Monitoring

7.4.4 Periodic Education

7.4.5 Pill Counts
8.0 Principles of Opioid Usage

8.1 Introduction

8.2 Basic Philosophy

8.3 Evaluation

8.3.1 History

8.3.2 Effect on Functional Status

8.3.3 Drug History

8.4 Physical Examination

8.5 Laboratory Studies

8.6 Psychological Evaluation

8.7 Medical Decision Making and Treatment Plan

8.8 Consultation

8.9 Informed Consent and Controlled Substance Agreement

9.0 Documentation and Medical Records

10.0 Key Points

\subsection{INTRODUCTION}

\subsection{Purpose}

Guidelines for the use of opioids in the treatment of chronic non-cancer pain are statements developed by the American Society of Interventional Pain Physicians (ASIPP) to improve quality and appropriateness of care, improve patient access, improve patient quality of life, improve efficiency and effectiveness, minimize abuse and diversion, and achieve cost containment by improving the costbenefit ratio.

\subsection{Rationale and Importance}

Available evidence documents a wide degree of variance in the prescribing patterns of physicians in regard to opioids for chronic pain, as suggested by different specialties, medical boards, advocacy groups, and the Drug Enforcement Administration (DEA).

Opioids are commonly used in managing chronic non-cancer pain, even though this practice is controversial (13 ). However, documented abuse of opioids is increasing at an alarming rate (411). While speaking at ASIPP's 2004 annual meeting in Washington, DC, Patricia Good of the DEA's Drug Diversion Control division, stated that the United States, with $4.6 \%$ of the world's population, uses $80 \%$ of the world's opioids.

Interventional pain management, as defined by the National Uniform Claims Committee (NUCC), is the discipline of medicine devoted to the diagnosis and treatment of pain and related disorders, with the application of interventional techniques to manage subacute, chronic, persistent, and intractable pain, indepen- dently or in conjunction with other modalities of treatments. Multidisciplinary or comprehensive pain management differs among specialties and may elicit confusion. An interventionalist perceives comprehensive treatment programs as programs with interventional techniques as the primary treatment modality, with physical therapy, medical therapy, and psychological management as supplementary.

\subsection{Objectives and Benefits}

The objectives of these guidelines are to bring consistency in opioid prescribing to the many diverse groups involved; to provide analysis of evidence to treat a chronic pain patient with opioids, thus, maintaining reasonable patient access while reducing the risk of drug diversion; to provide practical prescribing guidelines for physicians to reduce the risk of legal and regulatory sanctions; and to emphasize the need for systematic evaluation and ongoing care of patients with chronic or persistent pain.

The perceived benefits of these guidelines include:

- Improved patient compliance

- Improved patient care with appropriate medical management

- $\quad$ Reduced misconceptions among providers and patients about opioids

- Improved ability to manage patient expectations

- Reduced abuse and diversion

- Improved cooperation among patients, providers, and regulatory agencies.

\subsection{Population and Preferences}

The population covered by these guidelines includes all patients suffering with chronic non-cancer pain who may be eligible for appropriate, medically-nec- essary management. This management may include, or be independent of, interventional techniques.

\subsection{Implementation and Review}

The dates for implementation and review were established:

- Effective date - February 1, 2006

- Scheduled review - July 1, 2007

- Expiration date - January 31, 2008

\subsection{Application}

These guidelines are primarily intended for use by interventional pain physicians. Others managing chronic pain patients with opioids may also find these guidelines useful.

These guidelines do not constitute inflexible treatment recommendations. It is expected that a provider will establish a plan of care on a case-by-case basis, taking into account an individual patient's medical condition, personal needs, and preferences, as well as the physician's experience. Based on an individual patient's needs, treatment different from that outlined here could be warranted. These guidelines do not represent a "standard of care."

\subsection{Focus}

These guidelines focus on the effective management of chronic non-cancer pain as well as the multiple issues related to opioid administration. It is recognized that management of chronic non-cancer pain takes place in a wide context of healthcare involving multiple specialists and multiple techniques. Consequently, the decision to implement a particular management approach should be based on a comprehensive assessment of the patient's overall health status, disease state, patient preference, and physician training and skill. 


\subsection{Methodology}

In developing these guidelines, evidence-based approaches were given the highest priority. If evidence-based approaches failed to give acceptable levels of information consensus, expert opinions were utilized. These approaches are described in separate publications (12-16).

A policy committee was convened and included a broad representation of academic and clinical practitioners recognized as experts in one or more aspects of opioids, and representing a variety of practices and geographic areas. This committee formalized the essentials of the guidelines. This was followed by the formulation of a series of potential evidence linkages representing conclusions and statements about relationships between clinical interventions and outcomes. The elements of the guideline preparation process included literature searches, literature syntheses, systematic review, consensus evaluation, open forum presentations, formal endorsement by the ASIPP Board of Directors and blinded peer review.

In synthesizing the evidence, systematic reviews, randomized clinical trials, and observational studies were evaluated utilizing reporting criteria and quality evaluation criteria $(13,14,17-19)$. Details of evidence synthesis are escribed in multiple publications $(13,16,17)$. If the available systematic reviews met the criteria of inclusion, only those studies published af-

Table 1. Designation of levels of evidence

\begin{tabular}{|l|l|}
\hline Level I & $\begin{array}{l}\text { Conclusive: Research-based evidence with multiple relevant and high-quality } \\
\text { scientific studies or consistent reviews of meta-analyses }\end{array}$ \\
\hline Level II & $\begin{array}{l}\text { Strong: Research-based evidence from at least one properly designed random- } \\
\text { ized, controlled trial; or research-based evidence from multiple properly de- } \\
\text { signed studies of smaller size; or multiple low quality trials. }\end{array}$ \\
\hline Level III & $\begin{array}{l}\text { Moderate: a) Evidence obtained from well-designed pseudorandomized con- } \\
\text { trolled trials (alternate allocation or some other method); b) evidence obtained } \\
\text { from comparative studies with concurrent controls and allocation not random- } \\
\text { ized (cohort studies, case-controlled studies, or interrupted time series with a } \\
\text { control group); c) evidence obtained from comparative studies with historical } \\
\text { control, two or more single-arm studies, or interrupted time series without a } \\
\text { parallel control group. }\end{array}$ \\
\hline Level IV & $\begin{array}{l}\text { Limited: Evidence from well-designed nonexperimental studies from more than } \\
\text { one center or research group; or conflicting evidence with inconsistent findings } \\
\text { in multiple trials }\end{array}$ \\
\hline Level V & $\begin{array}{l}\text { Indeterminate: Opinions of respected authorities, based on clinical evidence, } \\
\text { descriptive studies, or reports of expert committees. }\end{array}$ \\
\hline
\end{tabular}

Reproduced from Boswell et al (12) Interventional techniques in the management of chronic spinal pain: Evidence-based practice guidelines; with permission from the authors and the American Society of Interventional Pain Physicians.

ter the publication date of the systematic reviews were evaluated.

While an evidence-based approach may seem to enhance the scientific rigor of guideline development, recommendations may not always meet the highest scientific standards (13-15). Evidence-based medicine is defined as the conscientious, explicit, and judicious use of current best evidence in making decisions about the care of individual patients (16).

In the preparation of these guidelines, it is recognized that at the core of an evidence-based approach to clinical or public health issues is, inevitably, the evidence itself, which needs to be carefully gathered and collated from a systematic literature review of the particular issues. Consequently, the process by which the strength of scientific evidence is evaluated in the development of evidence-based medicine recommendations and guidelines is crucial. The practice of evidencebased medicine requires the integration of individual clinical expertise with the best available clinical evidence from systematic research.

Systems for grading the strength of a body of evidence are much less uniform and consistent than are those for rating study quality. Consequently, the guideline committee designed levels of evidence from Level I through Level V, modified from various publications (Table 1) $(13,17)$.

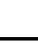


both, to individuals and to society as it leads to a decline in quality of life and disability (39,41-49). Estimates and patterns of direct healthcare expenditures among individuals with back pain in the United States reached $\$ 90.7$ billion for the year 1998 (39). On average, individuals with back pain generate healthcare expenditures about $60 \%$ higher than do individuals without back pain $(\$ 3,498$ per year versus $\$ 2,178)$. It was estimated that the cost of healthcare for patients with chronic pain might exceed the combined cost of treating patients with coronary artery disease, cancer, and AIDS (45). In the United States, it was estimated that the cost of treatment in the first year after failed back surgery for pain was approximately $\$ 18,883$ in 1997 (46). Even further, annual healthcare cost incurred by chronic pain patients, excluding cost for surgical procedures, may range from $\$ 500$ to as high as $\$ 35,400$, with averages ranging from $\$ 12,900$ to $\$ 18,883$ annually $(46,47)$.

\section{3.o Opioids in Chronic Pain}

\subsection{General Considerations}

Considerable controversy exists about the use of opioids for treatment of chronic pain of non-cancer origin. Inadequate treatment of pain has been attributed to a lack of knowledge about pain management options, inadequate understanding of addiction, or to fears of investigation or sanction by federal, state, and local regulatory agencies $(2,3,50-73)$. Many authors contend that drug therapy with opioid analgesics plays an important role in pain management and should be available when needed for the treatment of all kinds of pain, including non-cancer pain (50,52-55,64-69). The DEA also took the position that clinicians should be knowledgeable about using opioids to treat pain, and should not hesitate to prescribe them when opioids are the best clinical choice of treatment (70).

\subsection{Response to undertreatment}

The alleged undertreatment of pain as a major health problem in the United States led to the development of initiatives to address the multiple alleged barriers responsible for the undertreatment of pain (50). Patient advocacy groups and professional organizations have been formed with a focus on improving the management of pain (50). Consequently, numerous clinical guidelines also have been de-

Table 2. Retail sales of opioid medications (grams of medication) 1997-2002

\begin{tabular}{|l|c|c|c|}
\hline & $\mathbf{1 9 9 7}$ & $\mathbf{2 0 0 2}$ & \% change \\
\hline Morphine & $5,922,872$ & $10,264,264$ & 73.3 \\
\hline Hydrocodone & $8,669,311$ & $18,822,618$ & 117.1 \\
\hline Oxycodone & $4,449,562$ & $22,376,891$ & 402.9 \\
\hline Methadone & 518,737 & $2,649,559$ & 410.8 \\
\hline
\end{tabular}

veloped, even though none of them have been developed using evidence-based medicine.

In 1998 and 2004, to alleviate physician uncertainty about opioid use and to encourage better pain control, the Federation of State Medical Boards (FSMB) issued model guidelines or policies for the use of controlled substances for the treatment of pain (73). Over half of the state medical boards either adapted or modified these guidelines and implemented them in their states. In addition, based on the influence of advocacy groups, over one-third of the state legislatures have instituted intractable pain treatment acts that provide immunity from discipline for physicians who prescribe opioids within the requirements of the statute. However, the guidelines, policies, and legislative actions sometimes have been criticized as having created new barriers to appropriate pain management.

\subsection{Opioid Use in Chronic Pain}

In pain management settings, as many as $90 \%$ of patients have been reported to receive opioids for chronic pain management (74-93). A prospective evaluation (74) showed that $90 \%$ of the patients were on opioids and $42 \%$ were on benzodiazepines prior to presenting to an interventional pain management center. Many of the patients also received more than one type of opioid, most commonly one for sustained release and one for breakthrough pain. The frequency of overall opioid use among patients with back pain was reported as approximately $12 \%$ (94). It was found that rheumatologists, family practitioners, and internists were much more likely to prescribe opioids for patients with chronic pain than were surgeons and neurologists $(48,95)$. A cross-sectional analysis of analgesic use by patients with low back pain, showed that in $2001,55.5 \%$ of insurance plan members with low back pain had insurance claims for analgesics, with $68 \%$ of those claimants receiving an opioid (96). Further, Medicaid patients were more likely to receive prescription drugs, particularly opioids (73\% Medicaid vs. $40 \%$ commercial insurance), for 30 days or longer and to visit the emergency room more frequently (97). Multiple other reports (98-114) revealed widespread use of opioids in the management of chronic pain. Finally, the increasing retail sale of opioid medications is the proof that opioids are used much more frequently (Table 2). Retail sales of opioid medications represented as grams of medication increased significantly from 1997 to 2002 (106-108). Illicit drug use and dose escalations have been demonstrated in a similar proportion of patients on long-acting and short-acting opioids $(78,79)$.

\subsection{Non-Medical Use of Prescription Drugs}

3.4.1 Center on Addiction and Substance Abuse (CASA) Findings

Joseph A. Califano, Jr., Chairman and President of the National Center on Addiction and Substance Abuse at Columbia University (CASA), in a July 2005 editorial on the Diversion and Abuse of Controlled Prescription Drugs in the United States (4) noted the following:

"While America has been congratulating itself in recent years on curbing increases in alcohol and illicit drug abuse and in the decline in teen smoking, abuse and addiction of controlled prescription drugs - opioids, central nervous system depressant and stimulants - have been stealthily, but sharply, rising. Between 1992 and 2003, while the U.S. population increased $14 \%$, the number of people abusing controlled prescription drugs jumped $94 \%$ - twice the increase in the number of people abusing marijuana, five times in the number abusing cocaine and 60 times the increase in the number abusing heroin. Controlled prescription drugs 
like OxyContin ${ }^{\circledR}$, Ritalin $^{\circledR}$, and Valium ${ }^{\circledR}$ are now the fourth most abused substances in America behind only marijuana, alcohol, and tobacco."

The CASA report (4) presented alarming statistics including a $212 \%$ increase from 1992 to 2003 in the number of 12- to 17-year-olds abusing controlled prescription drugs, and the increasing number of teens trying these drugs for the first time. The report also illustrated that new abuse of prescription opioids among teens is up an astounding 542\%, more than four times the rate of increase among adults. Furthermore, disturbing statistics also show that teens who abuse opioids are likely to use other drugs including alcohol, marijuana, heroin, ecstasy, and cocaine at rates respectively of 2, 5 , 12,15 , and 21 times that of teens who do not abuse such drugs.

As per the CASA report (4), the bottom line is that the United States is in the throes of an epidemic of controlled prescription drug abuse and addiction with 15.1 million people admitting to abusing prescription drugs - more than the combined number of those who admit abusing cocaine (5.9 million), hallucinogens (4 million), inhalants (2.1 million), and heroin (0.3 million).

\subsubsection{Physician Survey Highlights}

A CASA survey of 979 physicians regarding the diversion and abuse of controlled prescription drugs showed the following:

- Physicians perceive the three main mechanisms of diversion to be:

- Doctor shopping (when patients obtain controlled drugs from multiple doctors) (96.4\%)

- Patient deception or manipulation of doctors $(87.8 \%)$

- Forged or altered prescriptions (69.4\%).

- $59.1 \%$ believe that patients account for the bulk of the diversion problem.

- $47.1 \%$ said that patients often try to pressure them into prescribing a controlled drug.

- Only $19.1 \%$ of surveyed physicians received any medical school training in identifying prescription drug diversion.

- Only $39.6 \%$ received any training in medical school in identifying prescription drug abuse and addiction.

- $\quad 43.3 \%$ of physicians do not ask about prescription drug abuse when taking a patient's health history.

- $33 \%$ do not regularly call or obtain records from the patient's previous (or other treating) physician before prescribing controlled drugs on a long-

Table 3. Past use of illicit drugs and illicit pain relievers among persons age 12 or older; 2003 survey

\begin{tabular}{|l|c|c|c|c|}
\hline \multirow{2}{*}{} & \multicolumn{4}{|c|}{ Number (Percentage) } \\
\cline { 2 - 5 } & $\begin{array}{c}12-17 \\
\text { years of age }\end{array}$ & $\begin{array}{c}18-25 \\
\text { years of age }\end{array}$ & $\begin{array}{c}>26 \\
\text { years of age }\end{array}$ & $\begin{array}{c}\text { Total } \\
>=12 \text { years }\end{array}$ \\
\hline U.S. Population & $24,995,000$ & $31,728,000$ & $180,958,000$ & $237,682,000$ \\
\hline Any illicit drug & $\begin{array}{c}5,448,000.9 \\
(21.8 \%)\end{array}$ & $\begin{array}{c}10,977,000.8 \\
(34.6 \%)\end{array}$ & $\begin{array}{c}18,638,000.7 \\
(10.3 \%)\end{array}$ & $\begin{array}{c}34,993,000 \\
(14.7 \%)\end{array}$ \\
\hline $\begin{array}{l}\text { Non-medical } \\
\text { use of any } \\
\text { psychotherapeutic } \\
\text { drug }\end{array}$ & $\begin{array}{c}2,229,000.5 \\
(9.2 \%)\end{array}$ & $\begin{array}{c}4,600,000.6 \\
(14.5 \%)\end{array}$ & $\begin{array}{c}8,143,000 \\
(4.5 \%)\end{array}$ & $\begin{array}{c}14,986,000 \\
(6.3 \%)\end{array}$ \\
\hline $\begin{array}{l}\text { Non-medical use } \\
\text { of pain relievers }\end{array}$ & $\begin{array}{c}1,924,000.6 \\
(7.7 \%)\end{array}$ & $\begin{array}{c}3,807,000.4 \\
(12.0 \%)\end{array}$ & $\begin{array}{c}5,971,000.6 \\
(3.3 \%)\end{array}$ & $\begin{array}{c}11,671,000 \\
(4.9 \%)\end{array}$ \\
\hline
\end{tabular}

Source: 2003 SAMHSA Survey (112)

term basis. HIPPA regulations have made this step much more difficult.

- $74.1 \%$ have refrained from prescribing controlled drugs during the past 12 months because of concern that a patient might become addicted to them.

\subsubsection{Pharmacist Survey Highlights}

A CASA survey of 1,303 pharmacists regarding diversion and abuse of controlled prescription drugs showed the following:

- When a patient presents a prescription for a controlled drug:

- $78.4 \%$ of pharmacists become "somewhat or very" concerned about diversion or abuse when a patient asks for a controlled drug by its brand name;

- $26.5 \%$ "somewhat or very often" think it is for purposes of diversion or abuse.

- $51.8 \%$ believe that patients account for the bulk of the diversion problem.

- Only about half of the pharmacists surveyed received any training in identifying prescription drug diversion (48.1\%) or abuse or addiction (49.6\%) since pharmacy school.

- $\quad 61 \%$ do not regularly ask if the patient is taking any other controlled drugs when dispensing a controlled medication; $25.8 \%$ rarely or never do so.

- $\quad 28.9 \%$ have experienced a theft or robbery of controlled drugs at their pharmacy within the last five years; $20.9 \%$ do not stock certain controlled drugs in order to prevent diversion.

- $28.4 \%$ do not regularly validate the prescribing physician's DEA number when dispensing controlled drugs; one in $10(10.5 \%)$ rarely or never do so.

- $83.1 \%$ have refused to dispense a controlled drug in the past year because of suspicions of diversion or abuse.

Increasing abuse and diversion of prescription drugs "on the street" are se- rious problems. A study evaluating severe dependence on oral opioids illustrated that the majority of patients with severe dependence (39\%) obtained opioids by going to different physicians (11). Another frequent form of obtaining opioids included "street" purchase by $26 \%$ of the patients. This study also showed that many patients used more than one method of acquiring the drugs. In evaluating prescription opioid abuse in patients presenting for methadone maintenance treatment (10), at admission most patients $(83 \%)$ had been using prescription opioids with or without heroin. This study showed that $24 \%$ had used prescription opioids only, $24 \%$ used prescription opioids initially and heroin later, 35\% used heroin first and prescription opioids subsequently, and $17 \%$ had used heroin only. Subjects reported regular use of prescription opioids at higher than therapeutic doses. In 2001, prescription drug abuse and misuse was estimated to impose approximately $\$ 100$ billion annually in health care costs $(9,110,111)$. The abuse of prescription medications has increased steadily over the last 10 years, and every year more and more Americans try them for the first time. The abuse of controlled prescription drugs was foreshadowed by dramatic increases in their manufacture and distribution and the number of prescriptions written and filled (106108). Between 1992 and 2002, while the population of the United States increased by $13 \%$ and the number of prescriptions written for non-controlled drugs increased by $57 \%$, the number of prescriptions filled for controlled drugs increased by $154 \%$. During this same period, there was a $90 \%$ increase (from 7.8 million to 
14.8 million) in the number of people by $42 \%$. who admitted abusing controlled prescription drugs (4).

\subsubsection{Substance Abuse and Mental Health Services Administration (SAMHSA) Survey}

The SAMHSA 2003 survey of drug abuse (112) revealed that $6.3 \%$ of the U.S. populace over 12 years of age $(14,986,000$ individuals) used psychotherapeutic drugs for non-medical purposes; of these, $4.9 \%$ of the U.S. population $(11,671,000$ individuals) over 12 years of age used pain relievers for non-medical purposes during the past year (Table 3, p 5). The number of individuals abusing pain medications for the first time grew from 628,000 in 1990 to nearly 3 million in 2000 (Fig. 1). First-time use of stimulants and tranquilizers is also on the rise. Increases for specific opioids are illustrated in Table 3, with the highest increase that of oxycodone at $345 \%$ (106-108).

\subsubsection{Drug Abuse Warning Network (DAWN) Reports}

Drug-related emergency department visits also reveal that prescription drug abuse is on the rise (Fig. 2) $(107,108)$. From 1994 to 2002, mentions of pain medications during emergency department visits increased by $168 \%$, while mentions of benzodiazepines increased
During the same time period, the percentage of increase mentioned by the Drug Abuse Warning Network (DAWN) for prescription pain relievers has been greater than the percentage of increase for marijuana, cocaine, and heroin.

\subsection{Substance Abuse in Chronic Pain}

It has been reported that the principle drug of abuse for nearly $10 \%$ of youths in drug treatment programs is a prescription drug (115). In a comprehensive review (80), between $3.2 \%$ and $18.9 \%$ of patients were found to have been diagnosed with a substance abuse disorder. In addition, it was also concluded that diagnoses of abuse, drug dependency, and drug addiction occur in a significant proportion of chronic pain patients.

While opioids are by far the most abused drugs, other controlled substances such as benzodiazepines, sedative hypnotics, and central nervous system stimulants, though described as having less potential for abuse, are also of major concern to interventional pain specialists as they appear to be widely used for non-medical purposes as well (106$108,112)$. This is exemplified by the fact that benzodiazepine-related emergency department visits increased from 71,609 in 1995 to 100,784 in 2002 (108). Fur- ther, it has been reported that $77.3 \%$ of suicide attempts involved benzodiazepines (114).

Multiple investigators (81-85,116119) have shown a prevalence of drug abuse in $18 \%$ to $41 \%$ in patients receiving opioids for chronic pain. A study evaluating the prevalence, comorbidities and utilization of opioid abuse in a cohort of managed care patients with matched controls showed that opioid abuse rose from 2000 to 2002 (105). The authors concluded that opioid abuse was 6.7 per 10,000 patients in 2002. Opioid abusers also presented with higher prevalence of opioid prescriptions and comorbidities as compared to controls.

Illicit drug use is also a common phenomenon in chronic pain patients. Table 4 illustrates the prevalence of prescription drug abuse in a typical interventional pain management practice setting. Illicit drug use without controlled substance abuse was found in $14 \%$ to $16 \%$ of patients, and illicit drug use in patients with controlled substance abuse was present in $34 \%$ of the patients $(120,121)$. Based on their type of insurance, the prevalence of illicit drug use among individuals with chronic pain was shown to be highest in patients on Medicaid (86) (Table 5). Others $(87,122)$ also showed significant illicit drug use in patients with chronic non-

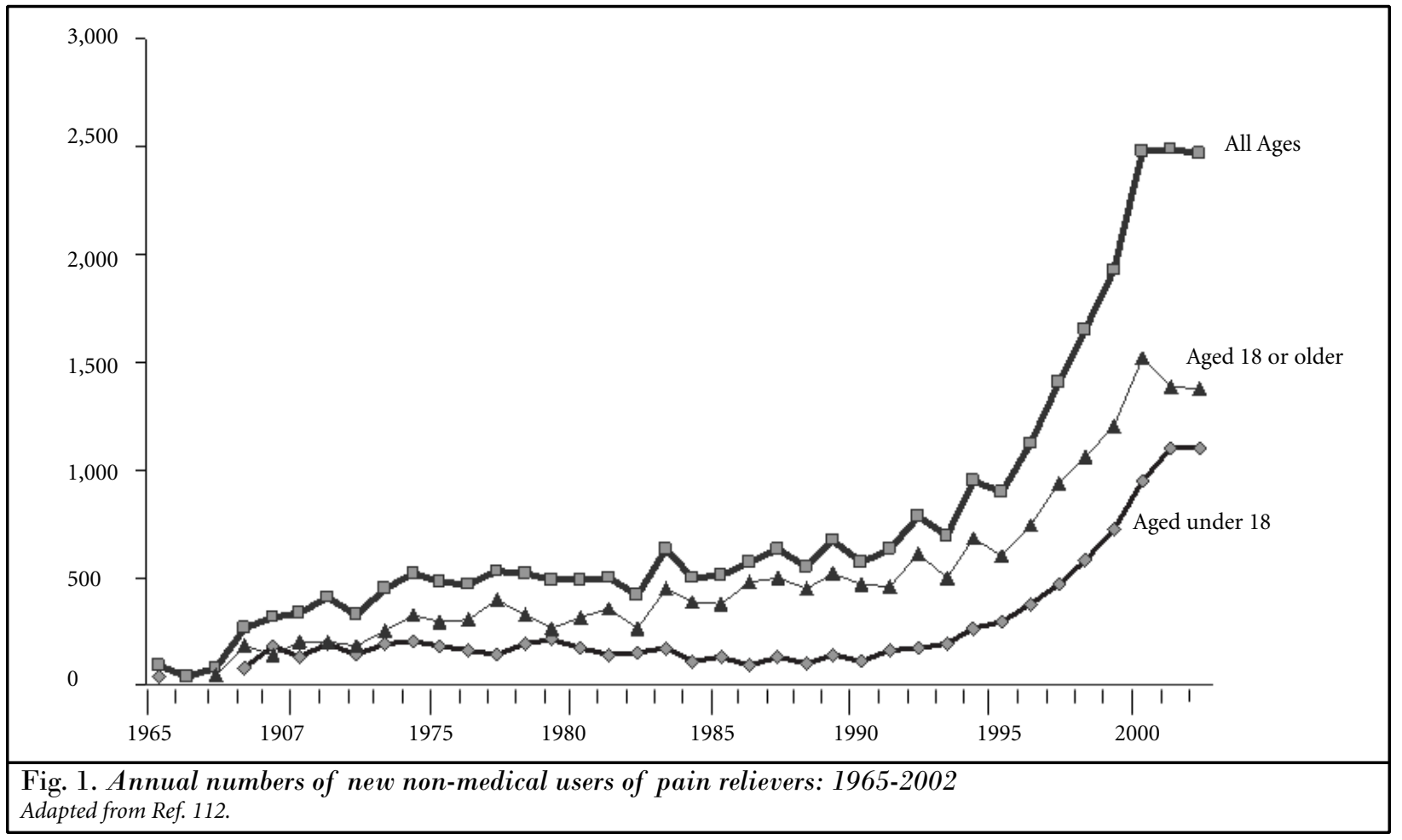

Pain Physician Vol. 9, No. 1, 2006 
malignant pain treated with opioids.

Overall use and abuse of opioids and other controlled substances in conjunction with illicit drug use appears to be prevalent in pain management settings (86,87,120-124). Advocacy and unproven Joint Commission standards may be leading to the overuse of opioids and subsequent abuse. At the same time Americans continue to be dissatisfied with their pain relief options.

\subsection{Economic Impact}

In 1995, the Center on Addiction and Substance Abuse (CASA) estimated the costs of substance abuse to federal entitlement programs and found that
Table 4. Prevalence of controlled prescription drug abuse in an interventional pain practice

\begin{tabular}{|l|c|c|}
\hline & Total of 500 patients & Proportion \\
\hline Grade '0' - No abuse & 444 & $\mathbf{7 2 . 2 \%}$ \\
\hline Grade I - Low grade abuse & 47 & $9.4 \%$ \\
\hline $\begin{array}{l}\text { Grade II - Moderate abuse } \\
-3 \text { or more physicians } \\
- \text { Receiving Schedule II drugs } \\
\text { - Abusing Schedule II drugs }\end{array}$ & 30 & $6 \%$ \\
\hline $\begin{array}{l}\text { Grade III - High grade abuse- } \\
\text { Trafficking- Overdose }\end{array}$ & 12 & $2.4 \%$ \\
\hline Total Abuse & 89 & $17.8 \%$ \\
\hline
\end{tabular}

Modified from Manchikanti et al (84)

Table 5. Prevalence of illicit drug use in an interventional pain practice

\begin{tabular}{|c|c|c|c|c|c|}
\hline & $\begin{array}{c}\text { Group I } \\
(100) \\
\text { Third party }\end{array}$ & $\begin{array}{c}\text { Group II } \\
(100) \\
\text { Medicare with or } \\
\text { without third party }\end{array}$ & $\begin{array}{l}\text { Group III } \\
\quad(100) \\
\text { Medicare \& } \\
\text { Medicaid } \\
\end{array}$ & $\begin{array}{l}\text { Group IV } \\
(100) \\
\text { Medicaid }\end{array}$ & P Value \\
\hline Cocaine & $7 \%$ & $4 \%$ & $6 \%$ & $8 \%$ & 0.684 \\
\hline $95 \% \mathrm{CI}$ & $2 \%-12 \%$ & $0 \%-8 \%$ & $1 \%-11 \%$ & $3 \%-13 \%$ & \\
\hline Marijuana (THC) & $11 \%$ & $8 \%$ & $20 \%^{\mathrm{b}}$ & $34 \% \%^{a, b, c}$ & 0.0000 \\
\hline $95 \%$ CI & $5 \%-17 \%$ & $3 \%-13 \%$ & $12 \%-28 \%$ & $25 \%-43 \%$ & \\
\hline Methamphetamine/Amphetamine & $3 \%$ & $2 \%$ & $4 \%$ & $3 \%$ & 0.876 \\
\hline $95 \% \mathrm{CI}$ & $0 \%-6 \%$ & $0 \%-5 \%$ & $0 \%-8 \%$ & $0 \%-6 \%$ & \\
\hline Total & $17 \%$ & $10 \%$ & $24 \%^{\mathrm{b}}$ & $39 \% \%^{\mathrm{a}, \mathrm{b}, \mathrm{c}}$ & 0.0000 \\
\hline $95 \% \mathrm{CI}$ & $10 \%-24 \%$ & $4 \%-6 \%$ & $16 \%-32 \%$ & $29 \%-49 \%$ & \\
\hline
\end{tabular}

Totals may not correlate as some patients were included in more than one category

$\mathrm{CI}=$ Confidence Interval a: Indicates significant difference with Group I b: Indicates significant difference with Group II

c: Indicates significant difference with Group IIII

Adapted from Manchikanti et al (86)

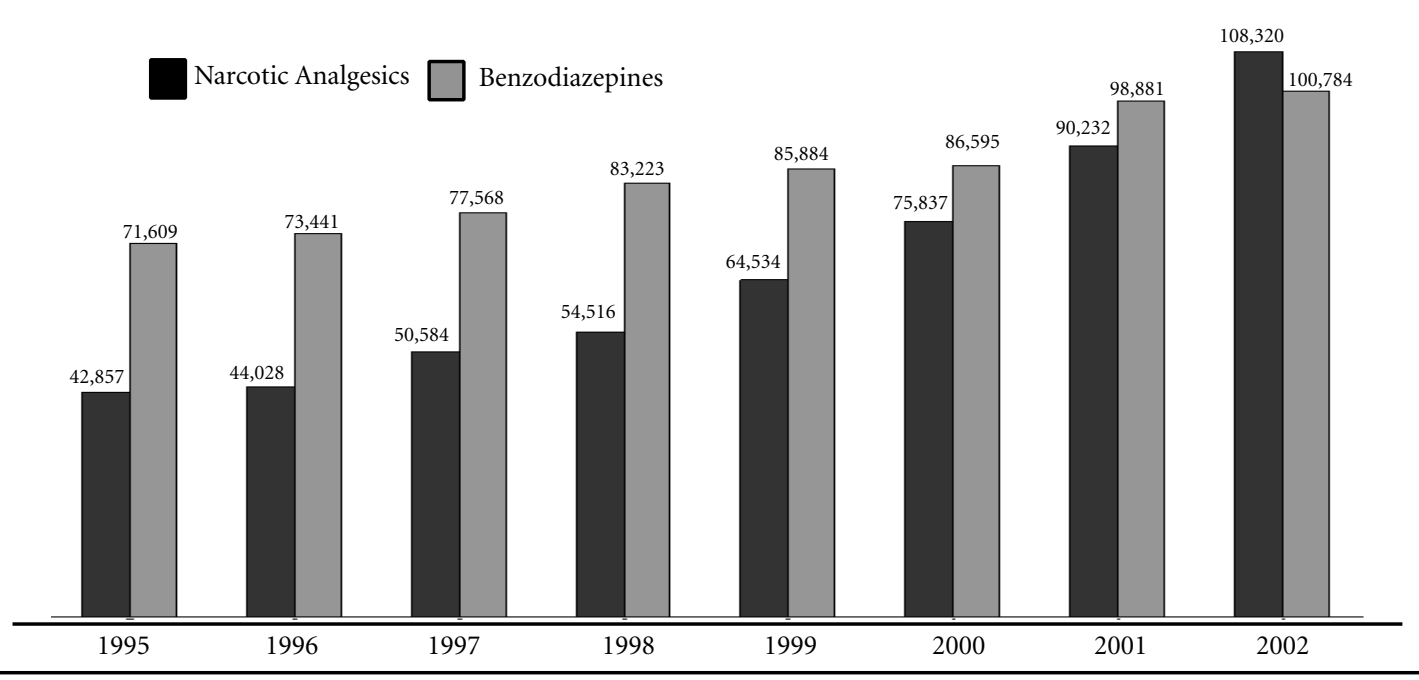

Fig. 2. Drug abuse related emergency department visits involving narcotic analgesics and benzodiazepines Adapted from Ref. 107, 108 
health care and disability costs alone were $\$ 77.6$ billion, representing nearly $20 \%$ of the $\$ 430$ billion health care budget (125). A study by the Office of Management and Budget estimated drug abuse costs to the United States government at $\$ 300$ billion a year, including government antidrug programs and the costs of the crime, healthcare (public and nonpublic), accidents, and lost productivity (126). In the Aid to Families with Dependent Children (AFDC), Medicaid and food stamp programs, the incidence of drug abuse varies from $9.4 \%$ to $16.4 \%$ (127).

\subsection{Drug Diversion}

Drugs can be diverted from their lawful purpose to illicit use at any point in the pharmaceutical manufacturing and distribution process. The diversion of prescription drugs among adults is typically described to occur through one of the following: doctor shopping, illegal Internet pharmacies, drug theft, prescription forgery, and illicit prescriptions by physicians. Youths typically acquire drugs by steal-
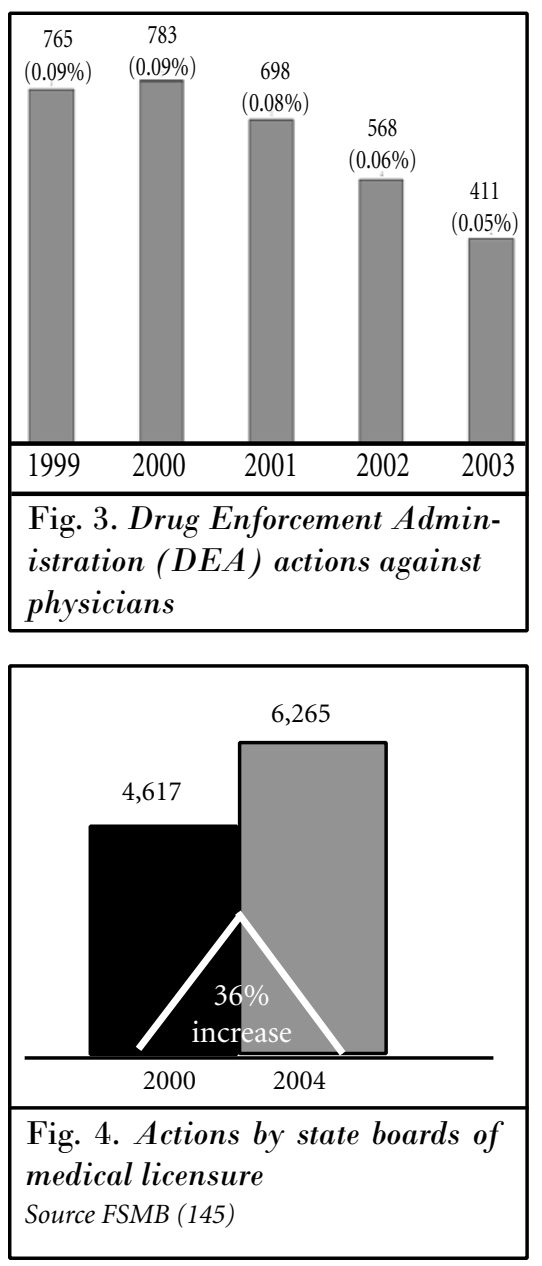

ing from their relatives or buying from classmates who sell their legitimate prescriptions.

"Doctor shopping" is one of the most common methods of obtaining prescription drugs for legal and illegal use $(9,11,78,79,83,84,86,87,121,122,128,129)$. The majority of physicians perceive "doctor shopping" as the major mechanism of diversion (4). Doctor shopping typically involves an individual going to several different doctors complaining of a wide array of symptoms in order to get prescriptions. This type of diversion can also involve individuals who use people with legitimate medical needs, like cancer patients, to go to various physicians in several cities to get prescription medications. Patients practicing doctor shopping may target physicians who readily dispense prescriptions without thorough examinations or screening. Some patients with a legitimate medical condition may get prescriptions from multiple physicians in various states or in the same state (9). It has been reported that individuals may collect thousands of pills during a one year period and sell them on the street (9).

Since 1999, illegal Internet pharmacies have provided a convenient alternative for individuals wishing to fill their prescriptions (9,130-132). In 2003, the Federal Drug Administration (FDA) estimated the number of Internet pharmacies selling drugs illegally to be about 400 , with approximately $50 \%$ of the pharmacies located outside the United States (130). Rogue sites, many under the guise of a legitimate pharmacy, provide controlled substances to people without prescriptions. This is particularly troubling with respect to the 30 million youth nationwide with Internet access (9). There are numerous concerns regarding rogue Internet pharmacies, such as the ability to evade state licensing requirements and standards, dispensing controlled substances without a prescription; and providing fake substandard or inappropriate medication (130). However, state and federal laws governing traditional pharmacy stores apply to Internet sales, regardless of the method used by an Internet pharmacy to dispense the medication.

Prescription drug theft can occur at any point from manufacturer to the patient. Thefts are on the rise, largely due to drastic increases in prescription drug abuse and high street prices $(9,131-138)$. Several drugs ranging from OxyContin to
Soma have been implicated. Prescription forgery is also fairly common, either by altering the prescription or stealing blank prescription pads in order to write fake prescriptions $(4,9,125,135,139)$. Prescription forgery may occur in two ways, either by stealing blank prescription pads or by making false prescription blanks or pads in order to write fake prescriptions (9). However, legitimate prescriptions may be altered typically to increase the quantity of controlled substances. Similarly, pharmacists may get involved in prescription drug diversion, first by selling the controlled substances and then, using their database of physicians and patients to write and forge prescriptions to cover their illegal sale. However, the vast majority of prescription forgery is from nonhealthcare professionals.

Illicit prescriptions written by physicians, though rare, are a real phenomenon. Making the headlines are criminal cases involving physicians who become involved in diverting prescription drugs for huge profits $(9,140-143)$. However, malprescribing, either due to lack of knowledge or due to prescribing inappropriately through "pill mills," is more common (141-147). Malprescribing often represents a lack of knowledge rather than a deliberate attempt to profit from writing these transactions. Adverse actions taken by the DEA against physician prescribers has, in fact, decreased from $0.9 \%$ in 1999 to $0.05 \%$ in 2003 (Fig. 3). However, actions by medical licensure boards have been increasing (Fig. 4). Figure 4 illustrates all types of actions, where as Figure 3, illustrates actions related to controlled substances.

\subsection{Controlling Diversion and Abuse}

Federal, state, and local governments, as well as professional associations and pharmaceutical companies, share responsibility for preventing diversion and abuse of controlled prescription drugs (4). However, the challenge is to eliminate or significantly curtail diversion and abuse of controlled prescription drugs while assuring proper treatment of patients who can be helped by these medications. Gaps exist between current efforts to control diversion and efforts to maintain access to patient care. These gaps involve international law, federal laws and regulations, activities of the DEA and FDA, scheduling drugs, drug refills, state laws and regulations, and existing prescription drug monitoring programs. 
3.8.1 Drug Enforcement Administration

The DEA, as an agency within the United States Department of Justice, is the lead federal law enforcement agency responsible for enforcing the Controlled Substance Act. In cooperation with state authorities and other federal agencies, the DEA is responsible for preventing the diversion of controlled substances for illicit purposes. However, the DEA must comply with international treaties to the extent that they are not in conflict with constitutional provisions; it must also work closely with foreign, state, and local governments. The DEA has increased its monitoring of Internet prescription drug sales. DEA investigations, enforcement, and intelligence programs have started to work more closely with other federal, state, and local agencies to target individuals and organizations involved in diversion and abuse of controlled prescription drugs.

\subsubsection{State Laws and Regulations}

Every state has professional oversight boards that license and discipline members within each profession. Further, the licensing boards for each health care profession have a designated national organization. However, many of these associations have not been proactive in addressing the problems of prescription drug diversion and abuse (4).

\subsubsection{Prescription Drug Monitoring \\ Programs}

Prescription drug monitoring programs (PDMPs) capture information that may be shared with law enforcement agencies, health care and regulatory agencies, and in some states, health care practitioners, to help identify inappropriate or illegal activities involving controlled prescription drugs. It has been stated that the scrutiny of professional boards and monitoring programs has, in some cases, created fear that legal action will be taken against physicians and pharmacists regarding their prescribing and dispensing practices. As a result, practitioners may under-treat patients or use less appropriate medications that are not covered by a monitoring program.

The United States Government Accountability Office (GAO) conducted a study on state monitoring programs of prescription drugs (7). They concluded that state monitoring programs provide a useful tool to reduce diversion.

The first prescription drug monitoring program (PDMP) was established in California in 1940. The number of states with PDMPs has grown only slightly over the past decade, from 10 in 1992 to 15 in 2002 (Table 6). These 15 programs cover $47 \%$ of the nation's population and DEAregistered practitioners, and about $45 \%$ of the nation's pharmacies. Since the GAO report on state monitoring systems was published, PDMPs have been increasing gradually (5).

Prescription drug monitoring programs vary as to objectives, design, and operation, even though the primary objective of PDMPs is to assist law enforcement in detecting and preventing drug diversion. In addition to helping law en- forcement identify and prevent prescription drug diversion, state programs may include educational objectives to provide information to physicians, pharmacies, and the public. The programs are also highly variable with regards to monitoring scheduled substances from Schedule II to Schedule IV. Only four states - Utah, Nevada, Kentucky, and Idaho - monitor Schedule II to IV drugs, while the majority monitor only Schedule II drugs. Also, the majority of these programs are retroactive with after-the-fact identification of abuse as reported by public health departments, pharmacy boards, and law enforcement; few are available to practitioners in real time and are useful as a prescribing decision tool. The major disadvantage of the programs is lack of interstate communication. Consequently, only a few programs operate proactively, while most operate reactively.

A few states routinely analyze prescription data collected by PDMPs to identify individuals, physicians, or pharmacies that have unusual use, prescribing, or dispensing patterns that may suggest potential drug diversion, abuse, or doctor shopping. However, only three states provide this information proactively to physicians. The GAO report cited many advantages, as well as disadvantages, to PDMPs. States with PDMPs experience considerable reductions in the time and effort required by law enforcement and regulatory investigators to explore leads and the merits of possible drug diversion cases. However, while the presence of a PDMP may

Table 6. Prescription drug monitoring programs

\begin{tabular}{|l|c|c|c|c|}
\hline \multicolumn{1}{|c|}{ State } & $\begin{array}{c}\text { Year } \\
\text { implemented }\end{array}$ & $\begin{array}{c}\text { Controlled substance } \\
\text { schedule(s)monitored }\end{array}$ & Type of monitoring system & Administrative agency \\
\hline California & 1940 & II & Electronic and triplicate form & Pharmacy and law enforcement \\
\hline Hawaii & 1943 & II & Electronic & Law enforcement \\
\hline Idaho & 1967 & II, III and IV & Electronic & Pharmacy board \\
\hline Illinois & 1961 & II & Electronic & Law enforcement \\
\hline Indiana & 1995 & II & Electronic & Public health \\
\hline Kentucky & 1999 & II, III, IV and V & Electronic & Public health \\
\hline Massachusetts & 1992 & II & Electronic & Pharmacy board and law \\
enforcement
\end{tabular}

Source: National Alliance for Model State Drug Laws. Information current through February 4, 2002. Adapted from Ref. 7 

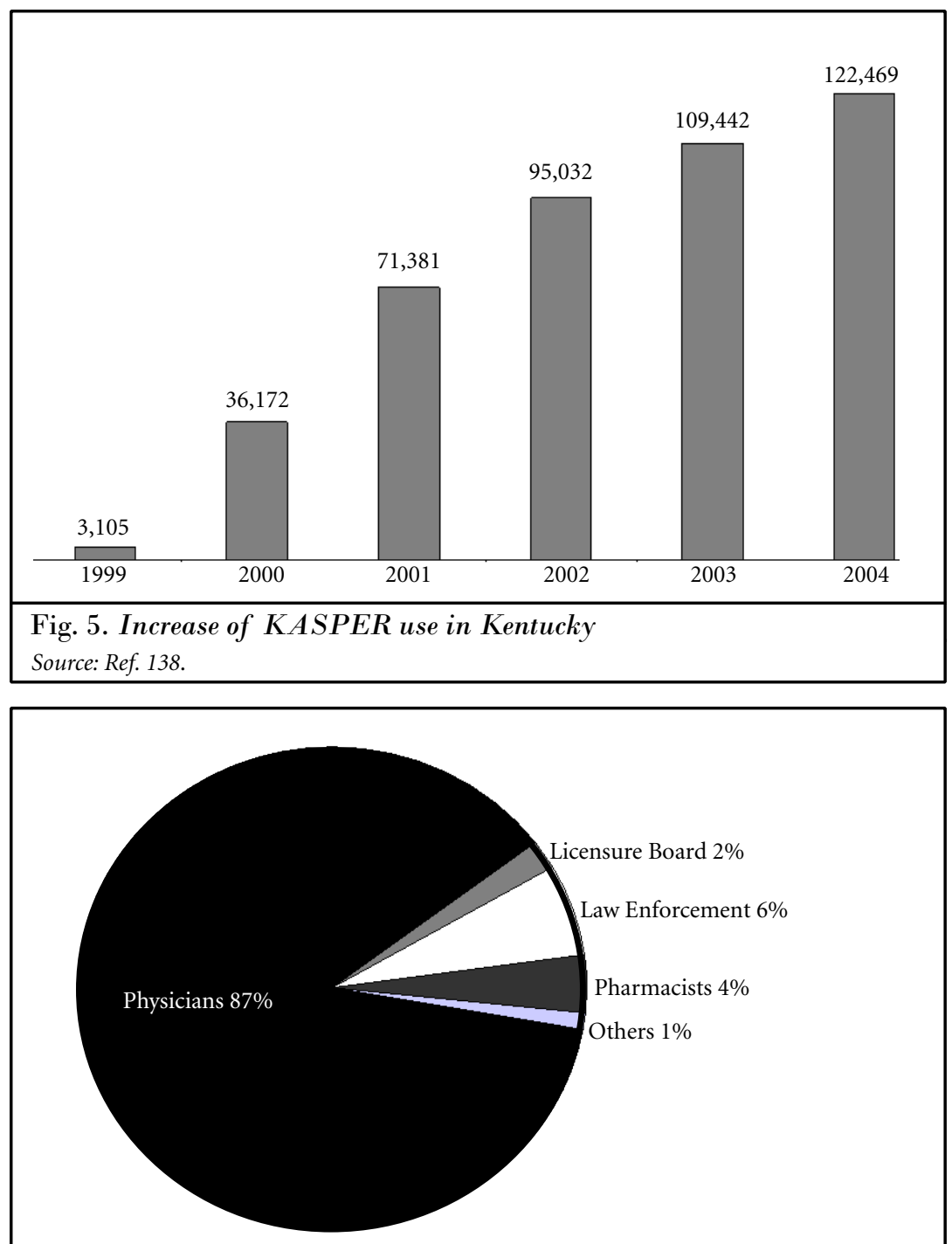

Fig. 6. Use of Kentucky's KASPER program

Source: Ref. 138.

help one state reduce its illegal drug diversion, diversion activities may actually increase in contiguous states that do not have PDMPs. All three of the states providing access to physicians - Kentucky, Nevada, and Utah - have helped reduce the unwarranted prescribing and subsequent diversion of abused drugs in their states. In both Kentucky and Nevada, an increasing number of PDMP reports are being used by physicians to check the prescription drug utilization history of current and prospective patients to determine whether it is necessary to prescribe certain drugs that are subject to abuse.

The success of a prescription drug monitoring program can be demonstrated by its use by physicians and other professionals in Kentucky (Fig. 5). Kentucky's
KASPER system was designed to produce 2,000 reports per year at its inception in 1999 ; in 2004, however, it produced in excess of 2,500 reports per week (138). Even then, it is estimated that only $50 \%$ of the physicians who prescribe controlled substances in the Commonwealth of Kentucky are using the KASPER system. Further, in Kentucky, $87 \%$ of the reports are requested by physicians and $4 \%$ by pharmacists. Further, only $6 \%$ were requested by law enforcement, and $2 \%$ by licensure boards (Fig. 6), dispelling the myth that law enforcement and other regulatory agencies use PDMPs for "witch hunting" physicians.

In addition to multiple state monitoring programs, on August 11, 2005, President Bush signed a new law into effect, enacted by the U.S. Senate and House of Representatives (6). This legislation, named the National All Schedules Prescription Electronic Reporting Act (NASPER), provides for the establishment of a controlled substance monitoring program in each state, with communication between state programs. It tasks the Public Health Service to require the United States Secretary of Health and Human Services to award 1-year grants to each state with an approved application in order to establish, or improve, a state controlled substance monitoring program (1). NASPER was introduced into Congress by the American Society of Interventional Pain Physicians with three major and important goals:

1) Physician and pharmacist access to monitoring programs

2) Monitoring of Schedule II to IV drugs 3) Information sharing across state lines

NASPER was modeled on the highly successful state monitoring program in Kentucky (KASPER) (1).

\section{4.o Pharmacological Considerations}

\subsection{Opioid Pharmacology}

Opioids are analgesics affecting nociception by modulation of ascending and descending pathways. Opioids may be classified by their function as agonists, mixed agonists-antagonists, or antagonists, as well as by their actions at various opioid receptors.

The opium poppy was cultivated as early as $3400 \mathrm{BC}$ in Mesopotamia. The term opium refers to a mixture of alkaloids from the poppy seed. Opiates are naturally occurring alkaloids such as morphine or codeine. Opioid is the term used broadly to describe all compounds that work at the opioid receptors. The term narcotic (from the Greek word for stupor), originally was used to describe medications for sleep, then was used to describe opioids, but now is a legal term for drugs that are abused.

Morphine (the archetypal opioid) consists of five rings with a phenolic hydroxyl group at Position 3 and an alcoholic hydroxyl group at Position 6 and at the nitrogen atom. Both hydroxyl groups can be converted to ethers or esters. For example, codeine is morphine $\mathrm{O}$-methylated at position 3, while heroin is morphine $\mathrm{O}$ acetylated at positions 3 and 6. Morphine is optically active, and only the levorotatory isomer is an analgesic. The tertiary 
Table 7. Analgesic effects at opioid receptors

\begin{tabular}{|c|c|c|c|}
\hline & $\mathbf{M u}(\mu)$ & $\operatorname{Delta}(\delta)$ & Kappa (к) \\
\hline & $\begin{array}{l}\text { - Mu } 1 \text { - Analgesia } \\
\text { - Mu } 2 \text { - Sedation, vomiting, respiratory } \\
\text { depression, pruritus, euphoria, } \\
\text { anorexia, urinary retention, physical } \\
\text { dependence }\end{array}$ & $\begin{array}{l}\text { - Analgesia, spinal } \\
\text { analgesia }\end{array}$ & $\begin{array}{l}\text { - Analgesia, sedation, dyspnea, psychomimetic } \\
\text { effects, miosis, respiratory depression, } \\
\text { euphoria, dysphoria, dyspnea, physical } \\
\text { dependence }\end{array}$ \\
\hline \multicolumn{4}{|c|}{ Endogenous Peptides } \\
\hline Enkephalin & Agonist & Agonist & \\
\hline$\beta$ endorphin & Agonist & Agonist & \\
\hline Dynorphin A & Agonist & & Agonist \\
\hline \multicolumn{4}{|l|}{ Agonists } \\
\hline Morphine & Agonist & & Weak agonist \\
\hline Codeine & Weak agonist & Weak agonist & \\
\hline Fentanyl, sufentanil & Agonist & & \\
\hline Meperidine & Agonist & & Agonist \\
\hline Methadone & Agonist & & \\
\hline Oxycodone & Agonist & & Agonist \\
\hline \multicolumn{4}{|l|}{ Agonist-antagonists } \\
\hline Buprenorphine & Partial agonist & & Antagonist \\
\hline Pentazocine & Partial agonist & & Agonist \\
\hline Nalbuphine & Antagonist & & Agonist \\
\hline Butorphanol & Partial agonist & & Antagonist \\
\hline Nalorphine & Antagonist & & Agonist \\
\hline \multicolumn{4}{|l|}{ Antagonists } \\
\hline Naloxone & Antagonist & Weak Antagonist & Antagonist \\
\hline Naltrexone & Antagonist & Weak Antagonist & Antagonist \\
\hline
\end{tabular}

form of the nitrogen appears to be crucial to the analgesia of morphine; making the nitrogen quaternary greatly decreases the analgesia, since it cannot pass into the central nervous system. Changes to the methyl group on the nitrogen will decrease analgesia as well, creating antagonists such as nalorphine.

\subsubsection{Opioid Receptors}

There are opioid receptors within the central nervous system (CNS) as well as throughout the peripheral tissues. These receptors are normally stimulated by endogenous peptides (endorphins, enkephalins, and dynorphins) produced in response to noxious stimulation. Greek letters name the opioid receptors, based on their prototype agonists (Table 7).

Mu $(\mu)$ (agonist morphine) - Mu receptors found primarily in the brainstem and medial thalamus. Mu receptors are responsible for supraspinal analgesia, respiratory depression, euphoria, sedation, decreased gastrointestinal motility, and physical dependence. Subtypes include Mul and Mu2, with Mul related to analgesia, euphoria, and serenity, while Mu2 is related to respiratory depression, pruritus, prolactin release, dependence, anorexia, and sedation.
Kappa (К) (agonist ketocyclazocine) Kappa receptors found in limbic and other diencephalic areas, brain stem and spinal cord are responsible for spinal analgesia, sedation, dyspnea, dependence, dysphoria, and respiratory depression.

Delta $(\delta)$ (agonist delta-alanine-deltaleucine-enkephalin) - Delta receptors restricted largely to the brain are not well studied. They may be responsible for psychomimetric and dysphoric effects.

Sigma $(\sigma)$ (agonist N-allylnormetazocine) - Sigma receptors are responsible for psychomimetic effects, dysphoria, stress-induced depression. They are no longer considered opioid receptors, but rather the target sites for phencyclidine (PCP) and its analogs.

These opioid receptors, concentrated in the ventral tegmental and periaqueductal grey areas, presynaptically inhibit the transmission of excitatory pathways: acetylcholine, catecholamine, serotonin, and substance P. Activation of the opioid receptor inhibits adenylate cyclase. All opioid receptors are G proteinlinked structures embedded in the plasma membrane of neurons; activation releases a portion of the $\mathrm{G}$ protein, which moves in the membrane until it reaches its target (either an enzyme or an ion channel).
These targets alter protein phosphorylation and/or gene transcription. Opioids and endogenous opioids activate presynaptic receptors on GABA neurons, which inhibit the release of GABA in the ventral tegmental area. This allows dopaminergic neurons to fire more vigorously, and the extra dopamine in the nucleus accumbens is intensely pleasurable. The varying effects of opioids may therefore be related to varying degrees of affinity for the various receptors.

The opioid receptors were discovered in 1972, and the first endogenous opioid (enkephalin) was discovered in 1975. Their location in the CNS allows them to function as neurotransmitters, and they may play a role in hormone secretion, thermoregulation, and cardiovascular control.

Enkephalins are derived from pro-enkephalin and are relatively selective $\delta$ ligands.

Endorphins are derived from pro-opiomelanocortin (also the precursor for $\mathrm{ACTH}$ and $\mathrm{MSH}$ ), and bind to the $\mu$ receptor.

Dynorphins are derived from pro-dynorphins, and are highly selective at the $\mu$ receptors. 
Nociceptin (orphanin), identified in 1995, may have potent hyperalgesic effects. It has little affinity for the $\mu$, $\delta$, or $\kappa$ receptors. Nociceptin antagonists may be antidepressants and analgesics.

Pure opioid agonists (e.g., morphine, hydromorphone, fentanyl) stimulate $\mu$ receptors and are the most potent analgesics. As the dose is increased, analgesia occurs in a log linear fashion; the degree of analgesia induced is limited only by intolerable dose-related adverse effects. In contrast, opioid agonists/antagonists and opioid partial agonists (buprenorphine, pentazocine, nalbuphine, butorphanol, nalorphine) exhibit a ceiling effect on the degree of analgesia that they can produce. Opiate agonist/antagonists and partial agonists can precipitate opioid withdrawal reactions. The respiratory depressant effects of partial agonists are not completely reversed with naloxone.

\subsubsection{Opioid categories}

The Drug Enforcement Agency (DEA) classifies opioids into schedules as illustrated in Table 8.

The phenanthrenes are the prototypical opioids. The presence of a 6-hydroxyl may be associated with a higher incidence of nausea and hallucinations. For example, morphine and codeine (both with 6hydroxl groups) are associated with more nausea than are hydromorphone and oxycodone (which do not have 6-hydroxyl groups). Opioids in this group include morphine, codeine, hydromorphone, levorphanol, oxycodone, hydrocodone, oxymorphone, buprenorphine, nalbuphine, and butorphanol.

The lone member of the benzomorphan class is pentazocine. It is an agonist/ antagonist with a high incidence of dysphoria.

Phenylpiperidines include fentanyl, alfentanil, sufentanil, and meperidine. Fentanyl has the highest affinity for the mu receptor.

Diphenylheptanes include propoxyphene and methadone.

Tramadol does not fit in the standard opioid classes (Fig. 7).

\section{Opioid antagonists}

Naloxone is a pure competitive antagonist at $\mu, \kappa$, and $\delta$ receptors (strongest at $\mu$ ). It rapidly reverses opioids, but the action is short lived, therefore has the potential for "re-narcotizing."

Table 8. DEA schedules of controlled drugs

\begin{tabular}{|c|l|l|}
\hline Schedule & \multicolumn{1}{|c|}{ Criteria } & \multicolumn{1}{c|}{ Examples } \\
\hline I & $\begin{array}{l}\text { No medical use: high addiction } \\
\text { potential }\end{array}$ & Heroin, marijuana. PCP \\
\hline II & $\begin{array}{l}\text { Medical use: high addiction } \\
\text { potential }\end{array}$ & $\begin{array}{l}\text { Morphine, oxycodone, methadone, } \\
\text { fentanyl, amphetamines }\end{array}$ \\
\hline III & $\begin{array}{l}\text { Medical use; moderate addiction } \\
\text { potential }\end{array}$ & Hydrocodone, codeine, anabolic steroids \\
\hline IV & Medical use; low abuse potential & $\begin{array}{l}\text { Benzodiazepines, meprobamate, } \\
\text { butorphanol, pentazocine, propoxyphene }\end{array}$ \\
\hline V & Medical use; low abuse potential & Buprenex, Phenergan with codeine \\
\hline
\end{tabular}

Naltrexone is used orally in high doses to detoxify opioid addicts. Its primary effect is from its metabolite, $6-\beta$-naltrexol.

\section{Opioid agonist-antagonists}

Opioid agonist-antagonists are classified into two types:

Partial agonists at $\mu$ receptor, such as buprenorphine, have a high affinity but low efficacy at the $\mu$ receptor.

Agonist/partial agonist at $\kappa$ receptor, such as nalorphine, pentazocine, nalbuphine, and butorphanol, act as $\kappa$ agonists but are competitive $\mu$ antagonists, with a high affinity but no efficacy at the $\mu$ receptor. Methylnaltrexone and alvimopan have poor oral absorption and are under investigation for use as oral agents to reverse the decreased GI motility of opioid agonists.

These agonist-antagonists are potent analgesics with ceiling effect and therefore potentially decreased abuse potential. It must be remembered that their antagonist properties may precipitate withdrawal.

\subsubsection{Opioid metabolism}

Many of the side effects of opioids, as well as their effects, may be related to the opioid metabolites. It is generally assumed that most of the metabolism occurs in the liver. The basal rate of metabolism is determined by genetic makeup, gender, age, as well as environment including diet, disease state, and concurrent use of medications. There is no clear evidence of renal metabolism, though the kidney is an important site of excretion. Most opioids are metabolized by glucuronidation or by the P450 (CYP) system. In humans, 57 cytochrome $\mathrm{P}-450$ genes have been identified (148).

CYP3A4 is the most abundant enzyme in the body at 25\% (149). Levels of CYP3A4 may vary as much as 30fold between individuals (149), leading to large variability in blood levels.
CYP1A2, CYP2C8 and CYP2C9 make up about $10 \%$ of the enzymes, CYP2D6 and CYP2E1 each around 5\%, and CYP2C19 around $1 \%$. CYP2D6 is entirely absent in some populations, for example, $6-10 \%$ of Caucasians are 2D6 deficient (150) while other persons have high levels of this enzyme, leading to rapid metabolism of the medicines. Because of genetic polymorphism and variant alleles of the cytochrome P-450 genes, patients may be either rapid or slow metabolizers of opioids. The possibility exists that genotyping will allow identification of these patients, with the ability to titrate their doses appropriately.

\subsection{Pharmacology of Specific Opioids}

\subsubsection{Morphine}

Morphine is a strong Schedule II analgesic, indicated for severe acute pain, or moderate to severe chronic pain. The primary site of action is the CNS. The oral form is available in immediate-release and extended-release dosage forms. The parenteral forms of morphine contain sulfites that may cause anaphylactic or life threatening, allergic-type reactions in individuals with sulfa allergies.

Morphine is a phenanthrene derivative and is the prototype $\mu$ receptor opioid agonist. The absorption of morphine after oral administration varies from $20 \%$ to $30 \%$. Morphine is a relatively long-lasting opioid with analgesic effects lasting 45 hours. Its elimination half-life is 2 hours which is actually less than shorter acting opioids such as fentanyl. Morphine is relatively water soluble. This discrepancy is explained by the low lipid solubility of morphine and its slower elimination from the brain compartment in relation to the plasma concentration, which also may be associated with its existence in an ionizable state in the relatively acid brain compartment. The relatively long analgesic ac- 
tivity of morphine may be associated with the presence of the active morphine metabolites, which have half-lives of elimination longer than morphine itself. As with other strong opioid analgesics, there is no ceiling to the analgesic effect. However, significant side effects, particularly sedation and confusion, may interfere with achieving optimal analgesia (151).

Approximately $50 \%$ to $80 \%$ of the dose administered is typically recovered as glucuronide metabolites, mostly morphine-3-glucuronide (M3G) and morphine-6-glucuronide (M6G), whereas approximately $2 \%$ to $8 \%$ of the dose typically is found in urine as unmetabolized morphine. Morphine is also metabolized to codeine, normorphine-3, 6-diglucuronide, and morphine-3-sulfate. The liver is the major site of metabolism of morphine, even though extrahepatic glucuronidation has been reported. Morphine glucuronides are eliminated from the body by urinary secretion. During long-term morphine administration, circulating concentrations of M3G and M6G markedly exceed those of morphine itself because hepatic metabolism converts approximately $70 \%$ of morphine into $\mathrm{M} 3 \mathrm{G}$ (60\%) and M6G (10\%). M6G and normorphine are both opioid agonists; M6G is 3-4 times more potent than morphine when injected subcutaneously, and 45 times more potent after intracerebroventricular injections in mice (152). M3G has a low affinity for the opioid receptor, and may be responsible for the side effects of hyperalgesia, and myoclonus (153-155). Hepatic (156) and renal (157) disease may significantly prolong the effect of morphine. Accumulation of morphine metabolites (especially M6G) becomes significant as creatinine clearance declines below $50 \mathrm{ml} / \mathrm{min}$ (158). A steady state for long acting preparations is usually reached in 1-2 days. In adults, longterm oral administration of morphine produces variable plasma ratios of $\mathrm{M} 3 \mathrm{G}$ and M6G, with reported mean ratios between 10:1 and 5:1.

\subsubsection{Codeine}

Codeine, first isolated in 1832, is the prototype of the weak opioid analgesics with weak affinity to $\mu$ opioid receptor. Codeine in its pure form is a Schedule II substance, but in combination with other analgesics, it is Schedule III. Its analgesic potency is approximately $50 \%$ of the morphine with a half-life of 2.5 to 3 hours.
Codeine is a pro-drug, and has no effect until metabolized by CYP2D6 to morphine $(159,160)$. Genetic deficiencies and multiple drugs interactions can lead to its ineffectiveness (151).

Codeine is also metabolized by glucuronidation to codeine-6-glucuronide (C6G). Minor metabolic pathways result in other metabolites including nor-codeine and morphine (161). C6G has been shown to be antinociceptive in rats (162). Doses of codeine greater than $65 \mathrm{mg}$ are not well tolerated. Codeine has a half-life of 3 hours, and $>80 \%$ of the dose is excreted in 24 hours.

\subsubsection{Dihydrocodeine}

Dihydrocodeine is similar to codeine and also has a pharmacokinetic pattern similar to it. In the commercial form it

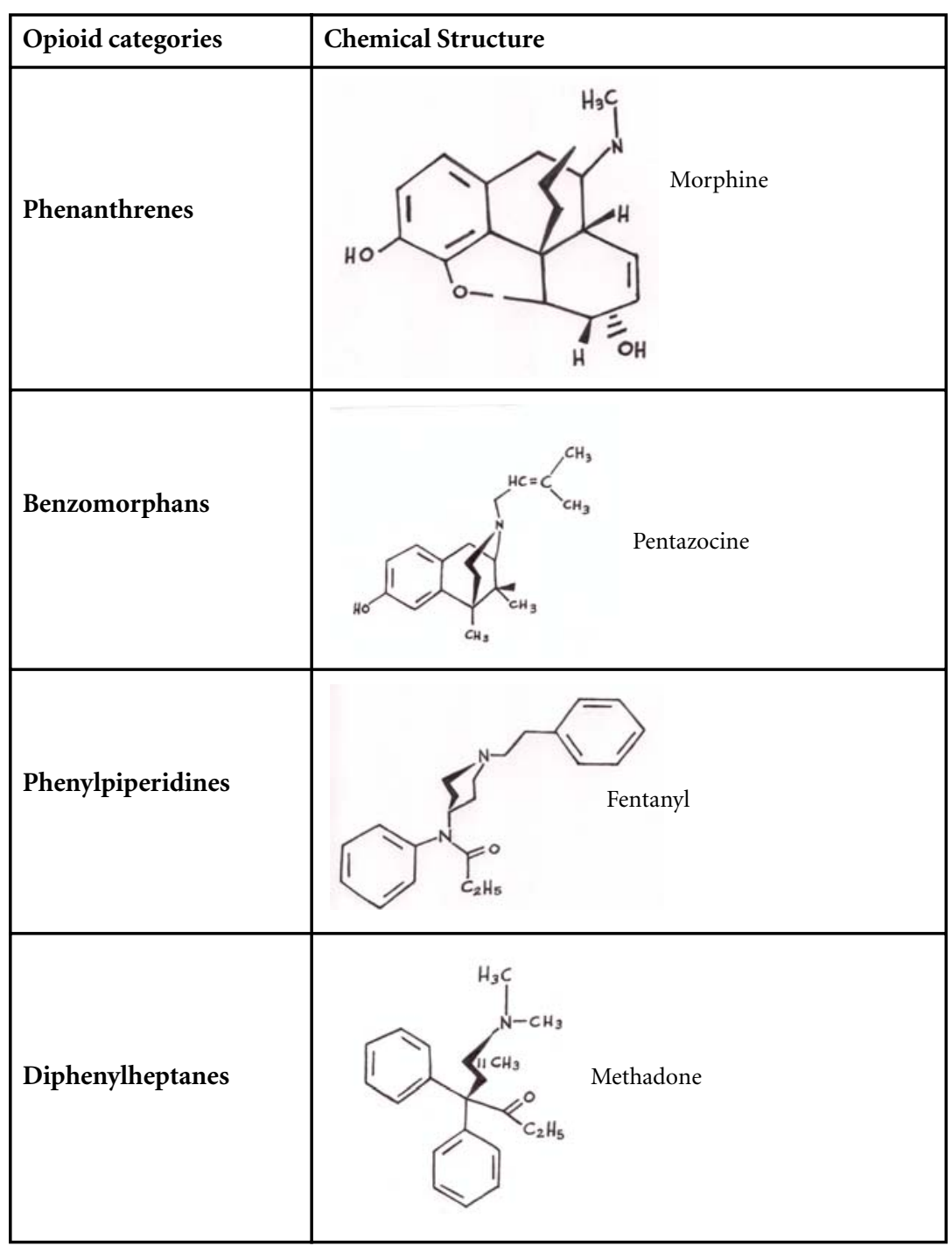

Fig. 7. Opioid classification is available as Synalgos-DC (163). Most of dihydrocodeine is conjugated to inactive dihydrocodeine-6-glucuronide. Less lized to nordihydrocodeine and to dihydromorphine (DHM). DHM has stronger affinity to $\mu$ opiate receptor than morphine itself, and it is also conjugated further to the next active metabolite, DHM6-glucuronide and inactive DHM-3-glucuronide (164). Dihydrocodeine has a halflife of about 4 hours.

\subsubsection{Hydrocodone}

Hydrocodone is a mild opioid agonist and is indicated for moderate to moderately severe pain as well as symptomatic relief of nonproductive cough. Hydrocodone is the most commonly used opioid. Hydrocodone in its pure form is a Schedthan $10 \%$ of dihydrocodeine is metabo- 
ule II substance; however it is only available for pain control as an oral, combination product with non-opioid analgesics, such as ibuprofen and acetaminophen. As a combination product, hydrocodone is a Schedule III substance because the amount of hydrocodone is limited to a maximum $15 \mathrm{mg}$ per dosage unit. The maximum recommended daily dose of hydrocodone is $37.5 \mathrm{mg}$ when combined with ibuprofen or $60 \mathrm{mg}$ when combined with acetaminophen (165).

Hydrocodone bioavailability after oral administration is high and its effectiveness is similar to that of morphine with oral administration. The half-life of hydrocodone is 2.5 to 4 hours. Hydrocodone undergoes extensive hepatic conjugation and oxidative degradation to a variety of metabolites excreted mainly in the urine. Two major metabolites of hydrocodone excreted in the urine are dihydrocodone and nordihydrocodone, both conjugated to approximately $65 \%$. Hydrocodone is also metabolized to dihydromorphone (DHM). DHM is produced only in minor amounts and is conjugated further to $85 \%$. Only about $25 \%$ of the dose is excreted in 72 hours. Some of the hydrocodone metabolites including DHM, hydromorphone, and dihydrocodone are pharmacologically active on the opioid receptors. They may contribute in various degrees to analgesic activity of hydrocodone or produce unexpected side effects when their excretion is impaired, and may show up on urine drug screens, leading to false accusations of abuse. On the other hand, patients who are CYP2D6 deficient, or patients who are on CYP2D6 inhibitors, may not produce these analgesic metabolites, and may have less than expected analgesia.

\subsubsection{Oxycodone}

Oxycodone is considered as a moderate to strong opioid agonist and is a Schedule II substance whether alone or in combination with aspirin or acetaminophen. It is used orally for moderate to moderately severe pain and postoperative, post exertional, and post partum pain (166). In recent years, extended-release preparations have been extensively used for moderate-to-severe chronic malignant and nonmalignant pain. The adverse effects of oxycodone are milder than those of morphine, but the addiction potential of oxycodone may be the same or higher than morphine.

Bioavailability of oxycodone is high in oral dosage, with a half-life of 2.5 to 3 hours. It undergoes extensive hepatic conjugation and oxidative degradation to a variety of metabolites excreted mainly in urine. Oxycodone is metabolized by glucuronidation to noroxycodone (which has less than $1 \%$ of the analgesia potency of oxycodone), and by 2D6 to oxymorphone. Oxycodone has activity at multiple receptors, but oxymorphone has high affinity for the $\mu$ receptor with negligible interaction with $\kappa$ and $\delta$ receptors (167). Oxymorphone is about 10 times more potent than morphine. Oxymorphone is not affected by CY2D6 or CY3A4. Oxycodone is conjugated extensively in the liver, ranging from $15 \%$ to $80 \%$ of the total dose. However, a minority of the dosage undergoes via hepatic pathways into noroxycodone, oxymorphone, oxycodols and their respective oxides. Less than $10 \%$ of unchanged oxycodone is excreted in the urine. Significant individual variation in oxycodone metabolism may account for abnormal responses (168).

\subsubsection{Hydromorphone}

Hydromorphone is a Schedule II semi-synthetic opioid agonist and a hydrogenated ketone of morphine (169, 170). It has been widely used for acute pain, chronic cancer pain, and to a lesser extent in chronic non-malignant pain. Hydromorphone is structurally very similar to morphine (171). Like morphine, it acts primarily on $\mu$ opioid receptors and to a lesser degree on delta receptors (172).

Hydromorphone is significantly more potent than morphine, with estimates of a relative potency of 7:1 up to $11: 1 \mathrm{com}-$ pared to morphine. It is highly water soluble which allows for very concentrated formulations. In patients with renal failure it may be preferred over morphine due to morphine's risk of toxic metabolite accumulation.

Hydromorphone is available in various formats: powder, solution, intermediate release tablet and modified-release tablet. Hydromorphone is extensively metabolized in the liver with approximately $62 \%$ of the oral dose being eliminated by the liver on the first pass, partly accounting for oral bioavailability in the range of 1:2 to $1: 8$ (173). For orally administered immediate release preparations, the onset of action is approximately 30 minutes with a duration of action of 4 hours (173). Hydromorphone can also be administered parenterally by intravenous, intra- muscular, and subcutaneous routes.

Hydromorphone is metabolized primarily to hydromorphone-3-glucuronide (H3G), which, similar to the corresponding M3G, is not only devoid of analgesic activity but in animal models also evokes a range of dose-dependent excited behaviors, including allodynia, myoclonus and seizures.

\subsubsection{Methadone}

Methadone is a synthetic $\mu$ opioid receptor agonist Schedule II drug (157). Methadone, in addition to its opioid receptor activity, is an antagonist of $\mathrm{N}$ methyl-D-aspartate (NMDA) receptors. Methadone is a racemic mixture of two enantiomers; R-methadone accounts for most of its opioid effect while L-methadone is the NMDA antagonist. The inherent NMDA antagonistic effects make it potentially useful in severe neuropathic and "opioid-resistant" pain states. The L isomer also inhibits reuptake of serotonin and norepinephrine, which should be recognized when using selective serotonin reuptake inhibitors (SSRIs).

Methadone is metabolized by $3 \mathrm{~A} 4$ primarily, and 2D6 secondarily (173, 174, 175). CYP182 is possibly involved, and a newly proposed enzyme CYP2B6 may be emerging as an important enzyme intermediary metabolic transformation. The potential differences in enzymatic metabolic conversion of methadone may explain the inconsistency of observed halflife.

Methadone has several advantages in the treatment of chronic pain. It has excellent oral bioavailability (up to $100 \%$ absorbed), though it is highly variable (from $40 \%$ to $100 \%$ ). It can be crushed or dissolved to deliver down a nasogastric (NG) tube. It can be used in patients with a true morphine allergy. Methadone is metabolized in the liver and intestines, and is excreted almost exclusively in feces, an advantage in patients with renal insufficiency or failure. It may also cause less constipation than morphine, and it is very inexpensive (176).

The plasma levels decline following a biexponential model -2 to 3 hours of initial phase followed by a 15 to 60 hours of terminal phase. This may partly explain its difference in analgesic action and accumulation of the drug with repeated dosing. Most would agree that the analgesic capacity of methadone is significantly shorter than its known half-life. Eight hours of analgesic relief may be overshad- 
owed by the up to 120-hour half-life of the drug. Methadone has the potential to initiate Torsade de Points, a potentially fatal arrhythmia caused by a lengthening of the QT interval.

Plasma levels of methadone are increased by concomitant administration of cimetidine, erythromycin, ketoconazole, and fluvoxamine. Conversely, plasma levels are decreased by concomitant administration of barbiturates, phenytoin, carbamazepine, isoniazid, rifampin, ritonavir, nevirapine, and possibly efavirenz.

Methadone may be unique in its lack of profound euphoria, and patient self-directed redosing and long half-life may result in accumulation, with ultimate adverse outcomes including respiratory depression and death. Even when prescribed in low doses, and used appropriately by individuals experienced with opioids, the long half-life of methadone may be underestimated while dosing is titrated to analgesic effect. Furthermore, the list of drug interactions with methadone is extensive, and further alteration in metabolism may occur innocently and unexpectedly, without the prescribing physician's awareness.

\subsubsection{Fentanyl}

Fentanyl is a strong opioid agonist, a Schedule II substance, available in parenteral, transdermal, and transbuccal preparations (157). Fentanyl is the oldest synthetic piperidine opioid agonist, interacting primarily with $\mu$ receptors. It is approximately 80 times more potent than morphine and is highly lipophilic and binds strongly to plasma proteins.

Fentanyl undergoes extensive metabolism in the liver. When administered as a lozenge for oral transmucosal absorption, a portion is swallowed and is subject to first-pass metabolism in the liver and possibly the small intestine. It is metabolized to hydroxyfentanyl and norfentanyl.

Fentanyl is metabolized by $3 \mathrm{~A} 4$, but to inactive and nontoxic metabolites. The transdermal formulation has a lag time of 6-12 hours to onset of action after application, and typically reaches steady state in 3-6 days. When a patch is removed, a subcutaneous reservoir remains, and drug clearance may take up to 24 hours.

\subsubsection{Meperidine}

Meperidine is a Schedule II, relatively weak opioid $\mu$ agonist with only approximately $10 \%$ of the effectiveness of morphine with significant anticholinergic and local anesthetic properties, and with an oral-to-parental ratio of $4: 1$. The half-life of meperidine is approximately 3 hours. It is metabolized in the liver to normeperidine, which has a half-life of 15-30 hours as well as significant neurotoxic properties. Meperidine must not be given to patients being treated with monoamine oxidase inhibitors (MAOI); combination with MAOIs may produce severe respiratory depression, hyperpyrexia, CNS excitation, delirium, and seizures.

Meperidine is metabolized by glucuronidation to normeperidine, which causes CNS stimulation and seizures, especially with high doses or renal insufficiency. Normeperidine has a terminal half life of 8-12 hours so significant amounts can accumulate in only 2 days. Adverse effects of normeperidine are not reversible by naloxone.

\subsubsection{Pentazocine}

Pentazocine is a semisynthetic derivative of the benzomorphans, a Schedule IV substance. It interacts with $\mu$ receptors and $\kappa$ receptors. It is considered a mixed opioid agonist-antagonist. It is manufactured as a racemic mixture (L:R 50:50), but only the L-isomer possesses analgesic activity. It is well absorbed after oral administration. The half-life of pentazocine is about 4 hours. It is metabolized almost exclusively in the liver to inactive glucuronides and oxidation of the terminal methyl groups.

\subsubsection{Propoxyphene}

Propoxyphene is a mild, opioid agonist used in mild to moderate pain and is a Schedule IV substance. Propoxyphene has CNS effects such as dizziness, sedation, weakness and falls, mild visual disturbances, agitation, paradoxical excitement, and insomnia. These effects become more common and can result in drug-related deaths when propoxyphene is used in combination with other drugs that can cause drowsiness $(166,177)$. The GAO, after two studies conducted in 1991 and 1995, recommended that propoxyphene not be used in elderly patients because of the existence of other analgesic medications that are more effective and safer $(177,178)$. Propoxyphene is a synthetic analgesic that is structurally related to methadone and has an opioid dose equipotency similar to codeine. The analgesic activity is confined to its d-stereoisomer (dextropropoxyphene) with a halflife of 6 to 12 hours, with duration of ef- fective analgesia of 3 to 5 hours. It is metabolized in the liver to norpropoxyphene, which has a long half-life of 30 to 60 hours and is considered to have cardiac toxicity. Further, propoxyphene itself can produce seizures (naloxone-reversible) after overdose. In addition to being a $\mu$ receptor agonist, propoxyphene is a weak and noncompetitive N-methyl-D-aspartate (NMDA) receptor antagonist.

\subsubsection{Tramadol}

Tramadol is a synthetic opioid that inhibits norepinephrine and serotonin reuptake and produces some central opioid receptor activity (179). The M1 derivative (O-demethyl tramadol) produced by CYP2D6, has a higher affinity for the $\mu$ receptor than the parent compound. Tramadol is a racemic mixture of two enantiomers - one form is a selective $\mu$ agonist and inhibits serotonin reuptake, while the other mainly inhibits norepinephrine. Maximum dose is $400 \mathrm{mg} /$ day. Toxic doses cause CNS excitation and seizures.

Tramadol is a non-scheduled drug according to federal standards. State regulations may vary. Tramadol is absorbed rapidly and extensively after oral doses, and is equal to the analgesic potency of codeine.

\subsection{Adverse Effects}

The majority of the adverse effects of opioids reflect the effects of opioids at multiple organ systems (180).

- Central nervous system

- A sense of emotional well being and euphoria

- Drowsiness, sedation, or hallucinations

- Potential for diminished psychomotor performance

- Dysphoria, agitation, and seizures

- Respiratory system

- Respiratory depression is the major adverse effect and may result from toxicity.

- Diminution of pain or pain relief by other modalities may exacerbate respiratory depression (181).

- Ocular system

- Miosis stimulation occurs through the parasympathetic ganglion.

- Gastrointestinal system

- Constipation, nausea and vomiting

- $\quad$ Delayed gastric emptying

- Genitourinary

- Urinary retention

- Sexual dysfunction

- Cardiovascular

- Reduction in systemic vascular 
resistance

- Decreased blood pressure but potentially increased cardiac output

- Bradycardia due to vagal stimulation

- Musculoskeletal system

- Muscle rigidity and myoclonus (182)

- Immune system

- Itching is common due to a direct histamine release (especially by morphine)

- $\quad$ Not an allergic reaction $(183,184)$

- Pregnancy

- All opioids cross the placenta

- Neonatal depression can occur if opioids are used during labor

- No teratogenic effects have been observed

- Tolerance

- Decreased duration of analgesia and then decreased effectiveness.

- Physical dependence

- Withdrawal symptoms include runny nose, shivering, "gooseflesh," diarrhea, and mydriasis

\subsection{Drug Interactions}

A drug interaction occurs when the amount or the action of a drug are altered by the administration of another drug or multiple drugs (185). Multiple hepatic drug interactions may influence opioid drug levels $(118,188)$, as illustrated in Table 9.

- There have been isolated reports of interactions between opioid and $\mathrm{H} 2$ blockers (cimetidine and ranitidine) causing breathing difficulties, confusion, and muscle twitching.

Table 9. Drug interactions of opioids

\begin{tabular}{|c|c|}
\hline Tricyclic antidepressants & $\begin{array}{l}\text { Inhibit morphine glucuronidation leading to } \Uparrow \text { blood levels } \\
\text { - Nortriptyline inhibits non-competitively } \\
\text { - Amitriptyline and clomipramine inhibit competitively }\end{array}$ \\
\hline Methadone and morphine & $\Downarrow$ metabolism of desipramine, leading to toxicity \\
\hline Quinine & $\Downarrow$ conversion of codeine to morphine leading to $\Downarrow$ analgesia \\
\hline Metoclopramide & Earlier peak plasma levels with controlled-released opioids \\
\hline Meperidine & MAO inhibitors trigger hyperpyrexia \\
\hline Propoxyphene & $\begin{array}{l}\Uparrow \text { carbamazepine, doxepin, metoprolol, propranolol levels } \\
\Downarrow \text { excretion of benzodiazepines, leading to accumulation and } \\
\text { overdose }\end{array}$ \\
\hline Erythromycin & 介 opioid effects \\
\hline Rifampin & $\Downarrow$ opioid effects \\
\hline CY2D6 inhibitors & $\begin{array}{l}\Uparrow \text { tramadol levels } \\
\Downarrow \text { analgesia from hydrocodone/codeine }\end{array}$ \\
\hline CY2D6 substrates & $\Uparrow$ tramadol levels because of competition for metabolism \\
\hline
\end{tabular}

- A patient taking Tamoxifen (a CY2D6 substrate) was noted to get poor relief with oxycodone (which is metabolized by CY2D6) but excellent relief with morphine (168).

Methadone has multiple drug interactions. Phenytoin, carbamazepine, rifampin, erythromycin, barbiturates, and several anti-retrovirals induce methadone metabolism, resulting in decreased blood levels and the potential for withdrawal. The azole antifungals, the SSRIs, and tricyclic antidepressants may increase methadone levels (189). Methadone may also increase TCA levels. Overmedication occurring within a few days is usually due to P450 (CYP) inhibition, while withdrawal reactions taking a week or more are usually due to CYP induction (190). Methadone also has the potential to cause cardiac arrhythmias, specifically prolonged QTc interval and/or torsade de pointes under certain circumstances. Combining methadone with a CYP3A4 inhibitor such as ciprofloxin (191), and even grapefruit, can increase that risk (192). It is recommended that a switch to methadone from another opioid be accompanied by a large (50\% to $90 \%$ ) decrease in the calculated equipotent dose (193).

\subsection{Drug Conversions}

While there have been multiple opioid conversion charts developed, none are reliable and none take into consideration the vast individual differences in effect and metabolism between patients and within medications. Brand name and ge-

eric medications may have significant differences in bioavailability, and metabolism of medications may be influenced by genetic polymorphism and drug interactions. It is therefore important to recognize that "equipotent" doses of medications may have very different degrees of analgesia and side effects. In general, to switch between medications, the clinician must calculate a rough equivalent 24 hour dose, divide by the dosing schedule, and then "under-dose," with subsequent titration to effect.

Most authors agree that oral morphine intravenous (IV) morphine: intrathecal morphine equivalency is $30: 10$ : 1. Hydromorphone is approximately five times more potent than morphine. Ten $\mathrm{mg}$ to $20 \mathrm{mg}$ of IV morphine is roughly equivalent to $25 \mathrm{mcg}$ of transdermal fentanyl. Oral oxycodone is about two-thirds as potent as morphine. Although methadone has been described as equipotent to morphine, it is now clearer that dosing methadone on a milligram-for-milligram basis will lead to life-threatening overdose. For doses of morphine under $100 \mathrm{mg}$, a ratio of 3:1 may be appropriate, while for higher doses of morphine a ratio of $20 \mathrm{mg}$ of morphine for each $\mathrm{mg}$ of methadone may be appropriate (194). It cannot be too strongly emphasized that the dosing of methadone can be potentially lethal and must be done with knowledge and caution.

\subsection{Opioid Therapy and Side Effects}

\subsubsection{Long-term opioid therapy}

While advocacy for appropriate opioid usage in chronic pain continues, it is well known that prolonged use of opioids may result in adverse consequences, including tolerance, hyperalgesia, hormonal effects, and immunosuppression (195). However, the clinical relevance of these problems is only known for opioid tolerance. It is postulated that prolonged use of high doses of opioids is likely to be more toxic than short-term use of low doses, and hormonal effects are most likely to occur in patients with chronic pain who receive high dose opioid therapy (89). The essential aim of a multitude of available guidelines is to protect patients from the adverse effects of opioid therapy in addition to providing access. Paradoxically, opioid treatment may be offered in an attempt to reduce pain and improve function, and thereby reduce the burden 
of care, but the treatment may actually increase the burden of care, because the management of opioid therapy in patients with complex problems is time consuming and difficult (89).

The adverse effects of long-term opioid therapy for the treatment of chronic pain may be avoided or reduced by multiple means. These include limiting the opioid dose, changing the drug formulation, opioid rotation, and understanding that despite all the changes and strategies, escalation of the opioid dose may fail (89).

\subsubsection{Opioid Induced Immunologic Effects}

Opioids are known to effect immune function in many ways that are measurable (196-212). It is accepted that acute administration of opioid agonists is immunosuppressive (197-199). The animal studies have shown that the prototypical opioid morphine suppresses natural killer cell activity (NKCA), inflammatory cytokine production, and mitogen-induced lymphocyte proliferation (196, 200, 201). The human studies provided similar results with morphine and fentanyl (205, 206). Repeated and chronic opioid ingestion in the absence of pain appears to result in significant consequences including high infectious disease prevalence (196, 207). However, in the presence of acute pain, there is evidence that opioid administration in analgesic doses is protective, since pain, in and of itself, has been shown to be immunosuppressive $(196,199,208$, 209). However, much less is known regarding the immune and disease implications related to chronic opioid treatments for chronic pain states. Despite exhibiting normal circulating levels of immunoglobulins throughout, pain patients exhibited reduced in vitro production of immunoglobulins, both before therapy initiation and throughout (210).

\subsubsection{Opioid Induced Hormonal Changes}

Opioids influence the hypothalamicpituitary-adrenal axis and hypothalamicpituitary-gonadal axis, along with others (213-226). Morphine has been reported to cause a strong, progressive decline in the plasma cortisol levels in laboratory animals and humans (213-215). The major effects of opioids include an increase in prolactin and a decrease in luteinizing hormone, follicle-stimulating hormone, testosterone, and estrogen by modulation of hormonal release involving hypo- thalamic-pituitary-gonadal access (216, $223,224)$. While there are no studies to address multiple hormonal issues related to chronic pain and opioid therapy, testosterone depletion has been demonstrated in patients on methadone maintenance therapy (217-219, 223-225). The effect of testosterone depletion may result in hypogonadism, decreased libido, aggression, and drive; amenorrhea or irregular menses; and galacturia $(220,221)$. In fact, clinically relevant testosterone depletion has been reported to develop in the majority of men receiving intrathecal opioid therapy for chronic pain, and they benefited from testosterone-replacement therapy $(221,222)$, with an increase in analgesia as well as a decrease in testosterone deficiency symptoms.

\subsubsection{Opioid Induced Hyperalgesia}

Hyperalgesia or abnormal pain sensitivity manifests as increased pain from noxious stimuli and as pain from previously non-noxious stimuli. Long-term use of opioids may be associated with the development of hyperalgesia (227-230). Experimental and clinical studies describe that cellular mechanisms of neuropathic pain may be similar to opioid-induced hyperalgesia (229-232). In an experimental setting, NMDA-receptor-mediated changes that cause abnormal pain sensitivity have been shown to occur in animals in the spinal cord dorsal horn cells of animals after repeated exposure to opioids (233). Similarly, these changes have been observed in the spinal cord in animal models of neuropathic pain. Consequently, interactions between neural mechanisms of opioid tolerance and neuropathic pain involving spinal and supraspinal neural circuits may have important clinical implications $(227,234)$.

Repeated administration of opioids not only results in the development of tolerance but also hyperalgesia. In fact, opioid-induced abnormal pain sensitivity has been observed in patients treated for both pain and addiction $(23,235-239)$. It also has been postulated that there may be correlation between tolerance which is a desensitization process, and hyperalgesia which is a pro-nociceptive process or sensitization. In prolonged opioid therapy, desensitization and sensitization together may contribute to tolerance or an afferent decrease in analgesia, regardless of the progression of the pain (238). Ballantyne and Mao (89) stated that the need for dose escalation during opioid therapy - that is, the development of "afferent" opioid tolerance - may result from pharmacologic opioid tolerance, opioid-induced abnormal pain sensitivity, or disease progression. The potential use of NMDA antagonists in the treatment of neuropathic pain, opioid tolerance, and opioid-induced hyperalgesia is the subject of multiple investigations.

\subsubsection{Psychomotor Performance In Opioid Therapy}

The negative effects of opioids on psychomotor performance in the opioid-naïve patient are well known (239242). In addition, some believe that once opioids are added to the management of pain, a patient's ability to operate heavy equipment is diminished and they should not be allowed to drive an automobile (243). However this view is contradicted by others who believe that patients on stable doses of opioid medications should be allowed to drive vehicles (244). The only direct evidence provided in a subset of patients with chronic pain on a stable opioid analgesic regimen (240) shows that these patients are capable of safely operating an automobile during daytime, in normal weather conditions. On virtually every dependent measure tested, this study showed no significant difference among patients with chronic pain without opioids, healthy patients or volunteers, and chronic pain patients on opioids. However, in another study evaluating the effects of immediate-release morphine and cognitive functioning in patients receiving chronic opioid therapy (245), the study suggested that immediate release morphine, when taken on top of sustained release opioid, produced transient anterograde and retrograde memory impairments and a decrement in two-target tracking, leading the authors to conclude that these impairments may have impact.

\subsubsection{Breakthrough Pain Management}

Breakthrough pain and its management is a controversial issue. A prospective study (246) of breakthrough pain and its clinical applications defined breakthrough pain as a transitory flare of pain beyond moderate intensity in the setting of chronic pain stabilized by opioid therapy. Evaluation of opioid therapy in 63 cancer pain patients showed that $64 \%$ of them experienced breakthrough pain. However, except for the application of cancer pain patient data to non- 
cancer pain patients, there have not been systematic evaluations. Indications for breakthrough pain may be abused for additional opioid therapy in chronic noncancer pain.

\section{5.o Terminology of Abuse and AdDICTION}

\subsection{Introduction}

The terminology related to abuse and addiction of opioids and other controlled substances is considered confusing and reflects a lack of understanding of the multiple issues related to abuse and addiction. Savage et al (247) described the scientific basis of addiction-related terms. They provided three fundamental concepts related to addiction in order for it to reflect current scientific and clinical understanding: 1) criteria determination of addiction rests with the user even though some drugs produce pleasurable reward; 2 ) addiction is a multidimensional disease with neurobiological and psychosocial dimensions; and 3) addiction is a phenomenon distinct from physical dependence and tolerance.

\subsection{History}

Historically terminology has not clearly reflected the above-mentioned essential elements and despite significant growth in understanding of the scientific basis of addiction, definitions and diagnostic criteria persist that are based on obsolete conceptualizations of addiction. The terms have been defined by the World Health Organization (WHO), the Diagnostic and Statistical Manual of Mental Disorders, fourth edition (DSM-IV) and United States federal and state policies, as well as other organizations by means of consensus statements.

In 1952, in connection with its role in the international control of drugs, the WHO used two terms: "addiction" and "habituation." Addiction was viewed primarily as the direct effect of certain drugs, and secondly as due to the psychologic make-up of the drug taker. In contrast, habituation was viewed as occurring in response to other drugs which never produce compulsive craving, yet their pharmacologic action is found desirable by some individuals to the point that they readily form a habit of administration (248). The distinction between the two terms lacked clarity and confused most professionals. In 1957, a commit- tee of experts on the addiction-producing drugs convened by the WHO introduced the terms psychological dependence and physical dependence (248). Addiction was characterized by the presence of both physical and psychological dependence and was viewed as primarily drug induced. In 1964, WHO stopped using the terms addiction and habituation altogether and introduced the term drug dependence in their place, noting that dependence is either psychological or physiologic or both, and is a common feature of both conditions (249). In 1969, the WHO re-conceptualized the definition of drug dependence to include significant behavioral criteria and to explicitly acknowledge that drug dependence is due to both host and drug factors (250). In 1993, the WHO expert committee on drug dependence noted the potential for confusion between the terms physical dependence and drug dependence and substituted the term withdrawal syndrome for physical dependence (251). In 1998, the expert committee replaced the term drug dependence with dependence syndrome, but reaffirmed its 1993 definition without revisions (252). Consequently, the 1998 term "dependence syndrome" and the 1993 term "withdrawal syndrome" represent the current WHO nomenclature (252).

The Controlled Substance Act defined addiction as a term meaning any individual who habitually uses any narcotic drug so as to endanger the public morals, health, safety, or welfare or who is so far addicted to the use of narcotic drugs as to have lost the power of self-control with reference to his or her addiction (70).

DSM-IV defines substance abuse and dependence. Substance abuse is a maladaptive pattern of substance use leading to significant impairment or distress in the last 12 months with one (or more) events such as failure to fulfill major role obligations, using inappropriate substances, participating in hazardous situations, being involved in recurrent substance related legal problems and/or continuing use in the face of adverse consequences. In contrast, DSM-IV defines substance dependence as a maladaptive pattern of substance use leading to significant impairment or distress in the last 12 months, meeting the criteria for substance abuse plus three or more of the following seven criteria during the same 12 month period: tolerance, withdrawal, inability to control use, unsuccessful attempts to de- crease or discontinue use, a great deal of time lost in obtaining the substance, using the substance, or recovering from its effects, important activities given up because of use, continued use despite physical or psychological problems caused by use, and continued use of a substance.

Considering that there is significant confusion among all the definitions, several organizations have also defined and clarified various terms. These definitions are related to tolerance, physical dependence, and addiction.

Tolerance is the need for an increased dosage of a drug to produce the same level of analgesia that previously existed. Tolerance is also suspected when a reduced physiologic effect is observed with constant dosing. Analgesic tolerance is not always evident during opioid treatment, and is not to be confused with addiction, which occurs as a dysfunctional craving of a drug action by physiologic action and psychologically driven factors.

Physical dependence is a state of adaptation manifested by a drug class specific withdrawal syndrome that can be produced by drug cessation, rapid dose reduction, decreasing blood level of the drug, and/or administration of an antagonist. Physical dependence is a normal adaptation to the drug, reinforced by continued use. Physical dependence is most commonly associated with withdrawal symptoms when the substance is abruptly discontinued.

Addiction by contrast, is compulsive use of a drug despite physical harm, and the terms tolerance and addiction are not interchangeable. The terminology may share similar characteristics, as many addicts do become tolerant of their chosen drug, which can be expected with regular use. Addiction is a dysfunctional use behavior that includes one or more of the following: impaired control over drug use, compulsive use, continued use despite harm and craving; however, tolerance is a physiologic alteration of metabolism.

In a chronic pain state, a patient may be exposed to a controlled substance for a prolonged period of time, developing tolerance and physical dependence. Addiction may occur, but is an unlikely event. Dependence does not foreshadow harm, or intent at self-destructive behavior. It is therefore, incumbent upon the pain management physician to determine that these definitions and their physiolog- 
ic undertones are well understood, and that the overlap of these definitions does not necessarily define a controlled substance risk, or an inappropriate patient. In other words, tolerance and dependence share many common physiologic characteristics, and addiction may be associated with, but not be defined by, either or both. Physical dependence, addiction, and tolerance are physiologic, social, and psychological considerations with prolonged substance management.

\section{6.o Clinical Effectiveness}

\subsection{Introduction}

Controversy over the prescription of opioids for chronic non-malignant pain continues despite the growing acceptance of this practice and claims that pain is undertreated. The use of opioids has been endorsed by multiple societies and advocacy organizations as appropriate treatment for refractory chronic noncancer pain in the general population as well as in older patients, when used judiciously and according to guidelines similar to those used for cancer patients. While all agree that opioids are indicated in cancer pain, questions continue to arise about opioid usage in non-cancer pain on a long term basis.

\subsection{Systematic Reviews}

Extensive review of the literature was presented by two systematic reviews and two narrative and analytic reviews.

A systematic review by Chou et al (90) evaluated the comparative efficacy and safety of long-acting oral opioids for the treatment of chronic non-cancer pain. This systematic review had a broad scope and key questions including evaluation of the population, drugs, outcomes, and study types. The methodology included an extensive search of literature published between 1980 and 2001, study selection, data abstraction, quality assessment, and data synthesis. Results gave an overview of included trials, answers to key question outcomes, and a summary of evidence. They identified 16 randomized trials with 1,427 enrolled patients that evaluated long-acting opioids in a chronic non-cancer pain population. They included controlled clinical trials to evaluate efficacy, and they also included observational trials to evaluate adverse event rates. In this systematic review, the results showed that only two of the 16 trials compared one long-acting opioid to another $(253,254)$. Seven trials (255-261) compared a longacting opioid to a short-acting opioid, and seven trials (262-268) compared a long-acting opioid to a non-opioid or placebo. The trials ranged in size from 12 patients to 295 patients, with an average enrollment of 79 patients. The trials were focused on multiple pain problems: five on back pain; five on osteoarthritis; two on neuropathic pain; one on phantom limb pain; and three on heterogenous chronic non-cancer pain. All of the trials were of relatively short duration, ranging from 5 days to 16 weeks. In head-to-head comparisons, the results showed poor evidence that one or more long-acting opioids were superior to other long-acting opioids in reducing pain and improving functional outcomes when used for treatment of adults with chronic non-cancer pain. The evidence was poor in comparing long-acting opioids to other types of drugs or to placebo in suggesting that one long-acting opioid was more effective than another. Evidence was also poor with regards to long-acting opioids being superior to short-acting opioids in reducing pain and improving functional outcomes when used for treatment in adults with chronic non-cancer pain. Finally, the evidence was also poor as to the effectiveness or fewer adverse effects of one longacting opioid versus another in evaluated subpopulations, or patients with chronic non-cancer pain. The authors were concerned over a lack of high-quality evidence comparing long-acting opioids to one another, and to short-acting opioids, in patients with chronic non-cancer pain. They felt that data was inadequate to determine whether long-acting opioid preparations, either compared to each other or to short-acting opioids, have different efficacy and safety profiles.

The second systematic review by Kalso et al (91) included in their methodology section the search criteria, inclusion criteria and reporting, data extraction, and analysis. They provided results of included studies, quality and validity, description of the patient population, oral opioid dosing, and open label follow-up studies. They included 18 randomized, double-blind, placebo-controlled trials which met inclusion criteria. In this systematic review, 11 studies $(254,256,262$, 264-266, 268-272) compared oral opioids with placebo, over periods ranging from 4 days to 8 weeks, with open follow-ups of up to 2 years. They included seven studies $(254,256,262,264-266,268)$ in the review, which were also included by Chou et al (90). Patients in most studies had previously used opioids. Six of the studies dealt with neuropathic pain, four with musculoskeletal pain, and one with mixed pain. Of 1,025 randomized patients, 674 completed the studies. Adverse effects and lack of efficacy were the most frequent reasons for discontinuation during both opioid and placebo treatments. They concluded that opioids alleviated nociceptive and neuropathic pain, but trials reported large individual variations. The mean pain relief with opioid was about $30 \%$. The lowest maximum doses, morphine $30 \mathrm{mg}$ and oxycodone $20 \mathrm{mg}$ daily were used in musculoskeletal pain and were not effective. About $80 \%$ of patients experienced at least one adverse event, with constipation $(41 \%)$, nausea (32\%), and somnolence $(29 \%)$ being most common. Only $44 \%$ of the 388 patients on open label treatments were still on opioids between 7 and 24 months after therapy. The conclusions were that the short-term efficacy of opioids was good in both neuropathic and musculoskeletal pain conditions. However, only a minority of patients in these studies went on to long-term management with opioids.

A narrative review by Ballantyne and Mao (89) also reviewed clinical studies. They concluded that a cautious approach must be used in dose escalation and further recommended discontinuation of opioid if treatment goals are not met. They also recommended that it is imperative physicians make every effort to control indiscriminate prescribing even when they are under pressure by patients to increase the opioid dose. They reviewed 16 randomized trials $(254,259,262,263$, 266-268, 270, 271, 273-279). Of these, 15 showed significant analgesic efficacy for periods of one week to several months. However, beneficial effects on functioning were observed less consistently (253, 254, 259, 260, 262, 266, 267). Ballantyne and Mao (89) included seven studies (254, 256, 259, 262, 263, 267, 268) from Chou et al (90). They also reviewed two studies $(270,271)$ from Kalso et al (91).

Bloodworth (88) reviewed and analyzed multiple issues in opioid management. She performed a review of published trials and identified 26 citations that evaluated the effects of short- or long-term opioids in adults experiencing 
chronic, non-malignant pain $(253,254$, $260,262,263,266,267,270,275,277,279$ 293). She included not only randomized trials but also observational reports (286289). She included eight studies from Chou et al (90), four studies from Kalso et al (91), and nine studies from Ballantyne and Mao (89). The average change in pain intensity from baseline was $27.8 \%$ for patients receiving opioids versus $6.8 \%$ for patients receiving placebo. Over one-third of patients receiving a trial of opioids rejected the trial because of adverse effects. Bloodworth also reported that, based on the results, long-term use of opioid therapy is not associated with fine motor or cognitive impairment in the majority of patients with chronic back pain.

The four reviews described above, two systematic and two narrative, evaluated a total of 32 controlled studies ( Table 10). All the reviews provided only limited strength of evidence with regards to the clinical effectiveness of opioids on a long-term basis.

There was also one systematic literature review of reasons for administration, prescription patterns, effectiveness, and side effects of oral methadone for chronic non-cancer pain (290). The authors of this study found a total of 21 papers, one of which was a small randomized trial (291), 13 were case reports, and seven were case series involving 545 patients under treatment for multiple non-cancer pain conditions. Methadone was administered primarily when previous opioid treatment was ineffective or produced intolerable side effects. Starting doses ranged from $0.2 \mathrm{mg}$ to $80 \mathrm{mg}$ per day and maximum doses ranged from $20 \mathrm{mg}$ to $930 \mathrm{mg}$ per day. Meaningful outcomes in pain were reported in $59 \%$ of the patients in the uncontrolled studies. The single randomized trial (291) demonstrated a statistically significant improvement in neuropathic pain with methadone $(20 \mathrm{mg}$ per day) as compared to placebo. Side effects were considered to be minor. However, the authors cautioned that the figure of $59 \%$ effectiveness of methadone should be interpreted very cautiously, as it seems overrated due to the poor quality of the uncontrolled studies and their tendency to report positive results.

\subsection{Other Controlled Trials}

Since the publication of the above reviews, our search yielded 10 additional references as shown in Table 10 (292-301).
Of the 10 additional trials found since the publication of the above systematic reviews, five studies evaluated tramadol, two evaluated oxycodone, one evaluated transdermal buprenorphine, one compared transdermal fentanyl to long-acting morphine, and one study evaluated extended-release oxymorphone. Of these, four studies included patients with chronic low back pain, two studies included patients with chronic non-specific pain and four studies included patients with osteoarthritis. None of the studies lasted more than 12 weeks, and therefore have limited applicability to chronic pain patients.

\subsection{Influence of Psychopathology on Opioid Effectiveness}

Psychopathology in pain patients is very common, with major depression and anxiety seen in as high as $80 \%$ of the patients, a factor that may have a negative affect on opioid analgesia in patients with chronic pain $(116,302-315)$. Depression, anxiety, and neuroticism are disorders of negative affect, which often co-occur in some combination in patients with chronic pain (300). Consequently, disorders of negative affect have been shown to correlate with increased pain intensity and poorer function, regardless of the treatment modality. It was shown that psychopathology predicts poor opioid analgesia in patients with chronic low back pain (302).

\subsection{Summary of Evidence}

As listed in Table 10, there were 43 studies included in the evaluation. As described in the systematic reviews, the quality of the studies was generally low with regards to chronic pain. Consequently, despite multiple randomized double-blind trials, the evidence was considered as limited due to lack of long-term studies, either comparative or placebo controlled.

In an editorial titled Potent opioids for chronic musculoskeletal pain: flying blind?, Von Korff and Deyo (92) discussed various issues related to opioid prescriptions. They concluded that the studies were inadequate in evaluating effectiveness and risks of opioids in chronic non-cancer pain, prescription opioid abuse is increasing, caution must be applied in utilizing consensus recommendations as they are not practical in the real world, and there should be no short cuts around rigorous effectiveness research. Breivik (93) dis- cussed indications and controversies of the use of opioids in treating chronic noncancer pain. Breivik reported that in some well selected patients with long-lasting or recurrent pain that is severe enough to markedly reduce their quality of life, and for whom no other more effective and less risky therapies are available, opioid analgesics may reduce the intensity of pain, increase functioning, and improved quality of life for prolonged periods.

\section{7.o Adherence Monitoring}

\subsection{Introduction}

Important issues in opioid therapy for the treatment of chronic pain revolve around the appropriate use of prescription opioids. Consequently, adherence monitoring is crucial to avoid abuse of the drugs and at the same time to encourage appropriate use. Adherence monitoring is achieved by screening tests, urine drug testing, and periodic monitoring.

Confusion surrounding a specific operational definition of opioid misuse among chronic pain patients has complicated the process of effectively assessing and predicting its occurrence (236,316318).

\subsection{Screening for Opioid Abuse}

Even though several investigators have described multiple screening instruments in detecting opioid abuse or misuse in chronic pain patients, there is no widely used screening instrument in current practice (319-325). Chabal et al (81) developed a prescription abuse "checklist" consisting of five criteria as listed in Table 11. Compton et al (319) identified three items which were particularly useful in identifying misuses of opioids (Table 11). Passik et al (320) evaluated a questionnaire among a small group of cancer and HIV patients, evaluating medication use, present and past drug use, patients beliefs about addiction risk, and aberrant drug-taking attitudes and behaviors. Atluri and Sudarshan (324) developed a screening tool to detect the risk of inappropriate prescription opioid use in patients with chronic pain, with identification of six clinical criteria as shown in Table 11. Manchikanti et al (322) evaluated Atluri and Sudarshan's (324) assessment tool with identification of three particularly useful factors (Table 11, p 22). Adams et al (316) developed a pain medication questionnaire based on a 26 -item in- 
Table 10. Analysis of controlled trials of opioids

\begin{tabular}{|c|c|c|c|c|c|c|}
\hline Authors & $\begin{array}{c}\text { Chou et al } \\
(90)\end{array}$ & $\begin{array}{l}\text { Kalso et al } \\
(91)\end{array}$ & $\begin{array}{c}\text { Ballantyne } \\
\text { and Mao (89) }\end{array}$ & $\begin{array}{c}\text { Bloodworth } \\
(88)\end{array}$ & Drug(s) Tested & Condition Evaluated \\
\hline Caldwell et al (254) & Yes & Yes & Yes & Yes & Morphine vs placebo & Osteoarthritis \\
\hline Caldwell et al (256) & Yes & Yes & Yes & No & $\begin{array}{l}\text { Oxycodone-CR vs Oxy } \\
\text { with acetaminophen }\end{array}$ & Osteoarthritis \\
\hline Harke et al (264) & Yes & Yes & No & No & $\begin{array}{l}\text { Morphine-CR vs } \\
\text { carbamazepine }\end{array}$ & Neuropathic pain \\
\hline Huse et al (265) & Yes & Yes & No & No & Morphine & Phantom-limb pain \\
\hline Moulin et al (266) & Yes & Yes & Yes & Yes & Morphine & Chronic pain \\
\hline Roth et al (262) & Yes & Yes & Yes & Yes & Oxycodone-CR vs placebo & Osteoarthritis \\
\hline Allan et al (253) & Yes & No & No & Yes & Fentanyl, morphine & Chronic pain \\
\hline Hale et al (255) & Yes & No & No & No & $\begin{array}{l}\text { Codeine-CR vs Codeine } \\
\text { with acetaminophen }\end{array}$ & Chronic low back pain \\
\hline Gostik et al (257) & Yes & No & No & No & Dihydrocodeine-CR vs IR & $\begin{array}{l}\text { Osteoarthritis \& } \\
\text { chronic back pain }\end{array}$ \\
\hline Jamison et al (259) & Yes & No & Yes & Yes & Morphine, oxycodone & Chronic low back pain \\
\hline Lloyd et al (260) & Yes & No & No & Yes & $\begin{array}{l}\text { Dihydrocodeine-CR vs } \\
\text { propoxyphene }\end{array}$ & Osteoarthritis \\
\hline Salzman et al (261) & Yes & No & No & No & Oxycodone-CR vs IR & Back pain \\
\hline Arkinstall et al (263) & Yes & No & Yes & Yes & Codeine-CR vs placebo & Chronic pain \\
\hline Peloso et al (267) & Yes & No & Yes & Yes & Codeine-CR & Osteoarthritis \\
\hline Watson and Babul (268) & Yes & Yes & Yes & No & Oxycodone & Neuropathic pain \\
\hline Moran (276) & Yes & Yes & Yes & No & Morphine & Rheumatoid arthritis \\
\hline Gimbel et al (269) & No & Yes & No & No & Oxycodone & Diabetic neuropathy \\
\hline Maier et al (270) & No & Yes & Yes & Yes & Morphine & Chronic pain \\
\hline Raja et al (271) & No & Yes & Yes & No & $\begin{array}{c}\text { Opioids vs anti- } \\
\text { depressants }\end{array}$ & $\begin{array}{l}\text { Post-herpetic } \\
\text { neuralgia }\end{array}$ \\
\hline Watson et al (272) & No & Yes & No & No & Oxycodone & Diabetic neuropathy \\
\hline $\begin{array}{l}\text { Haythornthwaite } \\
\text { et al (273) }\end{array}$ & No & No & Yes & No & $\begin{array}{c}\text { Oxycodone, } \\
\text { propoxyphene, codeine, or } \\
\text { hydrocodone }\end{array}$ & Chronic pain \\
\hline Rowbotham et al (274) & No & No & Yes & No & Levorphanol & Neuropathic pain \\
\hline $\begin{array}{l}\text { Kjaersgaard-Andersen } \\
\text { et al (275) }\end{array}$ & No & No & Yes & Yes & $\begin{array}{c}\text { Codeine + paracetamol vs } \\
\text { paracetamol }\end{array}$ & Osteoarthritis \\
\hline $\begin{array}{l}\text { Sheather-Reid and Cohen } \\
\text { (277) }\end{array}$ & No & No & Yes & Yes & Codeine vs ibuprofen & $\begin{array}{l}\text { Neck pain, } \\
\text { fibromyalgia }\end{array}$ \\
\hline Schofferman (278) & No & No & Yes & No & $\begin{array}{l}\text { Methadone, levorphanol, } \\
\text { morphine }\end{array}$ & Low back pain \\
\hline de Craen et al (279) & No & No & No & Yes & Tramadol & Chronic pain \\
\hline Messick (280) & No & No & No & Yes & Propoxyphene vs APAP & Musculoskeletal pain \\
\hline Muller et al (281) & No & No & No & Yes & $\begin{array}{l}\text { Codeine + paracetamol vs } \\
\text { tramadol }\end{array}$ & Chronic back pain \\
\hline Mullican and Lacy (282) & No & No & No & Yes & $\begin{array}{c}\text { Codeine + APAP vs } \\
\text { tramadol }\end{array}$ & Chronic back pain \\
\hline Palangio et al (283) & No & No & No & Yet & Hydrocodone vs codeine & Musculoskeletal pain \\
\hline $\begin{array}{l}\text { Salzman and Brobyn } \\
\text { (284) }\end{array}$ & No & No & No & Yes & Suprofen vs propoxyphene & Osteoarthritis \\
\hline Wilder-Smith et al (285) & No & No & No & Yes & $\begin{array}{c}\text { Tramadol SR vs } \\
\text { dihydrocodeine SR }\end{array}$ & Osteoarthritis \\
\hline Morley et al (291) & No & No & No & No & Methadone & Neuropathic pain \\
\hline Malonne et al (292) & No & No & No & No & Tramadol SR & Osteoarthritis \\
\hline Babul et al (293) & No & No & No & No & Tramadol SR & Osteoarthritis \\
\hline Ruoff et al (294) & No & No & No & No & $\begin{array}{c}\text { Tramadol + } \\
\text { acetaminophen }\end{array}$ & Chronic low back pain \\
\hline Schnitzer et al (295) & No & No & No & No & Tramadol & Chronic low back pain \\
\hline Sittl et al (296) & No & No & No & No & $\begin{array}{c}\text { Transdermal } \\
\text { buprenorphine }\end{array}$ & Chronic pain \\
\hline Gammaitoni et al (297) & No & No & No & No & $\begin{array}{l}\text { Oxycodone }+ \\
\text { acetaminophen }\end{array}$ & Chronic pain \\
\hline Pelosos et al (298) & No & No & No & No & $\begin{array}{l}\text { Tramadol }+ \\
\text { acetaminophen }\end{array}$ & Chronic low back pain \\
\hline Markenson et al (299) & No & No & No & No & Oxycodone-CR & Osteoarthritis \\
\hline Allan et al (300) & No & No & No & No & Fentanyl, morphine & Chronic low back pain \\
\hline Matsumoto et al (301) & No & No & No & No & Oxymorphone & Chronic Osteoarthritis \\
\hline
\end{tabular}


strument. They concluded that the higher prevalence scores were associated with increased disability and patients were at greater risk for opioid misuse.

While similarities exist in all the criteria described, they differ to a great extent. The criteria developed by Atluri and Sudarshan (324) and evaluated by Manchikanti et al $(322,323)$ consistently showed three criteria to be diagnostic of opioid misuse or abuse, including: excessive opiate needs, deception or lying to obtain controlled substances, and doctor shopping. In an elaborate evaluation by Atluri and Sudarshan (324), six criteria were identified which included focus on opioids, opioid overuse, other substance use, nonfunctional status, exaggeration of pain, and unclear pain etiology. However, all screening instruments do not agree. Portenoy (317) compiled a list of aberrant drug-related behaviors, which were divided into two risk categories. Among the strongly predictive behaviors identified were forging prescriptions, stealing or borrowing drugs from others, frequently losing prescriptions, and resisting changes to pain treatment despite adverse effects. Less predictive behaviors were aggressive complaining about the need for more drugs, drug hoarding, and unsanctioned dose escalation or other forms of noncompliance. With a similar list, Savage (318) suggested that opioid addiction might be revealed through such behaviors as unwillingness to taper opioids or try alternative pain treatments, decreased levels of function despite appropriate analgesia, and frequent requests for medication before renewal is due.

Based on the multiple criteria utilized and their validation, the following may be used to indicate potential abuse or inappropriate use of opioids in clinical practice: 1) excessive opioid needs; 2) deception or lying to obtain controlled substances; 3) doctor shopping; 4) nonfunctional status; 5) exaggeration of pain; and 6) prescription forgery.

\subsection{Urine Drug Testing}

Drug testing may be performed by either testing the urine, serum, or hair. However, urine is considered to be the best biologic specimen for detecting the presence or absence of certain drugs due to specificity, sensitivity, ease of administration, and cost. However, controversies exist regarding the clinical value of urine drug testing, partly because the most current methods are designed for, or adapted from, forensic or occupational deterrentbased testing for illicit drug use and are not necessarily optimized for clinical applications in chronic pain management. However, in chronic pain management, when used with an appropriate level of understanding, urine drug testing can improve a physician's professional ability to manage therapeutic prescription drugs with controlled substances, and to diagnose substance abuse or appropriate intake of drugs, thereby leading to proper treatment.
In principle, urine drug tests can detect the parent drug and/or its metabolite(s) and, therefore, demonstrate recent use of prescription medications and illegal substances. For most clinical applications, initial testing is done with class-specific immunoassay drug panels that typically do not identify individual drugs within a class. However, this may be followed by a more specific technique such as a gas chromatography/mass spectometry (GC/MS) to identify, or confirm the presence, or absence, of a specific drug and/or its metabolite(s). Numerous differences exist between various tests and even among the testing laboratories and manufacturers of various rapid drug screen tests, including the number of drugs tested, cross-reactivity patterns, cut-off concentrations, and drug interferences. Consequently, clinicians should remember that the cut-off concentrations used for drugs in federally-regulated testing, particularly opioids, are too high to be of value in clinical practice. Federallyregulated testing includes the five drugs or drug classes tested for in federal employees and employees of federally-regulated industries. The five include marijuana, cocaine, opiates, PCP, and amphetamines/ methamphetamines, with pre-determined cut-off levels with mandatory reconfirmation of results by GC/MS, along with split sample in chain of custody requirements. In contrast, non-regulated testing is used for many purposes, including monitoring patients clinically.

Table 11. Summary description of key criteria in the literature

\begin{tabular}{|c|c|c|c|c|}
\hline $\begin{array}{l}\text { Criteria by Atluri and } \\
\text { Sudarshan (324) }\end{array}$ & Criteria by Chabal et al (81) & $\begin{array}{c}\text { Criteria by } \\
\text { Compton et al (319) }\end{array}$ & $\begin{array}{c}\text { Criteria by } \\
\text { Manchikanti et al (322) }\end{array}$ & $\begin{array}{l}\text { Criteria by } \\
\text { Savage (235) }\end{array}$ \\
\hline Focused on opioids & $\begin{array}{l}\text { Overwhelming focus on opiate issues } \\
\text { during pain clinic visits, persistent } \\
\text { beyond the third clinic treatment session }\end{array}$ & $\begin{array}{l}\text { Belief of addiction } \\
\text { by the patient }\end{array}$ & Excessive opiates needs & $\begin{array}{l}\text { Unwillingness to } \\
\text { taper opioids }\end{array}$ \\
\hline Opioid overuse & $\begin{array}{l}\text { The pattern of early refills ( } 3 \text { or more) or } \\
\text { escalating drug use in the absence of an } \\
\text { acute change in the medical condition }\end{array}$ & $\begin{array}{l}\text { Increasing analgesic } \\
\text { dose or frequency }\end{array}$ & $\begin{array}{l}\text { Deception or lying } \\
\text { to obtain controlled } \\
\text { substance }\end{array}$ & $\begin{array}{l}\text { Effective } \\
\text { analgesia, but } \\
\text { decreased } \\
\text { function }\end{array}$ \\
\hline Other substance use & $\begin{array}{l}\text { Multiple telephone calls or visits with } \\
\text { requests for more opiates, early refills, } \\
\text { or problems associated with the opiate } \\
\text { prescription }\end{array}$ & $\begin{array}{l}\text { Route of } \\
\text { administration } \\
\text { preference }\end{array}$ & Doctor shopping & Early refills \\
\hline Non-functional & $\begin{array}{l}\text { Prescription problems, including lost } \\
\text { medications, spilled medications, or } \\
\text { stolen medications }\end{array}$ & & & \\
\hline Exaggeration of pain & $\begin{array}{l}\text { Opiates obtained from multiple } \\
\text { providers, emergency rooms, or illegal } \\
\text { sources }\end{array}$ & & & \\
\hline Etiology of pain unclear & & & & \\
\hline
\end{tabular}


In clinical practice, urine drug testing is used for accurate record keeping, to identify use of undisclosed substances, to uncover diversion or trafficking, and to determine appropriate intake of prescribed substances. There are typically two types of urine drug testing. These approaches used in proper combination can reduce cost, ensure accuracy, and improve efficiency. The two main types of urine drug testing methods are:

1) Immunoassay drug testing, either laboratory based or by rapid drug testing

2) Laboratory-based specific drug identification with GC/MS, highperformance liquid chromatography (HPLC), etc.

Immunoassays, which are based on the principle of competitive binding, use antibodies to detect the presence of a particular drug or metabolite in a urine sample. Immunoassay drug testing is provided either in the laboratory or by means of rapid drug testing at the point of service. An immunoassay's ability to detect drugs will vary according to the drug concentration in the urine and the assay's cut-off concentration. Any response above the cut-off is deemed positive and any response below the cut-off is negative. Further, immunoassays are subject to cross-reactivity. For example, tests for cocaine are highly predictive of cocaine use. By contrast, tests for amphetamine/ methamphetamine are highly cross-reactive and are unreliable. They may detect other sympathomimetic amines such as ephedrine and pseudoephedrine and, therefore, are not very predictive for amphetamine/methamphetamine use. Further, standard tests for opiates are very responsive for morphine and codeine, but do not distinguish which is present. They also show a lower sensitivity for semisynthetic/synthetic opioids such as oxycodone, fentanyl, methadone, and buprenorphine - a negative response does not exclude use of these opioids. Specific immunoassay tests for semisynthetics/ synthetic opioids may be available.

In contrast to immunoassays or rapid drug testing, laboratory-based specific drug identification is more sophisticated and expensive. Laboratory-based specific drug identification is needed to specifically confirm the presence of a given drug and to identify drugs not included in a screening test. Table 12 illustrates cut-off levels for various drugs detected by urine analysis. Ideally, in chronic pain man-

Table 12. Typical detection times for urine drug testing of common drugs of abuse

\begin{tabular}{|l|c|c|}
\hline Drug & $\begin{array}{c}\text { Detection Time } \\
\text { in Urine }\end{array}$ & $\begin{array}{c}\text { Cutoff Level } \\
\text { (ng/mL) }\end{array}$ \\
\hline Morphine & 1 to 3 days $(2 \mathrm{wks})$ & 300 \\
\hline Methadone & 2 to 4 days $(2 \mathrm{wks})$ & 300 \\
\hline Hydrocodone & 2 to 4 days $(2 \mathrm{wks})$ & 50 \\
\hline Oxycodone & 2 to 4 days $(2 \mathrm{wks})$ & 100 \\
\hline Benzodiazepines & Up to 30 days & 300 \\
\hline Barbiturates (short-acting) & 2 to 4 days & 300 \\
\hline Barbiturates (long-acting) & Up to 30 days & 300 \\
\hline Marijuana (chronic use) & Up to 30 days & 50 \\
\hline Cocaine (benzoylecgonine-cocaine metabolite) & 1 to 3 days & 300 \\
\hline Amphetamine or methamphetamine & 2 to 4 days & 1000 \\
\hline
\end{tabular}

agement settings a panel for rapid drug screening should include not only opiates, but also oxycodone and methadone. In addition, the panel should include cocaine, marijuana, amphetamines and methamphetamines for illicit drugs, and benzodiazepines and barbiturates for other controlled substances. If a custom panel is not available, multiple tests may have to be performed as rapid drug screening. Since false-negatives and false-positives are possible, when questions arise, prior to taking any actions, a confirmatory test or no-threshold test must be performed in the laboratory.

Note that detection times can vary considerably, depending upon acute versus chronic use, the particular drug used within a class, individual characteristics of the patient, and the method used to test for a substance.

Physicians should establish a policy regarding their response to a positive drug screen. This may include referral to an addictionologist or psychologist, or may result in the refusal to prescribe opioids. However, it usually does not warrant dismissal of the patient. Furthermore, a policy regarding inappropriate use of prescription drugs provided by the physician, as well as doctor shopping, also should be addressed systematically and consistently. Interpretation of drug screens must include knowledge of the opioid metabolites. For example, a urine screen positive for hydromorphone in a patient receiving hydrocodone reflects not drug abuse but the appropriate metabolism of hydrocodone. In the same way, since codeine is metabolized to morphine, a screen positive for morphine in a patient taking codeine would be ex- pected. Physicians not familiar with the opioid metabolites have wrongly accused too many patients of drug abuse.

\subsection{Periodic Review and Monitoring}

\subsubsection{Periodic Review}

Periodic reviews should assess: the medical diagnoses; psychological diagnoses; informed consent; treatment agreement; appropriate opioid therapy with or without adjuvant medications or with or without interventional techniques; pre and post intervention assessment of pain level and function; and reassessment of pain score and level of function.

Regular assessment of the patient along with the periodic review of the diagnosis is extremely important. Routine assessment of the " 4 As" (analgesia, activity, aberrant behavior, and adverse effects) will help to direct therapy and support the pharmacologic actions taken.

Further assessment should be performed by periodic monitoring, utilizing drug screening tests, and urine drug testing.

\subsubsection{Periodic Monitoring}

At reasonable intervals, depending on the specific circumstances of a given patient, the physician should review the course of treatment and any new information about the etiology of the pain. Continuation or modification of therapy should depend on the physician's evaluation of progress towards stated treatment goals, such as a reduction in a patient's pain scores and improved physical and/or psychosocial function (i.e., ability to work, utilization of healthcare resources, activities of daily living, and quality of social life). If treatment goals are not be- 
ing achieved despite medication adjustments, the physician should reevaluate the appropriateness of continued treatment with the current medications. The physician should monitor patient compliance in medication usage and related treatment plans.

\subsubsection{Prescription Drug Monitoring}

Prescription monitoring programs are changing as the result of recently enacted NASPER legislation that will assist physicians and pharmacists in identifying controlled substance abuse (1,2,5-9). While some existing monitoring programs intend to support state laws to ensure legitimate access to drugs, while preventing illegal diversion $(7,9)$, many represent information collected to assist state law enforcement and regulatory agents in identifying and investigating illegal practices related to controlled substances.

NASPER legislation will allow for electronic sharing of information across state lines, with physicians and pharmacists as primary users of the system. State by state development of NASPER programs will allow for electronic sharing of information across state lines and will ultimately replace most of the current prescription monitoring programs. Current programs generally involve either use of multiple-copy prescriptions or electronic transmission. Multiplecopy prescription programs require physicians to use state-issued duplicate copy prescription pads that contain serial numbers. After a prescription is filled, one copy of the prescription form is sent to a state regulatory agency. However, in recent years these programs have increasingly been replaced by electronic variations that require pharmacists to transmit prescription information via computer to a designated state agency.

Physicians can use these prescription programs to their advantage in monitoring patients. Monitoring can be achieved by initial assessment followed by intermittent assessment of a patient's drug profile. However, if abuse is suspected or the physician's office receives complaints from family, friends, neighbors, law enforcement, appropriate action should be taken, along with frequent monitoring.

\subsubsection{Periodic Education}

Drug education for physicians, providers, and patients is crucial. While it appears that certain medications have revolutionized the treatment of chronic pain in the United States, physicians must balance medical need with the possibility of abuse and diversion, as well as the necessity to comply with state and federal regulations. It is obvious that healthcare practitioners are not only expected to prescribe medications when there is medical need and document appropriately, but they are also expected to prevent illegal diversion and identify drug abuse. Consequently, education is a critical component of any program to control the diversion of prescription drugs (326).

However, data shows that many physicians get little to no training regarding

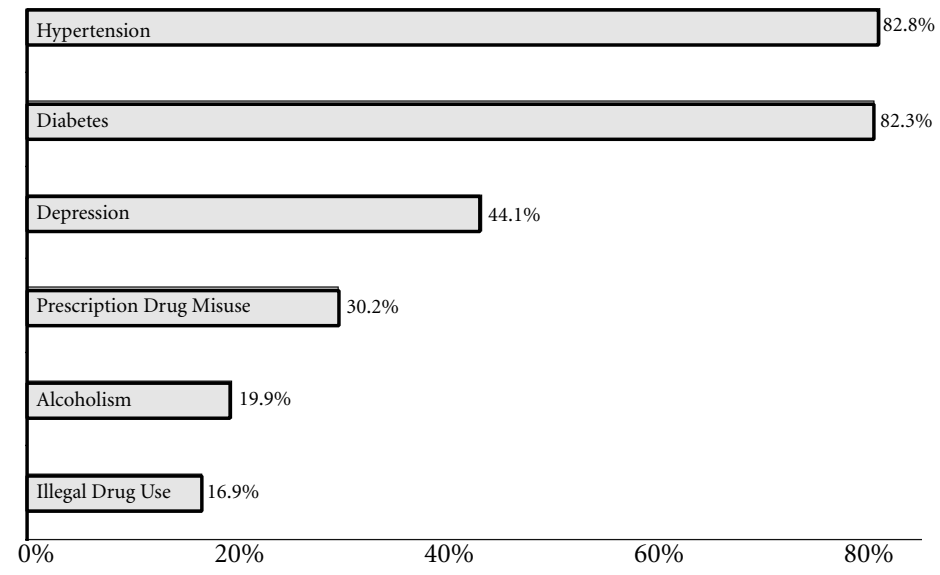

Fig. 8. Conditions that physicians feel "very prepared" to diagnose, 1999 Source: The National Center on Addiction and Substance Abuse at Columbia University, Missed Opportunity: National Survey of Primary Care Physicians and Patients on Substance Abuse (New York: CASA, 2000) (327)

drug abuse $(4,9)$. A 1999 survey of primary care physicians found there was a general lack of training in medical schools about addiction and the signs of substance abuse (327). This survey revealed that $46.6 \%$ of physicians had difficulty discussing prescription drug abuse with patients, and only $32.1 \%$ carefully screened their patients for substance abuse (327). This leads to difficulty discussing substance abuse with patients and an inability to recognize the signs of addiction. Figure 8 shows that the majority of the physicians surveyed did not feel "very prepared" to diagnose substance abuse.

The educational aspects have been improving gradually. The American Society of Interventional Pain Physicians (ASIPP) assists in preventing diversion while maintaining the availability of prescription drugs for medical treatment. ASIPP has devised guidelines for the use of controlled substances in the management of pain, which include information on how to conduct a comprehensive evaluation to select patients for drug therapy and how to use a "controlled substance agreement" as part of patient care. Other ASIPP activities have included actions and support leading to the passage of the National All Schedules Prescription Electronic Reporting Act (NASPER) for uniform drug monitoring programs across the states with interstate communication and physician access to the monitoring programs. In addition, the American Board of Interventional Pain Physicians has made a competency certification available for interested physicians. Other organizations involved in substance abuse training include the American Academy of Family Physicians which has taken steps to make physicians aware of practices such as doctor shopping, and the American Society of Addiction Medicine which conducts seminars and also provides certification in addiction management.

Additionally, several states have taken steps to educate physicians about prescription drugs.

\subsubsection{Pill Counts}

Random pill counts, along with urine drug testing and prescription monitoring, would greatly reduce controlled substance abuse and diversion. Pill counts are essential in patients suspected of abuse. However, these can also be performed randomly on high risk patients.

A pill count is performed by notifying the patient a day before or on the day of the 
patient's appointment that they are requested to bring any unused pills to the appointment. Inability to provide pills, or providing a reduced number, will indicate use beyond the prescription. Pill counts above expected ranges would indicate inappropriate intake. Recently, it has been reported that unsuspecting elderly patients may be selling their prescriptions of controlled substances to supplement their incomes (328).

\section{8.o Principles OF OpIOID USE}

\subsection{Introduction}

In interventional pain management, patients may receive not only opioid analgesics, but also other controlled or noncontrolled drugs. Further, patients may be receiving controlled substances as an adjunct to interventional techniques, as well as to manage comorbid psychiatric and psychological disorders. Thus, the effectiveness studies published may not apply in the majority of cases in interventional pain management. Indeed, controlled substances, particularly opioid analgesics, may be prescribed at lower doses to maintain functional status in conjunction with interventional techniques. It has also been shown that interventional techniques reduce psychological distress significantly once the pain improves. More likely than not, the requirement for opioids and adjuvant drugs may be reduced (329-336). Hence, interventional pain physicians probably should not compare the patients in their settings who are undergoing interventional techniques with others who are receiving drug therapy as a mainstay. Monotherapy, particularly with opioids, may be appropriate for only a small subgroup of those with chronic pain.

Gourlay et al (336) described a rational approach to the treatment of chronic pain with opioids. They described a pain and addiction continuum of substance use in pain patients leading to implementation of "universal precautions" in pain medicine. Ballantyne and Mao (89) also described the potential adverse consequences of prolonged opioid therapy, the clinical implications, and a suggested pro- tocol and algorithmic approach for opioid therapy.

Model guidelines for the use of opioids for the treatment of pain by the Federation of Medical Boards, adapted by several states also provide guidance in the principles of opioid management (73).

\subsection{Basic Philosophy}

Principles for prescribing opioids must require a comprehensive evaluation (mandatory physical and optional psychological), appropriate documentation at regular intervals to assess the efficacy of therapy, with specific evaluation of the impact on functional status, degree of pain relief, identification and treatment of undesirable side effects, and monitoring for abuse behaviors. In addition, there must be adherence to a controlled substance agreement and with regulatory guidelines promulgated by various agencies. Figure 9 shows an algorithmic approach to patient evaluation and management. Table 13 (page 26) shows an algorithmic approach for chronic opioid therapy.

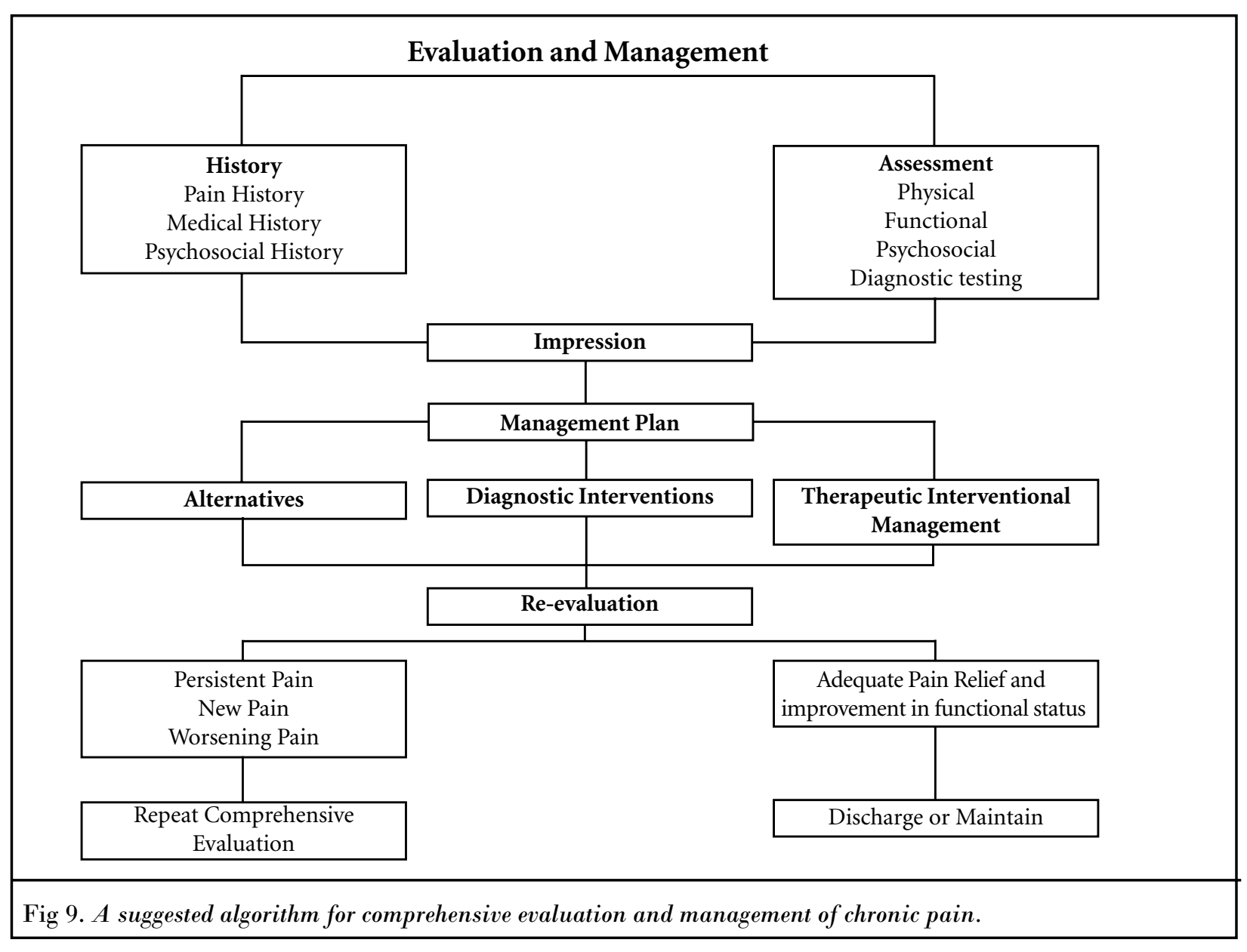




\subsection{Evaluation}

Appropriate history, physical examination, and medical decision-making based on the initial evaluation of a patient's presenting symptoms are essential. Guidelines by the Centers for Medicare and Medicaid Services (CMS) provide various criteria for five levels of service (337-339). The three crucial components of evaluation and management services are: history, physical examination, and medical decision-making. Other components include counseling, coordination of care, nature of the presenting problem, and time required for face-toface evaluation. While there are numerous techniques to evaluate a chronic pain patient, and these vary from physician to physician, institution to institution, and textbook to textbook, following the guidelines established by CMS will assist a physician in performing a comprehensive and complete evaluation while complying with regulations.

\subsubsection{History}

The history includes the chief complaint, history of the present illness, review of systems, and past, family, and/or social history (337-339).

History of the present illness is a chronological description of the development of a patient's present illness from the first sign and/or symptom. It includes multiple elements: location; quality, severity, duration, timing, context, and modifying factors; and associated signs and symptoms.

Review of systems is an inventory of body systems obtained through a series of questions seeking to identify signs and/or symptoms that the patient may be experiencing or has experienced.

Past, family, and/or social history is crucial for chronic pain patients who may be treated with opioids. It consists of a review of the past history of the patient, including past experiences, illnesses, operations, injuries, and treatment; family history, including a review of medical events in the patient's family, hereditary diseases, and other factors; and social history appropriate for age reflecting past and current activities.

Past history in interventional pain management includes history of past pain problems; motor vehicle, occupational, or non-occupational injuries; history of various pain problems; disorders such as arthritis, fibromyalgia, systemic lupus ery-

Table 13. Ten step process: An algorithmic approach for long-term opioid therapy in chronic pain

\begin{tabular}{|c|c|}
\hline STEP I & Comprehensive initial evaluation \\
\hline STEP II & $\begin{array}{l}\text { Establish diagnosis } \\
\text { • X-rays, MRI, CT, neuro-physiological studies } \\
\text { • Psychological evaluation } \\
\text { • Precision diagnostic interventions }\end{array}$ \\
\hline STEP III & $\begin{array}{l}\text { Establish medical necessity (lack of progress or as supplemental therapy) } \\
\text { Physical diagnosis } \\
\text { Therapeutic interventional pain management } \\
\text { • Physical modalities } \\
\text { • Behavior therapy }\end{array}$ \\
\hline STEP IV & $\begin{array}{l}\text { Assess risk-benefit ratio } \\
\text { Treatment is beneficial }\end{array}$ \\
\hline STEPV & Establish treatment goals \\
\hline STEP VI & Obtain informed consent and agreement \\
\hline STEP VII & $\begin{array}{l}\text { Initial dose adjustment phase (up to 8-12 weeks) } \\
\text { Start low dose } \\
\text { Utilize opioids, NSAIDs and adjuvants } \\
\text { - Discontinue due to } \\
\text { • Lack of analgesia } \\
\text { - Side effects } \\
\text { - Lack of functional improvement }\end{array}$ \\
\hline STEP VIII & $\begin{array}{l}\text { Stable phase (stable - moderate doses) } \\
\text { - Monthly refills } \\
\text { Assess for four As } \\
\text { • Analgesia } \\
\text { - Activity } \\
\text { - Aberrant behavior } \\
\text { - Adverse effect } \\
\text { - Manage side effects }\end{array}$ \\
\hline STEP IX & $\begin{array}{l}\text { Adherence monitoring } \\
\text { Prescription monitoring programs } \\
\text { - Random drug screens } \\
\text { Pill counts }\end{array}$ \\
\hline STEP $X$ & $\begin{array}{l}\text { Outcomes } \\
\qquad \text { Successful - continue } \\
\text { • Stable doses } \\
\text { • Analgesia, activity } \\
\text { • No abuse, side effects } \\
\bullet \text { Failed - discontinue if } \\
\text { • Dose escalation } \\
\text { - No analgesia } \\
\text { - No activity } \\
\text { - Abuse } \\
\text { - Side effects } \\
\text { - Non-compliance }\end{array}$ \\
\hline
\end{tabular}

thematosus; drug dependency, alcoholism, or drug abuse; and psychological disorders such as depression, anxiety, schizophrenia, suicidal tendencies, etc.

Family history is also important, and should include not only the history of different pain problems, including degenerative disorders, but also should include familial disorders, drug or chemical dependency, alcoholism, or drug abuse and psychological disorders such as depression, anxiety, schizophrenia, and suicidal tendencies, etc., specifically in first degree relatives.

Social history is also of crucial importance in administering opioids, including environmental information, education, marital status, children, habits, hobbies, occupational history, family support system, and recreational drug usage. 


\subsubsection{Effect on Functional Status}

Some of the aspects specific in controlled substance abuse and chronic pain include evaluation of effect of pain on physical and psychological function, such as activities of daily living.

\subsubsection{Drug History}

It is important to obtain a patient drug profile, including drug history and family history of drugs, and other chronic pain patients in the patient's social circles. It is also important to obtain a pre-drug screening prior to embarking on opioid therapy in conjunction with obtaining a patient's opinion with regards to the doses of controlled substances, the importance of adherence, and its monitoring.

\subsection{Physical Examination}

Physical examination involves general, musculoskeletal, and neurological examinations. Examination of other systems, specifically cardiovascular, lymphatic, skin, eyes and cranial nerves is recommended based on the presenting symptomatology (337-339).

\subsection{Laboratory Studies}

To complement the history and physical examination, a review of the records, either previous records or various investigations, must be obtained or new investigations must be ordered as appropriate. These include multiple radiological studies such as X-rays, MRIs, CT, bone scan, etc.; electrophysiologic studies such as EMG and nerve conduction studies; and blood work.

\subsection{Psychological Evaluation}

Psychological evaluation is an extension of the evaluation process similar to the laboratory evaluation, imaging techniques, electromyography and nerve conduction studies.

By definition, pain is a subjective description of the patient's perception of actual or potential tissue damage. The distinction between pain and suffering should be established. A patient may suffer due to pain, but may have other reasons for suffering as well. The assessment of a patient's overall condition should be made at the initial evaluation and frequently thereafter. It is the goal of the physician to assist in the relief of suffering, no matter the cause. Financial, emotional, mental, physical, and spiritual factors may contribute to the patient's suf- fering. Relief of the underlying causes of suffering, as well as the pain, will lead to optimal treatment and utilization of controlled substances.

\subsection{Medical Decision Making and Treatment Plan}

Medical decision making refers to the complexity of establishing a diagnosis and/or selecting a management option, including providing controlled substances to a patient, and is measured by three components: diagnosis/management options with a number of possible differential diagnoses and/or the number of management options; review of records/ investigations, with number and/or complexity of medical records, diagnostic tests, and other information that must be obtained, reviewed, and analyzed; and risks of significant complications, morbidity and mortality, as well as comorbidities associated with the patient's presenting problem(s), the diagnostic procedures, and/or the possible management options (337-339).

Prior to embarking on a regimen of opioids, the physician must determine, through actual clinical trial or through patient records and history, that non-addictive medication regimens and/or interventional techniques have been inadequate or are unacceptable for solid, clinical reasons. If this information is not available entirely through the patient, a family conference may be helpful to evaluate the patient's integrity. However, because of HIPPA regulations, the ability to have family conferences may be limited. An extensive drug utilization history of the patient must be documented through previous medical records, state drug monitoring programs, and multiple other avenues.

Diagnostic interventional techniques will assist in making the proper diagnosis by following an algorithmic approach (12). It has been shown that in approximately $70 \%$ to $85 \%$ of patients with spinal pain an accurate diagnosis may not be determined in spite of the available history, physical examination, EMG nerve conduction studies, and radiological evaluation. With precise diagnostic interventional techniques, the chances of diagnosis may be improved substantially, and proper treatment may be offered (12,340-345).

Therapeutic interventional techniques also may be used as a monotherapy rather than using opioids for pain man- agement and functional improvement. The effectiveness of various interventional techniques has been evaluated in systematic reviews (12,341,346-350).

A written treatment plan should document objectives that will be used to evaluate treatment success, including pain relief and improved physical and psychosocial function, and should indicate if additional diagnostic tests, consultations, or treatments are planned. After starting treatment, the physician should carefully adjust the drug therapy to the individual medical needs of each patient. In the continuum of treatment, other modalities including interventional techniques, rehabilitation, and psychological therapy may be necessary depending on the etiology of pain and the extent to which pain is associated with physical, functional, and psychosocial impairment.

\subsection{Consultation}

To achieve treatment objectives, physicians should be willing to refer a patient for additional evaluation as clinically indicated. Special attention should be given to those patients who are at risk of misusing their medications and those whose living arrangements create a risk for medication misuse or diversion. The management of patients with a history of substance abuse or with a coexisting psychiatric disorder may require extra care, monitoring, documentation, and consultation with, or referral to, an addictionologist. The lack of well-trained psychologists and psychiatrists in many regions of the country may make this referral difficult to obtain. In many locations there are no clinically trained addiction specialists with whom to collaborate.

\subsection{Informed Consent and the Controlled Substance Agreement}

At the outset, the physician should discuss the risks and benefits of the use of controlled substances with the patient or surrogate, including the risk of tolerance and drug dependence. It is advisable to employ the use of a written agreement between physician and patient outlining patient responsibilities. Agreements are helpful, specifically if the patient is determined to be at high risk for medication abuse or has a history of substance abuse. Possible items of a controlled substance agreement between a physician and patient include:

1. One prescribing doctor and one 
designated pharmacy

2. Urine/serum drug screening when requested

3. No early refills and no medications can be called in. If medications are lost or stolen, then a police report could be required before considering additional prescriptions.

The reasons for which opioid drug therapy may be discontinued should be delineated, such as violation of a documented doctor/patient agreement. Additional items to be included in an agreement are listed in Figure 10.

\subsection{Documentation and Medical RECORDS}

The physician should keep accurate and complete medical records which include all aspects of interventional pain management and medical care. These comprise, but are not limited to:

- The medical history and physical examination

- Diagnostic, therapeutic, and laboratory results

- Evaluations and consultations

- Treatment objectives

- Discussion of risks, benefits, and limitations of treatments

- Details of different treatments and medications, including date, type, dosage, and quantity prescribed

- Instructions to the patient

- Periodic reviews of outcomes, including documentation of functional status, preferably using validated tools

Records should remain current and be maintained in an accessible manner and readily available for review, not only for the physician and other members of the practice, but also the authorities.

To be in compliance with controlled substance laws and regulations required to prescribe, dispense, or administer controlled substances, the physician must have an active license in the state and comply with applicable federal and state regulations. Various boards have published regulations and recommendations for prescribing controlled substances. Physicians are advised to refer to these regulations for their respective state.
Physicians, under all circumstances, except for unavoidable emergencies, should not prescribe scheduled drugs for themselves, immediate family, or staff.

The following criteria should be considered carefully in providing controlled substances:

1. Complete initial evaluation, including history and physical examination

2. Psychological evaluation

3. Physiological and functional assessment, as necessary and feasible

4. Definition of indications and medical necessity:

- Pain of moderate-to-severe degree

- Suspected organic problem

- Failure to respond to noncontrolled substances, adjuvant agents, physical therapy, and interventional techniques

- Patients with interventional techniques as primary modality and controlled substance drugs as a second line treatment.

- Responsiveness to prior interventions with improvement in physical and functional status for continued management, with or without interventions, must be documented.

- For non-opioid controlled substances, appropriate documentation of psychological disorders should be maintained.

- Continued opioid prescriptions require monitoring of:

- Analgesia

- Activity

- Aberrant behavior

- Adverse effects

5. Adherence to the controlled substance agreement with the patient understanding the risks and benefits of controlled substances and the policy and regulations of the practitioner, including controlled substances being prescribed by only one practitioner and being obtained from only one pharmacy.

6. Monitoring for drug abuse or diversion should be routine and, if confirmed, referral to rehabilitation centers may be made, along with termination of prescriptions for controlled substances.

\subsection{KeY POINTS}

1. Opioid guidelines for the treatment of chronic non-cancer pain are developed to improve quality and appropriateness of care, improve patient access, improve patient quality of life, improve efficiency and effectiveness, and achieve cost containment by improving the cost-benefit ratio.

2. Rationalization and importance of these guidelines derives from the fact that most available evidence documents a wide degree of variance in the prescribing patterns of opioids for chronic pain. The strength of available evidence for the use of opioids for chronic non-cancer pain remains Limited, Level IV.

3. Opioids are extensively used in managing chronic pain.

4. There is significant evidence of opioid abuse in conjunction with or without illicit drugs.

5. Abuse terminology is variable. This document attempts to standardize and provide common sense definitions.

6. Opioid pharmacology is variable but understanding it is essential to proper management of patients.

7. Among the rules of opioid administration, comprehensive evaluation and diagnostic assessment are crucial, including diagnosis by interventional techniques.

8. Establishing goals of treatment and using a controlled substance agreement are essential in the practice of pain management with opioids.

9. Periodic review of the patient on opioids is essential, using appropriate adjustments, with routine assessment of analgesia, activity, aberrant behavior, and adverse effects.

10. Documentation is essential, including the need to keep accurate and complete medical records with all the essential elements to provide proper patient care and also meet regulatory and legal requirements. 
We are committed to doing all we can to treat your chronic pain condition. In some cases, controlled substances are used as a therapeutic option in the management of chronic pain, which is strictly regulated by both state and federal agencies. This agreement is a tool to protect both you and the physician by establishing guidelines, within the laws, for proper and controlled substance use. The words "we" and "our" refer to the facility and the words "I," "you," "me," or "my" refer to you, the patient.

1. All controlled substances must come from the physician whose signature appears below or, during his/her absence, by the covering physician, unless specific authorization is obtained for an exception. I understand that I must tell the physician whose signature appears below or, during his/her absence, the covering physician, all drugs that I am taking, have purchased, or have obtained, even over-the-counter medications. Failure to do so may result in drug interactions or overdoses that could result in harm to me, including death. I will not seek prescriptions for controlled substances from any other physician, healthcare provider, or dentist. I understand it is unlawful to be prescribed the same controlled medication by more than one physician at a time without each physician's knowledge. I also understand that it is unlawful to obtain or to attempt or obtain a prescription for a controlled substance by knowingly misrepresenting facts to a physician, or his/her staff, or knowingly withholding facts from a physician or his/her staff (including failure to inform the physician or his/her staff of all controlled substances that I have been prescribed).

2. All controlled substances must be obtained at the same pharmacy, where possible. Should the need arise to change pharmacies, our office must be informed. The pharmacy that you have selected is:

phone:

3. You may not share, sell, or otherwise permit others, including spouse or family members ${ }_{2}$ to have access to any controlled substances that you have been prescribed.

4. Unannounced urine or serum toxicology specimens may be requested from you, and your cooperation is required. Presence of unauthorized substances in urine or serum toxicology screens may result in your discharge from this facility.

5. I will not consume excessive amounts of alcohol in conjunction with controlled substances. I will not use, purchase, or otherwise obtain any other legal drugs except as specifically authorized by the physician whose signature appears below or, during his/her absence by the covering physician, as set forth in Section 1 above. I will not use, purchase or otherwise obtain any illegal drugs, including marijuana, cocaine, etc. I understand that driving while under the influence of any substance, including a prescribed controlled substance, or any combination of substances (e.g., alcohol and prescription drugs) which impairs my driving ability, may result in DUI charges.

6. Medications or written prescriptions may not be replaced if they are lost, stolen, get wet, are destroyed, left on an airplane, etc. If your medication has been stolen it will not be replaced unless explicit proof is provided with direct evidence from authorities. A report narrating what you told authorities is not enough.

7. Early refills will not be given. Renewals are based upon keeping scheduled appointments. Please do not phone for prescriptions after hours or on weekends.

8. In the event you are arrested or incarcerated related to legal or illegal drugs (including alcohol), refills on controlled substances will not be given.

9. I understand that failure to adhere to these policies may result in cessation of therapy with controlled substances prescribed by this physician and other physicians at the facility and that law enforcement officials may be contacted.

10. I affirm that I have full right and power to sign and be bound by this agreement, and that I have read it and understand and accept all of its terms. A copy of this document has been given to me.

Patient's full name

Patient's signature

Date

Physician's signature

Date

Fig 10. Sample Controlled Substance Agreement

Adapted from Pain Management Center of Paducah, Paducah, KY (Courtesy of Laxmaiah Manchikanti, MD) 


\section{Author Affiliation}

Andrea M. Trescot, MD

Medical Director

The Pain Center

1564 Kingsley Ave.

Orange Park, FL 32073

E-mail:amt57@aol.com

Mark V. Boswell, MD, PhD

Professor of Anesthesiology

Division of Pain Medicine

Texas Tech University Health Sciences

Center

3601 4th Street, MS 8182

Lubbock, TX 79430

E-mail: boswellmv@earthlink.net

Sairam L. Atluri, MD

Medical Director

Tri-State Pain Management Institute

7655 Five Mile Road, Suite 117

Cincinnati, OH 45230

E-mail: atluri_ps@sprynet.com

Hans C. Hansen, MD

Medical Director

Pain Relief Centers

1224 Commerce Street SW

Conover, NC 28613

E-mail: hans@hippocrates.org

Timothy R. Deer, MD

Director

The Center for Pain Relief and

Clinical Professor, Anesthesiology

West Virginia University

Chairman, Committee on Pain

Medicine

The American Society of

Anesthesiology

400 Court Street, Suite 304

Charleston, WV 25301

E-mail: DocTDeer@aol.com

Salahadin Abdi, MD, PhD

Director, Massachusetts General

Hospital Pain Center

Department of Anesthesiology and

Critical Care

Associate Professor of Anesthesiology

Harvard Medical School

15 Parkman Street, Suite 333B

Boston, MA 02114

E-mail: sabdi@partners.org

Joseph F. Jasper, MD

Medical Director

Advanced Pain Medicine Physicians

1628 South Mildred Street, Suite 105

Tacoma, WA 98465-1613

E-mail: apmedicine@qwest.net
Vijay Singh, MD

Medical Director

Pain Diagnostics Associates

1601 Roosevelt Rd.

Niagara, WI 54151

E-mail: vj@wmpnet.net

Arthur E. Jordan, MD

Director, Pain Management Center

Carolina Health Specialists

945 82nd Parkway

Myrtle Beach, SC 29572

E-mail: paindoc@carolina-health.com

Benjamin W. Johnson, MD

Director, Vanderbilt Pain Control

Center

Associate Professor of Anesthesiology

Vanderbilt University Medical Center

Vanderbilt University School of

Medicine

Nashville, Tennessee

Roger S. Cicala, MD

Physician

Semmes-Murphey Neurosurgical

Institute

Associate Professor of Anesthesiology

University of Tennessee Center for

Health Sciences

8940 Meaghan Drive

Memphis, TN 38018

E-mail:rcicala@yahoo.com

Elmer E. Dunbar, MD

Medical Director

Pain Control Network

6400 Dutchman Parkway, Suite 60

Louisville, KY 40205

E-mail: eed@paincontrolnetwork.net

Standiford Helm II, MD

Medical Director

Pacific Coast Pain Management Center

23792 Rockfield Blvd., Suite 101

Lake Forest, CA 92630

E-mail: drhelm@pcpmc.com

Kenneth G. Varley, MD

Medical Director

Southern Pain Specialists

7500 Hugh Daniel Drive, \#360

Birmingham, AL 35242

and Clinical Associate Professor

Dept. of Anesthesiology

School of Medicine

University of Alabama at Birmingham

E-mail: kennethv@southernpain.com
Praveen K. Suchdev, MD

Medical Director

Pain Solutions

Centers for Pain Solutions-

Ambulatory Surgery Center

280 Main Street, Suite 420

Nashua, NH 03060

E-mail:pksuchdev@painsolutionsusa.com

John R. Swicegood, MD

Medical Director

Advanced Interventional Pain and

Diagnostics of Western Arkansas

P. O. Box 10206

Fort Smith, AR 72917

E-mail: aipd@sbcglobal.net

Aaron K. Calodney, MD

Director and Research Coordinator

Implantable Therapies

NeuroCare Network

P. O. Box 130459

Tyler, TX 75713-0459

E-mail: acmd2001@cs.com

Bentley A. Ogoke, MD

Medical Director

Northern Pain Management Center

125 Liberty Street, Suite 100

Springfield, MA 01103

E-mail: bogoke622@aol.com

W. Stephen Minore, MD

President, Rockford Anesthesiologists

Associated

2202 Harlem Road, Suite 200

Loves Park, IL 61111

and Clinical Assistant Professor

University of Illinois College of

Medicine

Rockford, IL

E-mail:minore@aol.com

Laxmaiah Manchikanti, MD

Medical Director

Pain Management Center of Paducah

2831 Lone Oak Road

Paducah, KY 42003

Associate Clinical Professor of

Anesthesiology and Perioperative

Medicine

University of Louisville School of

Medicine

Louisville, KY 40292

E-mail: drm@apex.net 


\section{RefEREnCES}

1. Manchikanti L, Whitfield E, Pallone F. Evolution of the national all schedules prescription electronic reporting act (NASPER): A public law for balancing treatment of pain and drug abuse and diversion. Pain Physician 2005; 8:335-347.

2. Manchikanti L, Brown K, Singh V. National All Schedules Prescription Electronic Reporting Act NASPER: Balancing substance abuse and medical necessity in interventional pain management. Pain Physician 2002; 5:294-319.

3. Atluri S, Boswell MV, Hansen HC, Trescot AM, Singh V, Jordan AE. Guidelines for the use of controlled substances in the management of chronic pain. Pain Physician 2003; 6:233-257.

4. Bollinger LC, Bush C, Califano JA, Chenault KI, Curtis JL, Dimon J, Dolan PR, Ganzi VF, Fisher M, Kelmenson LA, Keough DR, Kessler DA, Malloy EA, Pacheco MT, Plumeri II JJ, Redstone SE, Rosenwald Jr EJ, Schulhof MP, Sullivan LW, Sweeney JJ, Wiener MA. Under the counter. The diversion and abuse of controlled prescription drugs in the U.S. The National Center on Addition and Substance Abuse at Columbia University (CASA), July 2005.

5. Prescription Drug Monitoring: Strategies to Promote Treatment and Deter Prescription Drug Abuse. Hearings of Subcommittee on Health House Energy and Commerce Committee, March 4, 2004.

6. Public Law No: 109-60. H.R. 1132 signed by President George W. Bush on 8/11/05. http://frwebgate.access.gpo.gov/cgi-bin/ getdoc.cgi?dbname=109_cong_public laws\&docid=f:publo6o.109

7. GAO Report. GAO-02-634 Prescription drugs. State monitoring programs provide useful tool to reduce diversion. May 2002. http://searching.gao.gov/ query.html ? col $=+\& q \mathrm{t}=+\mathrm{GAO}-02$ $634 \&$ charset $=i s 0-8859-1 \& q l=\& x=9 \& y=14$. (Accessed December 29, 2005)

8. Drug Trafficking in the United States. DEA Briefs and Background, Drugs and Drug Abuse. www.usdoj.gov/dea/concern/ drug_trafficking.html. (Accessed December 29, 2005)

9. Kraman P. Drug abuse in America - prescription drug diversion. The Council of State Governments. April 2004. www.csg.org

10. Brands B, Blake J, Sproule BA, Gourlay D, Busto UE. Prescription opioid abuse in patients presenting for methadone maintenance treatment. Drug Alcohol Depend 2004; 73:199-207.

11. Busto UE, Sproule BA, Knight K, Romach MK, Sellers EM. Severe dependence on oral opioids. Can J Clin Pharmacol 1998; 5: 23-28.

12. Boswell MV, Shah RV, Everett CR, Sehgal N, Mckenzie-Brown AM, Abdi S, Bowman RC, Deer TR, Datta S, Colson JD, Spillane WF, Smith HS, Lucas-Levin LF, Burton AW, Chopra P, Staats PS, Wasserman RA,
Manchikanti L. Interventional techniques in the management of chronic spinal pain: Evidence-based practice guidelines. Pain Physician 2005; 8:1-48.

13. Manchikanti L, Abdi S, Lucas LF. Evidence synthesis and development of guidelines in interventional pain management. Pain Physician 2005; 8:73-86.

14. West S, King V, Carey T, Lohr K, McKoy $\mathrm{N}$, Sutton S, Lux L. Systems to rate the strength of scientific evidence. Evidence Report/Technology Assessment No. 47 University of North Carolina: Agency for Healthcare Research and Quality. AHRQ Publication No. 02-E016; April 2002.

15. Tunis SR, Stryer DB, Clancy CM. Practical clinical trials: Increasing the value of clinical research for decision making in clinical and health policy. JAMA 2003; 290:16241632.

16. Sackett D, Richardson WS, Roseberg W, Haynes RB. Evidence Based Medicine. Churchill Livingstone, Philadelphia, 1996.

17. O'Brien P, Silagy C, McCallum J, O'Connell, D, Glasziou P, Hill A. How to use the evidence: Assessment and application of scientific evidence. National Health and Medical Research Council, Canberra, Commonwealth of Australia, 2000, pp 1-84.

18. Stroup DF, Berlin JA, Morton SC, Olkin I, Williamson GD, Rennie D, Moher D, Becker BJ, Sipe TA, Thacker SB. Meta-analysis of observational studies in epidemiology: A proposal for reporting. JAMA 2000; 283: 2008-2012.

19. Moher D, Schulz KF, Altman D, for the CONSORT Group. The CONSORT statement: revised recommendations for improving the quality of report of parallel-group randomized trials. JAMA 2001; 285:1987-1991.

20. Verhaak PF, Kerssens JJ, Dekker J, Sorbi MJ, Bensing JM. Prevalence of chronic benign pain disorder among adults: A review of the literature. Pain 1998; 77:231-239.

21. Blyth FM, March LM, Brnabic AJ, Jorm LR, Williamson M, Cousins MJ. Chronic pain in Australia: A prevalence study. Pain 2001; 89:127-134

22. Gureje O, Von Korff M, Simon GE, Gater R. Persistent pain and well-being: A World Health Organization study in primary care. JAMA1998; 280:147-151.

23. Elliott AM, Smith BH, Hannaford PC, Smith WC, Chambers WA. The course of chronic pain in the community: Results of a 4-year follow-up study. Pain 2002; 99:299-307.

24. Yeung SS, Genaidy A, Deddens J, Alhe$\operatorname{mood}$ A, Leung PC. Prevalence of musculoskeletal symptoms in single and multiple body regions and effects of perceived risk of injury among manual handling workers. Spine 2002; 27:2166-2172.

25. Menefee LA, Cohen MJ, Anderson WR, Doghramji K, Frank ED, Lee H. Sleep disturbance and nonmalignant chronic pain: A comprehensive review of the literature. Pain Med 2000; 1:156-172.

26. Bressler HB, Keyes WJ, Rochon PA, Badley $E$. The prevalence of low back pain in the elderly. A systemic review of the literature. Spine 1999; 24:1813-1819.

27. Lawrence RC, Helmick CG, Arnett FC. Estimates of the prevalence of arthritis and selected musculoskeletal disorders in the United States. Arthritis Rheum 1998; 41: 778-799.

28. Mallen C, Peat G, Thomas E, Croft P. Severely disabling chronic pain in young adults: prevalence from a populationbased postal survey in North Staffordshire. BMC Musculoskeletal Disords 2005 , 6:42.

29. Enthoven P, Skargren E, Oberg B. Clinical course in patients seeking primary care for back or neck pain: A prospective 5-year follow-up of outcome and health care consumption with subgroup analysis. Spine 2004; 29:2458-2465.

30. Sjolie AN. Persistence and change in nonspecific low back pain among adolescents: A 3-year prospective study. Spine 2004; 29:2452-2457.

31. Brattberg G. Do pain problems in young school children persist into early adulthood? A 13-year follow-up. Eur J Pain 2004; 8:187-199.

32. Elders LA, Burdorf A. Prevalence, incidence, and recurrence of low back pain in scaffolders during a 3-year follow-up study. Spine 2004; 29:E101-E106.

33. Hoving JL, de Vet HC, Twisk JW, Deville WL, van der Windt D, Koes BW, Bouter LM. Prognostic factors for neck pain in general practice. Pain 2004; 110:639-645.

34. Smith BH, Elliott AM, Hannaford PC, Chambers WA, Smith WC. Factors related to the onset and persistence of chronic back pain in the community: Results from a general population follow-up study. Spine 2004; 29:1032-1040.

35. Cote P, Cassidy JD, Carroll LJ, Kristman V. The annual incidence and course of neck pain in the general population: A population-based cohort study. Pain 2004; 112: 267-273.

36. Daffner SD, Hilibrand AS, Hanscom BS, Brislin BT, Vaccaro AR, Albert TJ. Impact of neck and arm pain on overall health status. Spine 2003; 28:2030-2035.

37. Latza U, Kohlmann T, Deck R, Raspe H. Can health care utilization explain the association between socioeconomic status and back pain? Spine 2004; 29:1561-1566.

38. Dionne CE, Chenard M. Back-related functional limitations among full-time homemakers: A comparison with women employed full-time outside the home. Spine 2004; 29:1375-1382.

39. Luo X, Pietrobon R, Sun SX, Liu GG, Hey L. Estimates and patterns of direct health care expenditures among individuals with back pain in the United States. Spine 2004; 29:79-86.

40. Reyes-Gibby CC, Aday L, Cleeland C. Impact of pain on self-rated health in the community-dwelling older adults. Pain 2002; 95:75-82.

41. Leigh JP, Markowitz SB, Fahs M, Shin C, 
Landrigan PJ. Occupational injury and illness in the United States. Estimates of costs, morbidity, and mortality. Arch Intern Med 1997; 157:1557-1568.

42. Freedman VA, Martin LG, Schoeni RF. Recent trends in disability and functioning among older adults in the United States. JAMA 2002; 288:3137-3146.

43. Hurwitz EL, Morgenstern H, Yu F. Cross sectional and longitudinal associations of low-back pain and related disability with psychological distress among patients enrolled in the UCLA low-back pain study. $J$ Clin Epidemiol 2003; 56:463-471.

44. Turner JA, Franklin G, Heagerty PJ, Wu R, Egan K, Fulton-Kehoe D, Gluck JV, Wickizer TM. The association between pain and dis ability. Pain 2004; 112:307-314.

45. Hough J. Estimating the health care utilization costs associated with people with disabilities: Data from the 1996 Medical Expenditure Panel Survey (MEPS). Annual meeting of the Association for Health Services Research, Los Angeles, California, 2000.

46. Bell G, Kidd D, North R. Cost-effectiveness analysis of spinal cord stimulation in treat ment of failed back surgery syndrome. J Pain Symp Manage 1997; 13:286-295

47. de Lissovoy G, Brown RE, Halpern M, Hassenbusch SJ, Ross E. Cost-effectiveness of long-term intrathecal morphine therapy for pain associated with failed back surgery syndrome. Clin Ther 1997; 19:96-112.

48. Turk DC. Clinical effectiveness and cost-effectiveness of treatments for patients with chronic pain. Clin J Pain 2002; 18:355-365.

49. Walker BF, Muller R, Grant WD. Low back pain in Australian adults: The economic burden. Asia Pac J Public Health 2003; 15: 79-87.

50. Fishman SM, Papazian JS, Gonzalez S, Riches PS, Gilson A. Regulating opioid prescribing through prescription monitoring programs: Balancing drug diversion and treatment of pain. Pain Med 2004; 5: 309-324.

51. Cowan DT. Wilson-Barnett J, Griffiths P, Allan LG. A survey of chronic noncancer pain patients prescribed opioid analgesics. Pain Med 2003; 4:340-351.

52. Joranson DE, Carrow GM, Ryan KM, Schaefer L, Gilson AM, Good P, Eadie J, Peine S, Dahl JL. Pain management and prescrip tion monitoring. J Pain Symptom Manage 2002; 23:231-238.

53. National Institutes of Health Consensus Development Program. Symptom man agement in cancer: Pain, depression and fatigue. Statement prepared following a National Institutes of Health State-of-theScience Conference on Symptom Management in Cancer; Bethesda, MD, July 15-17, 2002. Available at consensus.nih.gov/ta/ 022/022_intro.htm.

54. Gilson AM, Ryan KM, Joranson DE, Dahl JL. A reassessment of trends in the medical use and abuse of opioid analgesics and implications for diversion control: 1997-
2002. J Pain Symptom Manage 2004; 28: 176-188.

55. Fleming DA. Relieving pain: What are today's ethical and legal risks? Mo Med 2002; 99:560-565.

56. Marlowe KF, Chicella MF. Treatment of sickle cell pain. Pharmacotherapy 2002; 22:484-491.

57. Kutner JS, Kassner CT, Nowels DE. Symptom burden at the end of life: Hospice providers' perceptions. J Pain Symptom Manage 2001; 21:473-480.

58. Weiss SC, Emanuel LL, Fairclough DL, Emanuel EJ. Understanding the experience of pain in terminally ill patients. Lancet 2001; 357:1311-1315.

59. Teno JM, Weitzen S, Wetle T, Mor V. Persistent pain in nursing home residents (re search letter). JAMA 2001; 285:2081.

6o. Tolle SW, Tilden VP, Rosenfeld AG, Hickman SE. Family reports of barriers to optimal care of the dying. Nurs Res 2000; 49: 310-317.

61. Bernabei R, Gambassi G, Lapane K, Landi F, Gatsonis C, Dunlop R, Lipsitz L, Steel K, Mor V. Management of pain in elderly patients with cancer. JAMA1998; 279:18771882.

62. Institute of Medicine Committee on Care at the End of Life. Approaching death: improving care at the end of life. Washington, DC: National Academy Press, 1997. Available at books.nap.edu/catalog/ 5801.html.

63. SUPPORT Study Principal Investigators. A controlled trial to improve care for seriously ill hospitalized patients: the Study to Understand Prognoses and Preferences for Outcomes and Risks of Treatments (SUPPORT). JAMA 1995; 274:1591-1598.

64. Hill CS. When will adequate pain treatment be the norm? JAMA 1995; 274:18811882.

65. Dahl JL. Improving the practice of pain management. JAMA 2000; 284:2785.

66. Joranson DE, Gilson AM, Dahl JL, Haddox JD. Pain management, controlled substances, and state medical board policy: a decade of change. J Pain Symptom Manage 2002; 23:138-147.

67. Gilson AM, Joranson DE. Controlled substances and pain management: Changes in knowledge and attitudes of state medical regulators. J Pain Symptom Manage 2001; 21:227-237.

68. Gunnarsdottir S, Serlin RC, Ward S. Patient-related barriers to pain management: The Icelandic barriers questionnaire II. J Pain Symptom Manage 2005; 29:273 285.

69. Glajchen M. Chronic pain: Treatment barriers and strategies for clinical practice. J Am Board Fam Pract 2001; 14:211-218.

70. Drug Enforcement Administration. Physician's manual: An informational outline of the Controlled Substances Act of 1970 . US Department of Justice, Washington, DC, 1990.
71. Lebovits $\mathrm{AH}$, Florence I, Bathina R, Hunko V, Fox MT, Bramble CY. Pain knowledge and attitudes of healthcare providers: Practice characteristic differences. Clin J Pain 1997; 13:237-243.

72. Weinstein SM, Laux LF, Thornby JI, Lorimor RJ, Hill CS Jr, Thorpe DM, Merrill JM. Medical students' attitudes toward pain and the use of opioid analgesics: Implications for changing medical school curriculum. Southern Med J 2000; 93:472-478.

73. Model Policy for the Use of Controlled Substances for the Treatment of Pain. The Federation of State Medical Boards of the United States. Inc., May 2004.

74. Manchikanti L, Damron KS, McManus CD, Barnhill RC. Patterns of illicit drug use and opioid abuse in patients with chronic pain at initial evaluation: A prospective, observational study. Pain Physician 2004; 7: 431-437.

75. Gajraj N, Hervias-Sanz M. Opiate abuse or undertreatment? Clin J Pain 1998; 14:9091.

76. Simon S, Bennett D, Rauck R, Taylor D, Shoemaker $\mathrm{S}$. Prevalence and characteris tics of breakthrough pain in noncancer patients with chronic neuropathic pain. Pain Med 2005; 6:192.

77. Bennett D, Simon S, Rauck R, Taylor D, Shoemaker S. Prevalence and characteristics of breakthrough pain in noncancer patients with chronic back pain. Pain Med 2005; 6:193.

78. Manchikanti L, Manchukonda R, Pampati $\mathrm{V}$, Damron KS. Evaluation of abuse of prescription and illicit drugs in chronic pain patients receiving short-acting (hydrocodone) or long-acting (methadone) opioids Pain Physician 2005; 8:257-261.

79. Manchikanti L, Damron KS, Pampati V, Mc Manus CD. Prospective evaluation of patients with increasing opiate needs: Prescription opiate abuse and illicit drug use. Pain Physician 2004; 7:339-344.

8o. Fishbain DA, Rosomoff HL, Rosomoff RS. Drug abuse, dependence, and addiction in chronic pain patients. Clin J Pain 1992; 8: 77-85.

81. Chabal C, Erjavec MK, Jacobson L, Mariano A, Chaney E. Prescription opiate abuse in chronic pain patients: Clinical criteria, incidence, and predictors. Clin J Pain 1997; 13: 150-155.

82. Katz NP, Sherburne S, Beach M, Rose RJ, Vielguth J, Bradley J, Fanciullo GJ. Behavioral monitoring and urine toxicology testing in patients receiving long-term opioid therapy. Anesth Analg 2003; 97:10971102.

83. Manchikanti L, Pampati V, Damron K, Fellows B, Barnhill RC, Beyer CD. Prevalence of opioid abuse in interventional pain medicine practice settings: A randomized clinical evaluation. Pain Physician 2001; 4: 358-365.

84. Manchikanti L, Pampati V, Damron K. Prevalence of prescription drug abuse and dependency in patients with chronic pain in 
western Kentucky. J KY Med Assoc 2003; 101:511-517.

85. Kell M. Monitoring compliance with OxyContin prescriptions in 14,712 patients treated in 127 outpatient pain centers. Pain Med 2005; 6:186-187.

86. Manchikanti L, Damron KS, Pampati V, McManus CD. Prevalence of illicit drug use among individuals with chronic pain in the commonwealth of Kentucky: An evaluation of patterns and trends. J KY Med Assoc 2005; 103:55-62.

87. Atluri S, Sudarshan G. Evaluation of abnormal urine drug screens among patients with chronic non-malignant pain treated with opioids. Pain Physician 2003; 6:407409.

88. Bloodworth D. Issues in opioid management. Am J Phys Med Rehabil 2005; 84: S42-S55.

89. Ballantyne JC, Mao J. Opioid therapy for chronic pain. N Engl J Med 2003; 349: 1943-1953.

90. Chou R, Clark E, Helfand M. Comparative efficacy and safety of long-acting oral opioids for chronic non-cancer pain: A systematic review. J Pain Symptom Manage 2003; 26:1026-1048.

91. Kalso E, Edwards JE, Moore RA, McQuay HJ. Opioids in chronic non-cancer pain: Systematic review of efficacy and safety. Pain 2004; 112:372-380.

92. Von Korff M, Deyo RA. Potent opioids for chronic musculoskeletal pain: Flying blind? Pain 2004; 109:207-209.

93. Breivik H. Opioids in chronic non-cancer pain, indications and controversies. Eur J Pain 2005; 9:127-130.

94. Luo X; Pietrobon R, Hey L. Patterns and trends in opioid use among individuals with back pain in the United States. Spine 2004; 29:884-891.

95. Turk DC, Brody MC, Okifuji EA. Physicians' attitudes and practices regarding the longterm prescribing of opioids for non-cancer pain. Pain 1994; 59:201-208.

96. Vogt MT, Kwoh CK, Cope DK, Osial TA, Culyba M, Starz TW. Analgesic usage for low back pain: Impact on health care costs and service use. Spine 2005; 30:1075-1081.

97. Pembrook L. Medicaid patients receive more medications, less alternative care. Pain Med News May/June 2005; 20.

98. Caudill-Slosberg MA, Schwartz LM, Woloshin S. Office visits and analgesic prescriptions for musculoskeletal pain in US: 1980 vs. 2000. Pain 2004; 109:514-519.

99. Ytterberg SR, Mahowald ML, Woods SR. Opioid use by patients in an orthopedics spine clinic. Arthritis Rheum 2005; 52:610.

10o. Katz N, Benoit C. Opioids for neuropathic pain. Curr Pain Headache Rep 2005; 9:153160.

101. Ackerman SJ, Mordin M, Reblando J, Xu X, Schein J, Vallow S, Brennan M. Patientreported utilization patterns of fentanyl transdermal system and oxycodone hy- drochloride controlled-release among patients with chronic nonmalignant pain. J Manag Care Pharm 2003; 9:223-231.

102. Hermos JA, Young MM, Gagnon DR, Fiore LD. Characterizations of long-term oxycodone/acetaminophen prescriptions in veteran patients. Arch Intern Med 2004; 164:2361-2366.

103. Ziegler DK. Opioids in headache treatment. Is there a role? Neurol Clin 1997; 15: 199-207.

104. Reid MC, Engles-Horton LL, Weber MB, Kerns RD, Rogers EL, O'Connor PG. Use of opioid medications for chronic noncancer pain syndromes in primary care. J Gen Intern Med 2002; 17:173-179.

105. Sikirica V, Vallow S, Schein J, Doshi D, Katz N, White A, Stang P. Prevalence, comorbidities, and utilization of services of opioid abusers in a managed care pain. Pain Med 2005; 6:190.

106. Novak S, Nemeth WC, Lawson KA. Trends in medical use and abuse of sustainedrelease opioid analgesics: $A$ revisit. Pain Med 2004; 5:59-65.

107. US Department of Health and Human Services. Office of Applied Studies, Substance Abuse and Mental Health Services Administration (SAMHSA). Drug Abuse Warning Network. The DAWN Report. Narcotic analgesics, 2002 update. September 2004 .

108. US Department of Health and Human Services. Office of Applied Studies, Substance Abuse and Mental Health Services Administration (SAMHSA). Drug Abuse Warning Network. The DAWN Report. Benzodiazepines in drug abuse-related emergency department visits: 1995-2002. April 2004 .

109. Sproule BA, Busto UE, Otton SV, Zhong $\mathrm{XH}$, Sellers EM. Abuse and dependence on prescription opiates. Clin Pharmacol Ther 1995; 57:161.

110. McCaskill C. Oversight Controls in the State's Medicaid Prescription Drug Program, 18 April 2002, Performance Audit Report No. 2002-29, 4.

111. National Community Pharmacists Association, NCPA Position Statements, Medicare Reform: JCPP Statement, August 10, 1999. www.ncpanet.org/about/ncpa_position_ statements/m.shtml\#10. (Accessed December 29, 2005.)

112. Substance Abuse and Mental Health Services Administration. (2004). Overview of Findings from the 2003 National Survey on Drug Use and Health (Office of Applied Studies, NSDUH Series H-24, DHHS Publication No. SMA 04-3963). Rockville, MD.

113. Simoni-Wastila L, Tompkins C. Balancing diversion control and medical necessity: The case of prescription drugs with abuse potential. Substance Use \& Misuse 2001; 36:1275-1296.

114. Lewin ICF. Analysis of Prescription Monitoring Programs. Prepared for HoffmanLaRoche by Lewin ICF. Washington DC, April 26, 1991.
115. Batten HL, Prottas JM, Horgan CM, Prottas JM, Simon LJ, Larson MJ, Elliott EA, Bowden ML, Lee MT. Drug Services Research Survey. Phase II Final Report. Submitted to the National Institute on Drug Abuse. Institute for Health Policy, Brandeis University, Waltham, MA February 12, 1993.

116. Polatin PB, Kinney RK, Gatchel RJ, Lillo E, Mayer TG. Psychiatric illness and chronic low back pain: The mind and the spine which goes first? Spine 1993; 18:66-71.

117. Maruta T, Swanson DW, Finlayson RE. Drug abuse and dependency in patients with chronic pain. Mayo Clin Proc 1979; 54:241244 .

118. Hoffmann NG, Olofsson O, Salen B, Wickstrom L. Prevalence of abuse and dependency in chronic pain patients. Int J Addict 1995; 30:919-927.

119. Jinks MJ, Raschko RR. A profile of alcohol and prescription drug abuse in a highrisk community based elderly population. DICP 1990; 24:971-975

120. Manchikanti L, Pampati V, Damron K, Beyer CD, Barnhill RC. Prevalence of illicit drug use in patients without controlled substance abuse in interventional pain management. Pain Physician 2003; 6:173178.

121. Manchikanti L, Beyer C, Damron K, Pampati V. A comparative evaluation of illicit drug use in patients with or without controlled substance abuse in interventional pain management. Pain Physician 2003; 6:281-285.

122. Atluri S, Sudarshan G. A screening tool to determine the risk of prescription opioid abuse among patients with chronic nonmalignant pain. Pain Physician 2002; 5 : 447-448.

123. Lentner S. Drug abuse. Winer Zeitschrift fur Suchforschung 1991; 14:65-68.

124. Hurwitz W. The challenge of prescription drug misuse: A review and commentary. Pain Med 2005; 6:152-161.

125. Center on Addiction and Substance Abuse. Substance abuse and federal entitlement programs. Columbia University, New York, 1995.

126. Feder J, Rowland D, Holahan J, Heslam D. The Medicaid Cost Explosion: Causes and Consequences. Henry J. Kaiser Family Foundation. Menlo Park, CA, 1993, pp 1822.

127. Held G. Linkages between substance abuse prevention and other human services. LiteratureReview June 1998, Part A.

128. GAO Report. United States General Accounting Office. Prescription drugs. OxyContin Abuse and Diversion and Efforts to Address the Problem. GAO Publication No. GAO-4-110, December 2003.

129. Gitchel GT. "Existing Methods to Identify Retail Drug Diversion," Impact of Prescription Drug Diversion Control Systems on Medical Practice and Patient Care, NIDA Research Monograph 131, Rockville, MD, 1993, p 135.

130. U.S. General Accounting Office. Internet 
Pharmacies: Adding Disclosure Would Aid State and Federal Oversight, GAO Publication No. GAO-01-69, October 2000, 3.

131. Cole N. "Rx Roulette on the Internet." Wall Street Journal, June 17, 2004, p A18.

132. Caywood T. "Online Drug Buying Can Turn Into a Nasty Habit; Deals are Illegal, Dangerous," The Boston Herald, 14 December 2003, sec. news.

133. "The Pharmacy Theft Prevention Program," On-Line with Industry, DEA, Office of Diversion Control, 2 (Winter 2002/ 2003), 10.

134. U.S. Department of Justice, Drug Enforcement Administration, DEA Congressional testimony, Statement of Asa Hutchinson, House Committee on Appropriations, 11 December 2001.

135. Office of National Drug Control Policy, Drug Facts: OxyContin http://www.whiteh ousedrugpolicy.gov/drugfact/oxycontin/ index.html (6 September 2005).

136. "Five Ogden-Layton Pharmacies Robbed for OxyContin," The Associated Press State and Local Wire, 28 November 2002, sec. state and regional.

137. "Crime Stoppers Pharmacy Burglary," Columbus Dispatch, 24 November 2003, sec. D8.

138. Overview and Demonstration of Enhanced KASPER (eKASPER) Program. Cabinet for Health and Family Services Office of the Inspector General, March 16, 2005.

139. Pulse Check: Trends in Drug Abuse, Office of National Drug Control Policy, NCJ 191248, Washington, D.C, November 2001, 93.

140. Voris BV. "OxyContin Maker Not Yet Feeling Much Pain; Some Lawyers Wary of Addicted Clients," The National Law Journal, 24 (29 April 2002): A1.

141. Estep B. "Doctor Guilty of Drug Count," Lexington Herald-Leader, 8 April 2003, sec. A8.

142. Mueller L. "Drug Doctor Caught Fleeing," Lexington Herald-Leader, 1 August 2003. sec. B1.

143. "Prescription Fraud, Abuse Costs Taxpayers, Patients," The Associated Press \& Local Wire, 3 December 2003, sec. State and Regional.

144. Richard J, Reidenberg MM. The risk of disciplinary action by state medical boards against physicians prescribing opioids. J Med Licens Discipl 2005; 91:14-19.

145. Federation of State Medical Boards Releases Annual Physician Discipline Report, For Immediate Release: April 18, 2005. http://www.fsmb.org/pub_news-200504-18.html (Accessed September 2005).

146. Kentucky Board of Medical Licensure Newsletter, Summer 2005. http://ky.gov/ agencies $/ \mathrm{kbml} /$ newsletters.html (Accessed September 2005)

147. DEA News Release. The myth of the "chilling effect." October 30, 2003.

148. Wilkinson GR. Drug metabolism and variability among patients in drug response. $N$
Engl J Med 2005; 352:2211-2221.

149. Breimer DD. Genetic polymorphism in drug metabolism: clinical implications and consequences in ADME studies. In Walker S. et al (eds.), The Relevance of Ethnic Factors in the Clinical Evaluation of Medicine. Kluwer Academic Publishers, Dor-drecht/ Boston, 1994, pp 13-26.

150. Evans DA, Mahgoub A, Sloan TP, Idle JR, Smith RL. A family and population study of the genetic polymorphism of debrisoquine oxidation in a white British population. J Med Genet 1980; 17:102-105.

151. Poulsen L, Brosen K, Arendt-Nielsen L, Gram LF, Elbaek K, Sindrup SH. Codeine and morphine in extensive and poor metabolizers of sparteine: Pharmacokinetics, analgesic effect and side effects. Eur J Clin Pharmacol 1996; 51:289-295.

152. Woolf $\mathrm{CJ}$. Intrathecal high dose morphine produces hyperalgesia in the rat. Brain Res 1981; 209:491-495.

153. Shimomura K, Kamata O, Ueki S, Ida S, Oguri K, Yoshimura H, Tsukamoto H. Analgesic effect of morphine glucuronides. Tohoku J Exp Med 1971; 105:45-52.

154. Lotsch J, Skarke C, Schmidt H, Grosch S, Geisslinger $\mathrm{G}$. The transfer half-life of morphine-6-glucuronide from plasma to effect site assessed by pupil size measurement in healthy volunteers. Anesthesiology 2001; 95:1329-1338.

155. Lotsch J, Kobal G, Stockmann A, Brune K, Geisslinger G. Lack of analgesic activity of morphine-6-glucuronide after short-term intravenous administration in healthy volunteers. Anesthesiology 1997; 87:13481358.

156. Twycross RG, Lack S. Symptom Control in Far Advanced Cancer Pain Relief. Pitman, London, 1983.

157. Bodd E, Jacobsen D, Lund E, Ripel A, Mørland J, Wiik-Larsen E. Morphine-6-glucuronide might mediate the prolonged opioid effect of morphine in acute renal failure. Hum Exp Toxicol 1990; 9:317-321.

158. Kaiko RF, Wallenstein SL, Rogers AG, Grabinski PY, Houde RW. Narcotics in the elderly. Med Clin North Am 1982; 66:10791089.

159. Yue QY, Svensson JO, Alm C, Sjoqvist F, Sawe J. Codeine O-demethylation cosegregates with polymorphic debrisoquine hydroxylation. $\mathrm{Br} / \mathrm{Clin}$ Pharmacol 1989; 28:639-645.

160. Eckhardt K, Li S, Ammon S, Schanzle G, Mikus G, Eichelbaum M. Same incidence of adverse drug events after codeine administration irrespective of the genetically determined differences in morphine formation. Pain 1998; 76:27-33.

161. Yue QY, Hasselstrom J, Svensson JO, Sawe J. Pharmacokinetics of codeine and its metabolites in Caucasian healthy volunteers: Comparisons between extensive and poor hydroxylators of debrisoquine. Br J Clin Pharmacol 1991; 31:635-542.

162. Srinivasan V, Wielbo D, Simpkins J,
Karlix J, Sloan K, Tebbett I. Analgesic and immunomodulatory effects of codeine and codeine 6-glucuronide. Pharm Res 1996; 13:296-300.

163. Janicki PK, Parris WC. Clinical pharmacology of opioids. In Smith H (ed). Drugs for Pain. Hanley \& Belfus, Inc., Philadelphia, 2003, pp 97-118.

164. Aderjan RE, Rolf E, Skopp G. Formation and clearance of active and inactive metabolites of opiates in humans. Ther Drug Monit 1998; 20:561-569.

165. McEvoy GK. In AHFS Drug Information $2004 C D$. American Society of Health-System Pharmacists, Bethesda, MD.

166. McLeod CM. A pharmacologic overview of pain management. An online program for pharmacists available at: ashpadvantage.com

167. Metzger TG, Paterlini MG, Ferguson DM, Portoghese PS. Investigation of the selectivity of oxymorphone-and naltrexonederived ligands via site-directed mutagenesis of opioid receptors: exploring the 'address' recognition locus. I Med Chem 2001; 44:857-862.

168. Heiskanen TE, Ruismaki PM, Seppala TA, Kalso EA. Morphine or oxycodone in cancer pain? Acta Oncol 2000; 39:941-947.

169. Murray A, Hagen NA. Hydromorphone. J Pain Symptom Manage 2005; 29:S57S66.

170. Quigley C. Hydromorphone for acute and chronic pain. Cochrane Database Syst Rev 2002; 1:CDo03447.

171. Babul N, Darke AC, Hagen N. Hydromorphone metabolite accumulation in renal failure. J Pain Symptom Manage 1995; 10: 184-186.

172. Benedetti CB, Butler SH. Systemic analgesics. In Bonica JJ (ed.), The Management of Pain, $2^{\text {nd }}$ edition. Lea \& Febiger, Philadelphia, 1990, pp 1640-1675.

173. Vallner JJ, Stewart JT, Kotzan JA, Kirsten EB, Honigberg IL. Pharmacokinetics and bioavailability of hydromorphone following intravenous and oral administration to human subjects. J Clin Pharmacol 1981; 214: 152-156.

174. Oda Y, Kharasch ED. Metabolism of methadone and levo-alpha-acetylmethadol (LAAM) by human intestinal cytochrome $\mathrm{P}_{450} 3 \mathrm{~A}_{4}$ (CYP3A4): Potential contribution of intestinal metabolism to presystemic clearance and bioactivation. J Pharmacol Exp Ther 2001; 298:1021-1032.

175. Eap CB, Buclin T, Baumann P. Interindividual variability of the clinical pharmacokinetics of methadone: Implications for the treatment of opioid dependence. Clin Pharmacokinet 2002; 41:1153-1193.

176. Moolchan ET, Umbricht A, Epstein D. Therapeutic drug monitoring in methadone maintenance: Choosing a matrix. J Addict Dis 2001; 20:55-73.

177. Office of Inspector General. Memorandum to the Under Secretary of Health. Review of prescribing practices for elderly out- 
patients. Department of Veterans Affairs, 1996. Available at http:// www.va.gov/ oig/52/reports/1997/7R1-A28-008prescrib.pdf. Accessed June 25, 2004.

178. U.S. General Accounting Office. Prescription drugs and the elderly. GAO, Washington, DC, 1995.

179. Dayer P, Desmeules J, Collart L. Pharmacology of tramadol. Drugs 1997; 53:18-24.

180. Harvard-MIT division of Health Sciences and Technology, HST.151 Principles of Pharmacology (Opioid Pharmacology), Spring 2003.

http://mitocw.hitce.net/OcwWeb/HealthSciences-and-Technology/HST-151Principles-of-PharmacologySpring2003/ CourseHome/index.htm

181. Hanks GW, Twycross RG, Lloyd JW. Unexpected complication of successful nerve block. Anaesthesia 1981; 36:37-39.

182. Ferris DJ. Controlling myoclonus after high-dosage morphine infusions. Am J Health Syst Pharm 1999; 56:1009-1010.

183. Kam P, Tan K. Pruritus-itching for a cause and relief? Anaesthesia 1996; 51:11331138.

184. Kuraishi Y, Yamaguchi T, Miyamoto T. Itchscratch responses induced by opioids through central mu opioid receptors in mice. J Biomed Sci 2000; 7:248-252.

185. Bochner F. Drug interactions with methadone: pharmacokinetics. In Hummeniuk R, Ali R, White J, Hall W, Farrell M (eds.), Proceeding of Expert Workshop on the Induction and Stabilization of $\mathrm{Pa}$ tients Onto Methadone. Monograph Series 39. Canberra: Commonwealth of Australia; 2000: 93-110. Available at: http:// www.health.gov.au.

186. Jackson, KC, Lipman AG. Opioid Analesics. In Talison CD, Satterwaite JR, Tollison JW (eds.). Practical Pain Management, $3^{\text {rd }}$ edition. Lippincott Williams \& Wilkins, Philadelphia, 2001:216-231.

187. Bergendal L, Friberg A, Schaffrath AM, holmdahl M, Landahl S. The clinical relevance of the interaction between carbamazepine and dextropropoxyphene in elderly patients in Gothenburg, Sweden. Eur J Clin Pharmacol 1997; 53:203-206.

188. Abernethy DR, Greenblatt DJ, Morse DS, Shader RI. Interaction of propoxyphene with diazepam, alprazolam and lorazepam. Br J Clin Pharmacol 1985; 19:51-57.

189. Iribarne C, Picart D, Dreano Y, Berthou F. In vitro interactions between fluoxetine or fluvoxamine and methadone or buprenorphine. Fundam Clin Pharmacol 1998; 12: 194-199.

190. Wolff K, Rostami-Hodjegan A, Hay AWM, Raistrick D, Tucker G. Population based pharmacokinetic approach for methadone monitoring of opiate addicts: potential clinical utility. Addiction 2000; 95:17711783.

191. Herrlin K, Segerdahl M, Gustafsson LL, Kalso E. Methadone, ciprofloxacin, and adverse drug reactions. Lancet 2000; 356: 2069-2070.
192. De Bels D, Staroukine M, Devriendt J. Torsades de pointes due to methadone. Ann Intern Med 2003; 139:58.

193. Gazelle G, Fine PG. Methadone for the treatment of pain. J Palliat Med 2003; 6: 621-622.

194. Mancini I, Lossignol DA, Body JJ. Opioid switch to oral methadone in cancer pain. Curr Opin Oncol 2000; 12:308-313.

195. Andersen G, Sjogren P, Hansen SH, Jensen $\mathrm{NH}$, Christrup L. Pharmacological consequences of long-term morphine treatment in patients with cancer and chronic nonmalignant pain. Eur J Pain 2004; 8:263271.

196. Page GG. Immunologic effects of opioids in the presence or absence of pain. J Pain Symptom Manage 2005; 29:S25-S31.

197. Shavit Y, Terman GW, Martin FC, Lewis JW, Liebeskind JC, Gale RP. Stress, opioid peptides, the immune system, and cancer. Immunol 1985; 135:834-837.

198. Shavit Y, Terman GW, Lewis JW, Zane CJ, Gale RP, Liebeskind JC. Effects of footshock stress and morphine on natural killer lymphocytes in rats: studies of tolerance and crosstolerance. Brain Res 1986; 372:382-385.

199. Shavit Y, Martin FC, Yirmiya R, Ben-Eliyahu $\mathrm{S}$, Terman GW, Weiner H, Gale RP, Liebeskind JC. Effects of single administration of morphine or footshock stress on natural killer cell cytotoxicity. Brain Behav Immun 1987; 1:318-328.

200. Lysle DT, Coussons ME, Watts VJ, Bennett EH, Dykstra LA. Morphine-induced alterations of immune status: Dose dependency, compartment specificity and antagonism by naltrexone. J Pharmacol Exp Ther 1993; 265:1071-1078.

201. Band LD, Pert A, Williams W, DeCosta BR, Rice KC Weber R. Central $\mu$-opioid receptors mediate suppression of natural killer activity in vivo. Prog Neuro Endocrin Immunol 1992; 5:95-101.

202. Shavit Y, Depaulis A, Martin FC, Terman GW, Pechnick RN, Zane CJ, Gale RP, Liebeskind JC. Involvement of brain opiate re ceptors in the immune suppressive effects of morphine. Proc Nat Acad Sci USA 1986; 83:7114-7117.

203. Weber RJ, Pert A. The periaqueductal gray matter mediates opiate-induced immunosuppression. Science 1989; 245:188-190.

204. Mellon RD, Bayer BM. Evidence for central opioid receptors in the immunomodulatory effects of morphine: Review of potential mechanism(s) of action. I Neuroimmunol 1998; 83:19-28.

205. Yeager MP, Colacchio TA, Yu CT, Hildebrandt L, Howell AL, Weiss J, Guyre PM. Morphine inhibits spontaneous and cytokineenhanced natural killer cell cytotoxicity in volunteers. Anesthesiology 1995; 83:500508.

206. Yeager MP, Procopio MA, DeLeo JA, Arruda $J \mathrm{~L}$, Hildebrandt L, Howell AL. Intravenous fentanyl increases natural killer cell cytotoxicity and circulating CD16 lymphocytes in humans. Anesth Analg 2002; 94:94-99. 207. Alonzo NC, Bayer BM. Opioids, immunology, and host defenses of intravenous drug abusers. Infect Dis Clin North Am 2002; 16: 553-569.

208. Gaspani L, Bianchi M, Limiroli E, Panerai $A E$, Sacerdote $P$. The analgesic drug tramadol prevents the effect of surgery on natural killer cell activity and metastatic colonization in rats. J Neuroimmunol 2002; 129:18-24.

209. Nelson CJ, Lysle DT. Severity, time, and beta*adrenergic receptor involvement in surgery-induced immune alterations. J Surg Res 1998; 80:115-122.

210. Palm S, Lehzen S, Mignat C, Steinmann J, Leimenstoll G, Maier C. Does prolonged oral treatment with sustained-release morphine tablets influence immune function? Anesth Analg 1998; 86:166-172.

211. Gomez-Flores R, Weber RJ. Differential effects of buprenorphine and morphine on immune and neuroendocrine functions following acute administration in the rat mesencephalon periaqueductal gray. Immunopharmacology 2000; 48:145-156.

212. Tsai YC, Won SJ, Lin MT. Effects of morphine on immune response in rats with sciatic constriction injury. Pain 2000; 88 : 155-160.

213. Bartolome MB, Kuhn CM. Endocrine effects of methadone in rats: Acute effects in adults. Eur J Pharmacol 1983; 95:231238.

214. Rolandi E, Marabini A, Franceschini $R$, Messina V, Bongera P, Barreca T. Changes in pituitary secretion induced by an agonist-antagonist opioid drug, buprenorphine. Acta Endocrinol (Copenh) 1983; 104:257-260.

215. Banki CM, Arato M. Multiple hormonal responses to morphine: Relationship to diagnosis and dexamethasone suppression. Psychoneuroendocrinology 1987; 12:3-11.

216. Malaivijitnond S, Varavudhi P. Evidence for morphine-induced galactorrhea in male cynomolgus monkeys. I Med Primatol 1998; 27:1-9.

217. Mendelson JH, Mendelson JE, Patch VD. Plasma testosterone levels in heroin addiction and during methadone maintenance. J Pharmacol Exp Ther 1975; 192: 211-217.

218. Mendelson JH, Meyer RE, Ellingboe J, Mirin SM, McDougle M. Effects of heroin and methadone on plasma cortisol and testosterone. J Pharmacol Exp Ther 1975; 195: 296-302.

219. Rasheed A, Tareen IA. Effects of heroin on thyroid function, cortisol and testosterone level in addicts. Pol J Pharmacol 1995; 47: 441-444.

220. Malik SA, Khan C, Jabbar A, Iqbal A. Heroin addiction and sex hormones in males. $J$ Pak Med Assoc 1992; 42:210-212.

221. Finch PM, Roberts LJ, Price L, Hadlow NC, Pullan PT. Hypogonadism in patients treated with intrathecal morphine. Clin J Pain 2000; 16:251-254. 
222. Abs R, Verhelst J, Maeyaert J, Van Buyten JP, Opsomer F, Adriaensen H, Verlooy J, Van Havenbergh T, Smet M, Van Acker K. Endocrine consequences of long-term intrathecal administration of opioids. J Clin Endocrinol Metab 2000; 85:2215-2222.

223. Roberts LJ, Finch PM, Pullan PT, Bhagat Cl, Price LM. Sex hormone suppression by intrathecal opioids: a prospective study. Clin J Pain 2002; 18:144-148.

224. Bhansali A, Velayutham P, Sialy R, Sethi B. Effect of opiates on growth hormone secretion in acromegaly. Horm Metab Res 2005; 37:425-427.

225. Rajagopal A, Vassilopoulou-Sellin R, Palmer JL, Kaur G, Bruera E. Hypogonadism and sexual dysfunction in male cancer survivors receiving chronic opioid therapy. J Pain Symptom Manage 2003; 26:10551061.

226. Hangaard J, Andersen M, Grodum E, Koldkjaer $\mathrm{O}$, Hagen $\mathrm{C}$. The effects of endogenous opioids and cortisol on thyrotropin and prolactin secretion in patients with Addison's disease. J Clin Endocrinol Metab 1999; 84:1595-1601.

227. Mao J, Price DD, Mayer DJ. Mechanisms of hyperalgesia and opiate tolerance: a current view of their possible interactions. Pain 1995; 62:259-274.

228. Mao J, Price DD, Mayer DJ. Thermal hyperalgesia in association with the development of morphine tolerance in rats: Roles of excitatory amino acid receptors and protein kinase C. J Neurosci 1994; 14:2301 2312.

229. Angst MS, Koppert W, Pahl I, Clark DJ, Schmelz M. Short-term infusion of the mu-opioid agonist remifentanil in humans causes hyperalgesia during withdrawal. Pain 2003; 106:49-57.

230. Wilson GR, Reisfield GM. Morphine hyperalgesia: A case report. Am J Hosp Palliat Care 2003; 20:459-461.

231. Kissin I. Tolerance to opioid analgesia: Why do we differ from rats? Anesth Anal 2005; 101:1727-1729.

232. Van Elstraete AC, Sitbon P, Trabold F, Maxoit J, Benhamou D. A single dose of intrathecal morphine in rats induces long-lasting hyperalgesia: The protective effect of prior administration of ketamine. Anesth Analg 2005; 101:1750-1756.

233. Mao J, Price DD, Mayer DJ. Experimental mononeuropathy reduces the antinociceptive effects of morphine: Implications for common intracellular mechanisms involved in morphine tolerance and neuropathic pain. Pain 1995; 61:353-364.

234. Mao J, Sung B, Ji RR, Lim G. Chronic morphine induces downregulation of spinal glutamate transporters: implications in morphine tolerance and abnormal pain sensitivity. J Neurosci 2002; 22:83128323.

235. Brodner RA, Taub A. Chronic pain exacerbated by long-term narcotic use in patients with non-malignant disease: Clinical syndrome and treatment. Mt Sinai J Med
1978; 45:233-237.

236. Savage SR. Long-term opioid therapy: Assessment of consequences and risks. J Pain Symptom Manage 1996; 11:274-286.

237. Compton MA. Cold-pressor pain tolerance in opiate and cocaine abusers: Correlates of drug type and use status. J Pain Symptom Manage 1994; 9:462-473.

238. Mao J. Opioid-induced abnormal pain sensitivity: Implications in clinical opioid therapy. Pain 2002; 100:213-217.

239. Compton P, Charuvastra VC, Ling W.. Pain intolerance in opioid-maintained former opiate addicts: effect of long-acting maintenance agent. Drug Alcohol Depend 2001; 63:139-146.

240. Byas-Smith MG, Chapman SL, Reed B, Cotsonis $G$. The effect of opioids on driving and psychomotor performance in patients with chronic pain. Clin J Pain 2005; 21:345352.

241. Ramaekers JG. Antidepressants and driver impairment: Empirical evidence from a standard on-the-road test. J Clin Psychiatry 2003; 64:20-29.

242. Zacny JP, Lichtor JL, Flemming D, Coalson DW, Thompson WK. A dose-response analysis of the subjective, psychomotor and physiological effects of intravenous morphine in healthy volunteers. J Pharmacol Exp Ther 1994; 268:1-9.

243. Meijler WJ. Driving ban for patients on chronic opioid therapy unfounded. Ned $\mathrm{Ti}$ jdschr Geneeskd 2000; 144:1644-1645.

244. Hanks GW. Morphine sans morpheus. Lancet 1995; 346:652-653.

245. Kamboj SK, Tookman A, Jones L, Curran $H V$. The effects of immediate-release morphine on cognitive functioning in patients receiving chronic opioid therapy in palliative care. Pain 2005; 117:388-395.

246. Portenoy RK, Hagen NA. Breakthrough pain: Definition, prevalence and charac teristics. Pain 1990; 41:273-281.

247. Savage SR, Joranson DE, Covington EC, Schnoll SH, Heit HA, Gilson AM. Definitions related to the medical use of opioids: Evolution towards universal agreement. J Pain Symptom Manage 2003; 26: 655-667.

248. World Health Organization. Expert Com mittee on Addiction-Producing Drugs. 7th report. Geneva, Switzerland: WHO 1957.

249. World Health Organization. WHO Expert Committee on Addiction-Producing Drugs. 13th report. Geneva, Switzerland: WHO 1964.

250. World Health Organization. WHO Expert Committee on Drug Dependence. 16th report. Geneva, Switzerland: WHO 1969

251. World Health Organization. WHO Expert Committee on Drug Dependence. 28th report. Geneva, Switzerland: WHO 1993

252. World Health Organization. WHO Expert Committee on Drug Dependence. 3oth report. Geneva, Switzerland: WHO 1998

253. Allan L, Hays $\mathrm{H}$, Jensen $\mathrm{NH}$, de Waroux BL, Bolt M, Donald R, Kalso E. Random- ized crossover trial of transdermal fentan$\mathrm{yl}$ and sustained-release oral morphine for treating chronic non-cancer pain. $\mathrm{Br}$ Med J 2001; 322:1154-1158.

254. Caldwell JR, Rapoport RJ, Davis JC, Offenberg HL, Marker HW, Roth SH, Yuan W, Eliot L, Babul N, Lynch PM. Efficacy and safety of a once-daily morphine formulation in chronic, moderate-to-severe osteoarthritis pain: results from a randomized, placebo-controlled, double-blind trial and an open-label extension trial. J Pain Symptom Manage 2002; 23:279-291.

255. Hale M, Speight K, Harsanyi Z, Iwan T, Slagle N, Lacouture P, Darke AC. Efficacy of 12 hourly controlled-release codeine compared with as required dosing of acetaminophen plus codeine in patients with chronic low back pain. Pain Res Manage 1997; 2:33-38.

256. Caldwell JR, Hale ME, Boyd RE, Hague JM, Iwan T, Shi M, Lacouture PG. Treatment of osteoarthritis pain with controlled- release oxycodone or fixed combination oxycodone plus acetaminophen added to nonsteroidal anti-inflammatory drugs: a double blind, randomized, multicenter, placebo controlled trial. J Rheumatol 1999; 26:862869.

257. Gostick N, Allen J, Cranfield R. A comparison of the efficacy and adverse effects of controlled-release dihydrocodeine and immediate-release dihydrocodeine in the treatment of pain in osteoarthritis and chronic back pain. In Twycross RG (ed.), Proceedings of the Edinburgh Symposium on Pain Control and Medical Education. 1989:137-143.

258. Hale ME, Fleischmann R, Salzman R, Wild J, Iwan T, Swanton RE, Kaiko RF, Lacouture PG. Efficacy and safety of controlled-release versus immediate-release oxycodone: Randomized, double blind evaluation in patients with chronic back pain. Clin J Pain 1999; 15:179-183.

259. Jamison RN, Raymond SA, Slawsby EA, Nedeljkovic SS, Katz NP. Opioid therapy for chronic noncancer back pain. A randomized prospective study. Spine 1998; 23 : 2591-2600.

260. Lloyd RS, Costello F, Eves MJ, James IG, Miller AJ. The efficacy and tolerability of controlled-release dihydrocodeine tablets and combination dextropropoxyphene / paracetamol tablets in patients with severe osteoarthritis of the hips. Curr Med Res Opin 1992; 13:37-48.

261. Salzman RT, Roberts MS, Wild J, Fabian C, Reder RF, Goldenheim PD. Can a controlled release oral dose form of oxycodone be used as readily as an immediate-release form for the purpose of titrating to stable pain control? J Pain Symptom Manage. 1999; 18:271-279.

262. Roth SH, Fleischmann RM, Burch FX, Dietz F, Bockow B, Rapoport RJ, Rutstein J, Lacouture PG. Around-the-clock, controlled-release oxycodone therapy for osteoarthritis-related pain: Placebo controlled trial and long-term evaluation. Arch 
Intern Med. 2000; 160:853-860.

263. Arkinstall W, Sandler A, Goughnour B, Babul N, Harsanyi Z, Darke AC. Efficacy of controlled-release codeine in chronic nonmalignant pain: a randomized, placebocontrolled clinical trial. Pain 1995; 62:169178.

264. Harke H, Gretenkort P, Ladleif HU, Rahman S, Harke O. The response of neuropathic pain and pain in complex regional pain syndrome I to carbamazepine and sustained-release morphine in patients pretreated with spinal cord stimulation: a double-blinded randomized study. Anesth Analg 2001; 92:488-495.

265. Huse E, Larbig W, Flor H, Birbaumer N. The effect of opioids on phantom limb pain and cortical reorganization. Pain 2001; 90 : 47-55.

266. Moulin DE, lezzi A, Amireh R, Sharpe WK, Boyd D, Merskey H. Randomized trial of oral morphine for chronic noncancer pain. Lancet 1996; 347:143-147.

267. Peloso PM, Bellamy N, Bensen W, Thomson GT, Harsanyi Z, Babul N, Darke AC. Double blind randomized placebo control trial of controlled-release codeine in the treatment of osteoarthritis of the hip or knee. J Rheumatol 2000; 27:764-771.

268. Watson CP, Babul N. Efficacy of oxycodone in neuropathic pain a randomized trial in postherpetic neuralgia. Neurology 1998; 50:1837-1841.

269. Gimbel JS, Richards P, Portenoy RK. Controlled-release oxycodone for pain in diabetic neuropathy. Neurology 2003; 60: 927-934.

270. Maier C, Hildebrandt J, Klinger R, HenrichEberl C, Lindena G. Morphine responsiveness, efficacy and tolerability in patients with chronic non-tumor associated pain - results of a double-blind placebo-controlled trial (MONTAS). Pain 2002; 97:223233.

271. Raja SN, Haythornthwaite JA, Pappagallo M, Clark MR, Travison TG, Sabeen S, Royall RM, Max MB. Opioids versus antidepressants in postherpetic neuralgia: A randomized placebo-controlled trial. Neurology 2002; 59:1015-1021.

272. Watson CPN, Moulin D, Watt-Watson J, Gordon A, Eisenhoffer J. Controlled-release oxycodone relieves neuropathic pain: A randomized controlled trial in painful diabetic neuropathy. Pain 2003; 105:71-78.

273. Haythornthwaite JA, Menefee LA, Quatrano-Piacentini AL, Pappagallo M. Outcome of chronic opioid therapy for non-cancer pain. J Pain Symptom Manage 1998; 15: 185-194.

274. Rowbotham MC, Twilling L, Davies PS, Reisner L, Taylor K, Mohr D. Oral opioid therapy for chronic peripheral and central neuropathic pain. $N$ Engl J Med 2003; 348: 1223-1232.

275. Kjaersgaard-Andersen P, Nafei A, Skov $\mathrm{O}$, Madsen $\mathrm{F}$, Andersen HM, Kroner $\mathrm{K}$, Hvass I, Gjoderum O, Pedersen L, Braneb- jerg PE. Codeine plus paracetamol versus paracetamol in longer-term treatment of chronic pain due to osteoarthritis of the hip. A randomised, double-blind, multicentre study. Pain 1990; 43:309-318.

276. Moran C. MST continuous tablets and pain control in severe rheumatoid arthritis. $\mathrm{Br} J$ Clin Res 1991; 2:1-12.

277. Sheather-Reid RB, Cohen M. Efficacy of analgesics in chronic pain: a series of $\mathrm{N}$-of1 studies. J Pain Symptom Manage 1998; 15:244-252.

278. Schofferman J. Long-term opioid analgesic therapy for severe refractory lumbar spine pain. Clin J Pain 1999; 15:136-140.

279. de Craen AJ, Lampe-Schoenmaeckers AJ, Kraal JW, Tijssen JG, Kleijnen J. Impact of experimentally-induced expectancy on the analgesic efficacy of tramadol in chronic pain patients: A $2 \times 2$ factorial, randomized, placebo-controlled, double-blind trial. J Pain Symptom Manage 2001; 21:210217.

280. Messick RT. Evaluation of acetaminophen, propoxyphene, and their combination in office practice. J Clin Pharmacol 1979; 19: 227-230.

281. Muller FO Odendaal CL, Muller FR, Raubenheimer J, Middle MV, Kummer M. Comparison of the efficacy and tolerability of a paracetamol/codeine fixed-dose combination with tramadol in patients with refractory chronic back pain. Arzneimittelforschung 1998; 48:675-679.

282. Mullican WS, Lacy JR. TRAMAP-ANAG-006 Study Group. Tramadol/acetaminophen combination tablets and codeine/ acetaminophen combination capsules for the management of chronic pain: a comparative trial. Clin Ther 2001; 23:14291445 .

283. Palangio M, Damask MJ, Morris E, Doyle RT Jr, Jiang JG, Landau CJ, de Padova A. Combination hydrocodone and ibuprofen versus combination codeine and acetaminophen for the treatment of chronic pain. Clin Ther 2000; 22:879-892.

284. Salzman RT, Brobyn RD. Long-term comparison of suprofen and propoxyphene in patients with osteoarthritis. Pharmacology 1983; 27:S55-S64.

285. Wilder-Smith CH, Hill L, Spargo K, Kalla A. Treatment of severe pain from osteoarthritis with slow-release tramadol or dihydrocodeine in combination with NSAID's: A randomized study comparing analgesia, antinociception and gastrointestinal effects. Pain 2001; 91:23-31.

286. Rangel-Guerra R. An open evaluation of oral butorphanol as long-term therapy in out-patients suffering from moderate to severe chronic pain. J Int Med Res 1981; 9: 120-123.

287. Milligan $\mathrm{K}$, Lanteri-Minet $M$, Borchert $\mathrm{K}$, Helmers H, Donald R, Kress HG, Adriaensen H, Moulin D, Jarvimaki V, Haazen L. Evaluation of long-term efficacy and safety of transdermal fentanyl in the treatment of chronic noncancer pain. J Pain 2001; 2:
197-204.

288. Jamison RN, Anderson KO, Peeters-Asdourian C, Ferrante FM. Survey of opioid use in chronic nonmalignant pain patients. Reg Anesth 1994; 19:225-230.

289. Zenz M, Strumpf M, Tryba M. Long-term oral opioid therapy in patients with chronic nonmalignant pain. J Pain Symptom Manage 1992; 7:69-77.

290. Sandoval JA, Furlan AD, Mailis-Gagnon A. Oral methadone for chronic non-cancer pain: a systematic literature review of reasons for administration, prescription patterns, effectiveness, and side effects. Clin J Pain 2005; 21:503-512.

291. Morley JS, Bridson J, Nash TP, Miles JB, White S, Makin MK. Low-dose methadone has an analgesic effect in neuropathic pain: a double-blind randomized controlled crossover trial. Palliat Med 2003; 17:576-587.

292. Malonne $H$, Coffiner $M$, Sonet $B$, Sereno A, Vanderbist F. Efficacy and tolerability of sustained-release tramadol in the treatment of symptomatic osteoarthritis of the hip or knee: A multicenter, randomized, double-blind, placebo-controlled study. Clin Ther 2004; 26:1774-1782.

293. Babul N, Noveck R, Chipman H, Roth SH, Gana T, Albert K. Efficacy and safety of extended-release, once-daily tramadol in chronic pain: A randomized 12-week clinical trial in osteoarthritis of the knee. J Pain Symptom Manage 2004; 28:59-71.

294. Ruoff GE, Rosenthal N, Jordan D, Karim $R$, Kamin M; Protocol CAPSS-112 Study Group. Tramadol/acetaminophen combination tablets for the treatment of chronic lower back pain: a multicenter, randomized, double-blind, placebo-controlled outpatient study. Clin Ther 2003; 25:11231141.

295. Schnitzer TJ, Gray WL, Paster RZ, Kamin M. Efficacy of tramadol in treatment of chronic low back pain. J Rheumatol 2000; 27: 772-778.

296. Sittl R, Griessinger N, Likar R. Analgesic efficacy and tolerability of transdermal buprenorphine in patients with inadequately controlled chronic pain related to cancer and other disorders: a multicenter, randomized, double-blind, placebo-controlled trial. Clin Ther 2003; 25:150-168.

297. Gammaitoni AR, Galer BS, Lacouture P, Domingos J, Schlagheck T. Effectiveness and safety of new oxycodone/acetaminophen formulations with reduced acetaminophen for the treatment of low back pain. Pain Med 2003; 4:21-30.

298. Peloso PM, Fortin L, Beaulieu A, Kamin M, Rosenthal N; Protocol TRP-CAN-1 Study Group. Analgesic efficacy and safety of tramadol/ acetaminophen combination tablets (Ultracet) in treatment of chronic low back pain: a multicenter, outpatient, randomized, double blind, placebo controlled trial. J Rheumatol 2004; 31:24542463.

299. Markenson JA, Croft J, Zhang PG, Richards 
P. Treatment of persistent pain associated with osteoarthritis with controlled-release oxycodone tablets in a randomized controlled clinical trial. Clin J Pain 2005; 21: 524-535.

300. Allan L, Richarz U, Simpson K, Slappendel $R$. Transdermal fentanyl versus sustained release oral morphine in strong-opioid naive patients with chronic low back pain. Spine 2005; 30:2484-2490.

301. Kabata T, Kubo T, Matsumoto T, Nishino M, Tomita K, Katsuda S, Horii T, Uto N, Kitajima I Apoptotic cell death in steroid induced osteonecrosis: An experimental study in rabbits. / Rheumatol 2000; 27 : 2166-2171.

302. Wasan AD, Davar G, Jamison R. The association between negative affect and opioid analgesia in patients with discogenic low back pain. Pain 2005; 117:450-461.

303. Rivera JJ, Singh V, Fellows B, Pampati V, Damron KS, McManus CD. Reliability of psychological evaluation in chronic pain in an interventional pain management setting. Pain Physician 2005; 8:375-383.

304. Dersh J, Gatchel RJ, Polatin P. Chronic spinal disorders and psychopathology: Research findings and theoretical considerations. Spine 2001; 1:88-94.

305. Bair MJ, Robinson RL, Katon W, Kroenke K. Depression and pain comorbidity: A literature review. Arch Intern Med 2003; 163 2433-2445.

306. Katon W. The impact of major depression on chronic medical illness. Gen Hosp Psychiatry 1996; 18:215-219.

307. McWilliams LA, Goodwin RD, Cox BJ. Depression and anxiety associated with three pain conditions: results from a nationally representative sample. Pain 2004; 111:77-83.

308. Rush AJ, Polatin P, Gatchel RJ. Depression and chronic low back pain. Spine 2000 25:2566-2571.

309. Fishbain DA, Cutler R, Rosomoff HL, Rosomoff RS. Chronic pain associated depression: Antecedent or consequence of chronic pain? A review. Clin J Pain 1997; 13:116-137.

310. Macfarlane GJ, Morris S, Hunt IM, Benjamin S, McBeth J, Papageorgiou AC, Silman A). Chronic widespread pain in the community: The influence of psychological symptoms and mental disorder on healthcare seeking behavior. I Rheumatol 1999; 26:413-419.

311. Von Korff M, Le Resch L, Dworkin S. First onset of common pain symptoms: A prospective study of depression as a risk factor. Pain 1993; 55:251-258.

312. McWilliams LA, Cox BJ, Enns MW. Mood and anxiety disorders associated with chronic pain: an examination in a nationally representative sample. Pain 2003; 106: 127-133.

313. Manchikanti L, Pampati VS, Fellows B, Beyer CD, Damron KS, Barnhill RC, Burks T. Characteristics of chronic low back pain in patients in an interventional pain man- agement setting: A prospective evaluation. Pain Physician 2001; 4:131-142.

314. Davis PJ, Reeves JL, Hastie BA, Graff-Radford SB, Naliboff BD. Depression determines illness conviction and pain impact: A structural equation modeling analysis. Pain Med 2000; 1:238-246.

315. Manchikanti L, Fellows B, Pampati VS, Damron KS, Beyer CD, Barnhill RC. Comparison of psychological status of chronic pain patients with general population. Pain Physician 2002; 5:40-48.

316. Adams LL, Gatchel RJ, Robinson RC, Polatin P, Gajraj N, Deschner M, Noe C. Development of a self-report screening instrument for assessing potential opioid medication misuse in chronic pain patients. $J$ Pain Symptom Manage 2004; 27:440-459.

317. Portenoy RK. Opioid therapy for chronic nonmalignant pain: A review of the critical issues. J Pain Symptom Manage 1996; 11: 203-217.

318. Savage SR. Opioid therapy of chronic pain: assessment of consequences. Acta Anaesth Scand 1999; 43:909-917.

319. Compton P, Darakjian MA, Miotto K Screening for addiction in patients with chronic pain and "problematic" substance use: evaluation of a pilot assessment tool. J Pain Symptom Manage 1998; 16:355363.

320. Passik SD, Kirsh KL, McDonald MV, Ahn S, Russak SM, Martin L, Rosenfeld B, Breitbart WS, Portenoy RK. A pilot survey of aberrant drug-taking attitudes and behaviors in samples of cancer and AIDS patients. J Pain Symptom Manage 2000; 19 : 274-286.

321. Robinson RC, Gatchel RJ, Polatin P, Deschner M, Noe C, Gajraj N. Screening for problematic prescription opioid use. Clin J Pain 2001; 17:220-228.

322. Manchikanti L, Singh V, Damron KS, Beyer CD, Pampati V. Screening for controlled substance abuse in interventional pain management settings: Evaluation of an assessment tool. Pain Physician 2003; 6 : 425-433.

323. Manchikanti L, Pampati V, Damron KS, McManus CD. Evaluation of variables in illicit drug use: Does a controlled substance abuse screening tool identify illicit drug use? Pain Physician 2004; 7:71-75.

324. Atluri SL, Sudarshan G. Developmen of a screening tool to detect the risk of inappropriate prescription opioid use in patients with chronic pain. Pain Physician 2004; 7:333-338

325. Michna E, Ross EL, Hynes WL, Nedeljkovic SS, Soumekh S, Janfaza D, Palombi D, Jamison RN. Predicting aberrant drug behavior in patients treated for chronic pain: importance of abuse history. J Pain Symptom Manage 2004; 28:250-258.

326. National Institute of Drug Abuse Research Report Series, Prescription Drugs: Abuse and Addiction, NIH Publication No. 014881, $2001,7$.

327. The National Center on Addiction and
Substance Abuse at Columbia University, Missed Opportunity: National Survey of Primary Care Physicians and Patients on Substance Abuse (New York: CASA, 2000): iii.

328. "Some seniors sell prescriptions to get by." The Paducah Sun, Paducah, KY, December 31, 2005

329. Santillan R, Hurle MA, Armijo JA, de los Mozos R, Florez J. Nimodipine-enhanced opiate analgesia in cancer patients requiring dose escalation: A double-blind, placebocontrolled study. Pain 1998; 76:17.

330. Manchikanti L, Rivera J, Pampati V, Damron KS, MCManus CD, Brandon DE, Wilson SR. One day lumbar epidural adhesiolysis and hypertonic saline neurolysis in treatment of chronic low back pain: A randomized double blind trial. Pain Physician. 2004; 7:177-186.

331. Manchikanti L, Pampati VS, Bakhit C, Rivera JJ, Beyer CD, Damron KS, Barnhill RC. Effectiveness of lumbar facet joint nerve blocks in chronic low back pain: A randomized clinical trial. Pain Physician 2001; 4:101-117.

332. Manchikanti L, Pampati VS, Fellows B, Rivera JJ, Beyer CD, Damron KS. Role of one day epidural adhesiolysis in management of chronic low back pain: A randomized clinical trial. Pain Physician 2001; 4:153-166.

333. Manchikanti L, Manchikanti KN, Damron KS, Pampati V. Effectiveness of cervical medial branch blocks in chronic neck pain: A prospective outcome study. Pain Physician 2004; 7:195-201.

334. Manchikanti L, Boswell MV, Rivera JJ, Pampati V, Damron KS, McManus CD, Brandon DE, Wilson SR. A randomized, controlled trial of spinal endoscopic adhesiolysis in chronic refractory low back and lower extremity pain. BMC Anesthesiol 2005; 5:10.

335. Manchikanti L, Staats PS, Singh V, Schultz DM, Vilims BD, Jasper JF, Kloth DS, Trescot AM, Hansen HC, Falasca TD, Racz GB, Deer T, Burton AW, Helm S, Lou L, Bakhit CE, Dunbar EE, Atluri SL, Calodney AK, Hassenbusch S, Feler CA. Evidence-based practice guidelines for interventional techniques in the management of chronic spinal pain. Pain Physician 2003; 6:3-80.

336. Gourlay DL, Heit HA, Almahrezi A. Universal precautions in pain medicine: a rational approach to the treatment of chronic pain. Pain Med 2005; 6:107-112.

337. Manchikanti L. Documentation for evaluation and management services. In Manchikanti L (ed.), Interventional Pain Management: Principles and Practice of Documentation, Billing, Coding, and Practice Management. ASIPP Publishing, Paducah, KY, 2004; pp 31-46.

338. 1997 Documentation Guidelines for Evaluation and Management Services. http:// www.cms.gov/medlearn/emdoc.htm

339. 1995 Documentation Guidelines for Evaluation and Management Services. http:// www.cms.gov/medlearn/emdoc.htm

340. Sehgal N, Shah RV, McKenzie-Brown A, Ev- 
erett CR. Diagnostic utility of facet (zygapophysial) joint injections in chronic spinal pain: A systematic review of evidence. Pain Physician 2005; 8:211-224.

341. McKenzie-Brown AM, Shah RV, Sehgal N, Everett CR. A systematic review of sacroiliac joint interventions. Pain Physician 2005; 8;115-125.

342. Boswell MV, Singh V, Staats PS, Hirsch JA. Accuracy of precision diagnostic blocks in the diagnosis of chronic spinal pain of facet or zygapophysial joint origin. Pain Physician 2003; 6:449-456.

343. Manchikanti L, Singh V, Pampati V, Damron KS, Barnhill RC, Beyer CD, Cash KA. Evaluation of the relative contributions of various structures in chronic low back pain. Pain Physician 2001; 4:308-316.

344. Shah RV, Everett CR, McKenzie-Brown AM, Sehgal N. Discography as a diagnostic test for spinal pain: A systematic and narrative review. Pain Physician 2005; 8:187-209.

345. Everett CR, Shah RV, Sehgal N, McKenzie-Brown AM. A systematic review of diagnostic utility of selective nerve root blocks. Pain Physician 2005; 8:225-233.

346. Boswell MV, Colson JD, Spillane WF. Therapeutic facet joint interventions in chronic spinal pain: A systematic review of effectiveness and complications. Pain Physician 2005; 8:101-114.

347. Manchikanti L, Singh V, Vilims BD, Hansen HC, Schultz DM, Kloth DS. Medial branch neurotomy in management of chronic spi- nal pain: Systematic review of the evidence. Pain Physician 2002; 5:405-418.

348. Abdi S, Datta S, Lucas LF. Role of epidural steroids in the management of chronic spinal pain: a systematic review of effectiveness and complications. Pain Physician 2005; 8:127-143.

349. Boswell MV, Hansen HC, Trescot AM, Hirsch JA, Epidural steroids in the management of chronic spinal pain and radiculopathy. Pain Physician 2003; 6: 319-334.

350. Chopra P, Smith HS, Deer TR, Bowman RC. Role of adhesiolysis in the management of chronic spinal pain: A systematic review of effectiveness and complications. Pain Physician 2005; 8:87-100. 
